\title{
Researoh Paper
}

\section{The Canadian Economy in Transition Series}

\section{Dimensions of occupational changes in Canada's knowledge economy, 1971-1996}

by Desmond Beckstead and Tara Vinodrai

Micro-economic Analysis Division

18th Floor, R.H. Coats Building, Ottawa, K1A 0T6

Telephone: 1800 263-1136

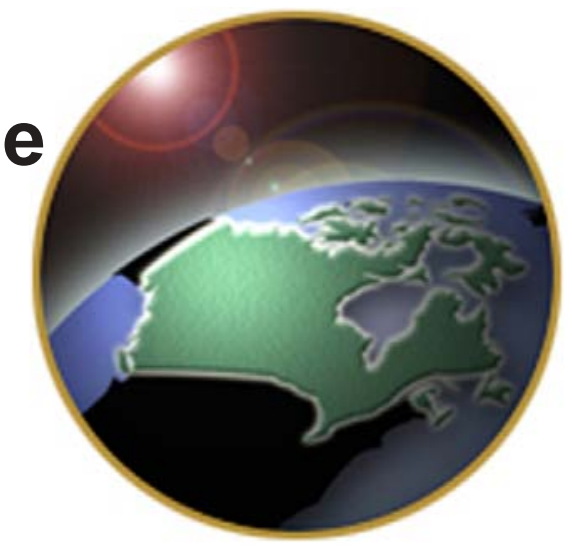

This paper represents the views of the authors and does not necessarily reflect the opinions of Statistics Canada. 


\section{How to obtain more information}

For information on the wide range of data available from Statistics Canada, you can contact us by calling one of our toll-free numbers. You can also contact us by e-mail or by visiting our Web site.

National inquiries line

National telecommunications device for the hearing impaired

$1800263-1136$

Depository Services Program inquiries

$1800363-7629$

Fax line for Depository Services Program

E-mail inquiries

Web site

$1800700-1033$

$1800889-9734$

infostats@statcan.ca

www.statcan.ca

\section{Ordering and subscription information}

This product is available in electronic format on the Statistics Canada Internet site, for free, as Catalogue no. 11-622-MIE. To obtain single issues, visit our Web site at www.statcan.ca, and select Products and Services.

\section{Standards of service to the public}

Statistics Canada is committed to serving its clients in a prompt, reliable and courteous manner and in the official language of their choice. To this end, the Agency has developed standards of service which its employees observe in serving its clients. To obtain a copy of these service standards, please contact Statistics Canada toll free at $1800263-1136$.

\section{The Canadian Economy in Transition Research Paper Series}

The Canadian Economy in Transition is a series of new analytical reports that investigate the dynamics of industrial change in the Canadian economy. This new series brings together a coherent set of research reports that provide users with a wide variety of empirical perspectives on the economy's changing industrial structure. These perspectives include the dynamics of productivity, profitability, employment, output, investment, occupational structure and industrial geography. Readers are encouraged to contact the authors with comments, criticisms and suggestions.

The primary distribution medium for the papers is the Internet. These papers can be downloaded from the Internet at www.statcan.ca for free. Papers in the series are distributed to Statistics Canada Regional Offices and provincial statistical focal points.

All papers in The Canadian Economy in Transition series go through institutional and peer review to ensure that they conform to Statistics Canada's mandate as a government statistical agency and adhere to generally accepted standards of good professional practice.

The papers in the series often include results derived from multivariate analysis or other statistical techniques. It should be recognized that the results of these analyses are subject to uncertainty in the reported estimates.

The level of uncertainty will depend on several factors: the nature of the functional form used in the multivariate analysis; the type of econometric technique employed; the appropriateness of the statistical assumptions embedded in the model or technique; the comprehensiveness of the variables included in the analysis; and the accuracy of the data that are utilized. The peer group review process is meant to ensure that the papers in the series have followed accepted standards to minimize problems in each of these areas. 


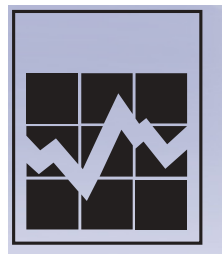

Statistics Canada

Micro-economic Analysis Division

\section{Dimensions of occupational changes in Canada's knowledge economy, 1971-1996}

Desmond Beckstead and Tara Vinodrai

Published by authority of the Minister responsible for Statistics Canada

(C) Minister of Industry, 2003

All rights reserved. No part of this publication may be reproduced, stored in a retrieval system or transmitted in any form or by any means, electronic, mechanical, photocopying, recording or otherwise, without prior written permission from Licence Services, Marketing Division, Statistics Canada, Ottawa, Ontario, Canada, K1A 0T6.

October 2003

Catalogue no.11-622-MIE no. 004

Frequency: Occasional

ISSN 1705-6896

ISBN 0-662-35159-2

Ottawa

La version française de cette publication est aussi disponible ( ${ }^{\circ}$ 11-622-MIF n ${ }^{\circ} 004$ au catalogue).

The authors' names are listed alphabetically.

This paper represents the views of the authors and does not necessarily reflect the opinions of Statistics Canada.

\section{Note of appreciation}

Canada owes the success of its statistical system to a long-standing partnership between Statistics Canada, the citizens of Canada, its businesses, governments and other institutions. Accurate and timely statistical information could not be produced without their continued cooperation and goodwill. 


\section{Acknowledgements}

$O$ $\mathrm{n}$ behalf of all researchers who contribute to The Canadian Economy in Transition Series, we would like to thank our production team at Statistics Canada, whose efforts make the publication of these reports possible. Louise Laurin and Valerie Thibault oversee different aspects of the production process and work extensively with authors on the development of final products. Nicolas Rahal, Francine Simoneau and Cindy Renaud provide critical production support. We would also like to thank Shannon McPhail for her excellent work in developing the cover design and graphics for this series.

The authors would like to thank John Baldwin, Chris Jackson and Guy Gellatly of the Micro-economic Analysis Division at Statistics Canada for their insightful comments and suggestions on the methodology and content of this paper. The authors would also like to thank Sëan Burrows for time spent preparing the databases used in this research.

Authors are also indebted to numerous referees, both internal and external to Statistics Canada, for their valuable comments and suggestions. We are especially grateful to John Baldwin for his contribution to many of the projects featured in this series. 


\section{Table of Contents}

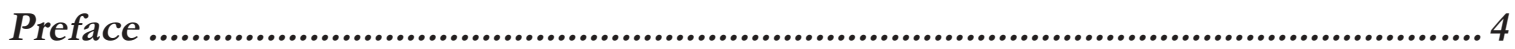

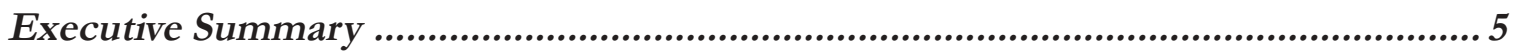

Chapter 1. Introduction ............................................................................ 7

Chapter 2. Defining the 'New Economy' ..........................................................9

Chapter 3. Data and definitions ............................................................... 13

Chapter 4. Changing dimensions of Canada's knowledge base .......................... 17

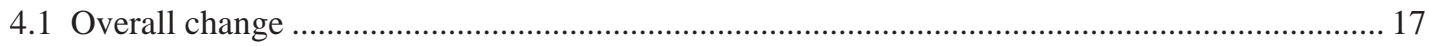

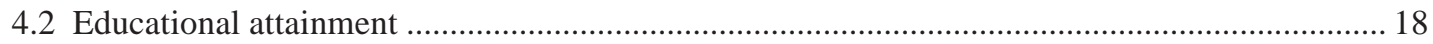

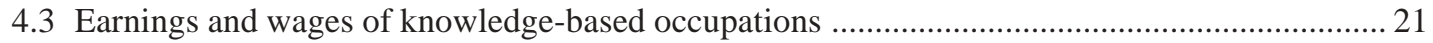

4.4 Shifts in Canada's knowledge base: Sectoral evidence ……......................................................... 23

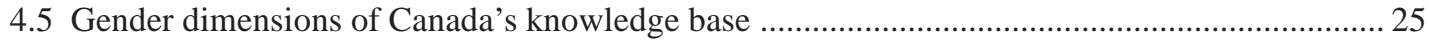

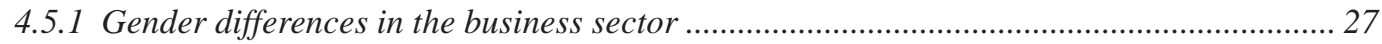

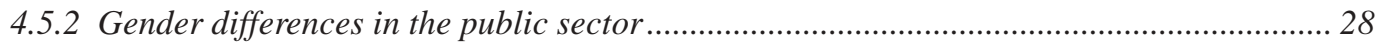

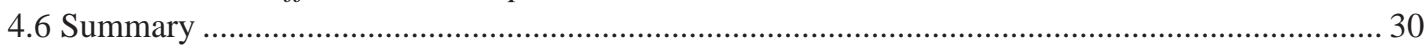

Chapter 5. Shifts in Canada's knowledge-base: Industry dimensions ...................... 33

Chapter 6. Geographic dimensions of Canada's evolving knowledge economy ...... 38

Chapter 7. Regional differences and industrial structure ................................... 45

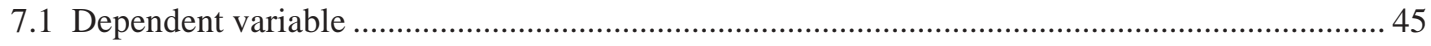

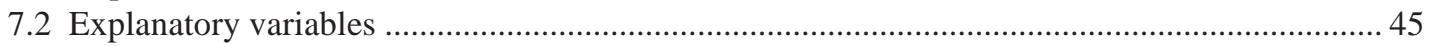

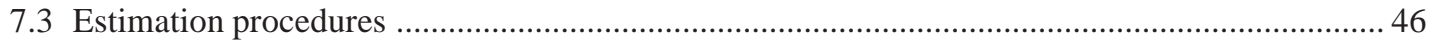

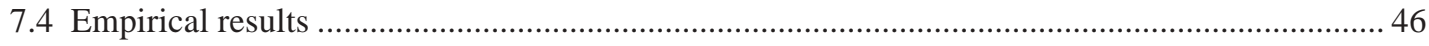

Chapter 8. Conclusion ............................................................................ 53

Appendix 1: A method of creating a file of occupational groups from Census data over

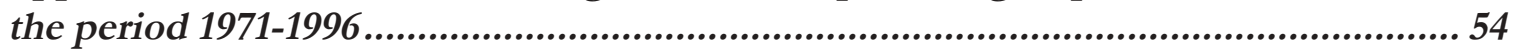

Appendix 2: Standard Occupational Classification Codes ................................... 67

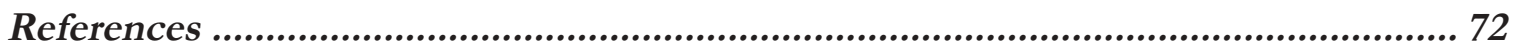




\section{Preface}

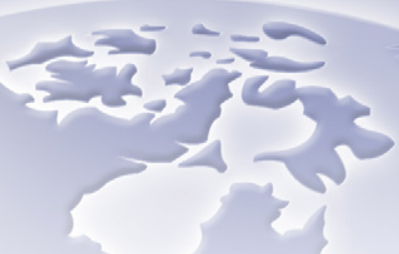

7 his paper examines the emergence of the knowledge economy by examining the 1 increasing importance of high-knowledge occupations over the period 1971-1996. It reports that the importance of knowledge occupations has continuously increased over the last three decades. It also examines differences in the changes that have occurred for different knowledge professions - managers, professionals and technical occupations, for industries and for geographic areas. It finds that the increase in the proportion of the labour force that is classified to knowledge occupations was widespread. It occurred for professionals, managers, and technical occupations. It occurred across most industries. It occurred across different regions. It occurred in both the female and male labour force. While there are differences in the rates of growth in some areas, the most important conclusion to emerge from the study is that the growth of skills, as proxied by the importance of knowledge occupations, was widespread and not restricted to narrow areas of interest, such as popularly defined high-tech sectors.

For additional analysis on Canada's knowledge workers that includes data for 2001, please see “Knowledge workers in Canada's economy, 1971-2001” (11-624-MIE No. 004). 


\section{Executive Summary}

Recent discussions of the 'new economy' sometimes leave the impression that it is a 1 phenomenon that emerged only in the 1990s and that it is restricted to a small hightech sector. Using data on individual firms taken from a survey, Baldwin and Gellatly (1998) challenge the latter view and argue that high-tech firms can be found in many industries. This paper uses an alternate source of micro-data to investigate the issue further. It uses Census of Population data to classify workers into the more knowledge-intensive occupations and then investigates how the share of these workers has varied over time and across sectors. In doing so, it allows us to investigate whether the emergence of the 'knowledge economy' has occurred only recently and whether is it restricted to relatively few sectors.

The paper is organized around a key set of questions:

1) Has the knowledge economy grown dramatically only in recent years or has it been a continuous process over the 1971-1996 period?

The knowledge segment of the workforce has grown at about the same rate over each of the last three decades.

2) Have one group of knowledge workers grown faster than others?

Professionals and managers have grown more than technical occupations.

3) Has the educational attainment of the different groups increased at different rates?

The probability of a university degree has increased most in professional occupations. Only 44\% of professional occupations had a post secondary degree in 1971 but $68 \%$ had such a degree in 1996.

4) Have relative earnings in the knowledge occupations increased?

While knowledge based occupations have significantly higher wage rates, their relative advantage has not increased over most of the period. 
5) Has the importance of knowledge workers increased more in one industrial sector than another?

Growth in the proportion of workers who are knowledge workers has been about equal in both goods and service industries.

Within the business sector, there are large differences in the percentage of employment that is found in knowledge based occupations, with finance, insurance, real estate, communications and mining having the highest percentages in 1996. But growth has been relatively widespread across all individual industries, thereby demonstrating that the knowledge economy has penetrated all industries.

6) Have knowledge workers grown equally in both the male and female segments of the labour force?

A greater percentage of males are in knowledge occupations than females. Over time, the increase in the business sector has been faster for males than for females.

7) Has the evolution of the knowledge sector influenced some regions more than others?

Increases in the share of employment in knowledge occupations have occurred across all regions. Ontario and Quebec experienced the greatest percentage point changes. However, this is primarily the effect of industrial and urban structure. After we allow for industry and urbanization differences in a multivariate analysis, there are few significant differences between provinces.

Throughout the study period, the percentage of workers in knowledge occupations was much higher in urban than in rural areas, but this disparity has lessened over the study period. 


\section{Chapter 1. Introduction}

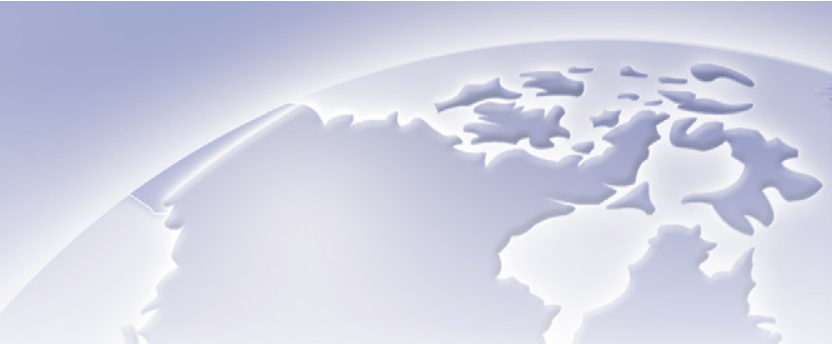

$I$ $\mathrm{t}$ is often claimed that there have been substantial shifts within the Canadian and global economies and that a 'new economy' is emerging or has already emerged.

The new economy is described in the media, policy documents, and academic literature as being increasingly based upon knowledge where human capital, skills, innovation and technology are necessary to be competitive. A number of studies have sought to understand the nature and extent of the structural changes that are occurring globally and within Canada in response to, or as part of, this shift towards a 'new economy'.

Many of these studies have defined knowledge intensity at the industry-level (Lee and Has, 1996; Gera and Mang, 1997). These studies implicitly assume that industries are homogenous in nature - that entire industries can be defined as belonging to the new economy while others are separate from it. In contrast, there are those who argue that the emerging 'new economy' is not restricted to a handful of industries but is more pervasive, involving a series of changes in the nature of work and production driven by technological advance, as well as other factors (Lavoie and Roy, 1998). For example, Baldwin and Gellatly (1998) use results of a survey on financing and operating practices to examine the innovative capacity of newly formed firms. They find that the existence of high-technology firms is not confined to industries commonly thought of as being high-technology industries.

Normally, industries are classified in a dichotomous fashion as either belonging or not belonging to the new economy because the data that are commonly available and that are used for classification purposes pertain to the industry as a whole as opposed to firms within the industry - measures of R\&D intensity, technology use, output, employment and productivity growth.

An exception is provided by Baldwin and Gellatly (1998) who use a survey of new firms to classify each firm as being high knowledge as opposed to low knowledge to calculate the percentage of the producers within each industry that fit the profile of high knowledge firms. But surveys such as this are rare and the fact that they have only been recently developed means they do not permit us to compare changes over time.

An alternate source of micro-data that allows a more detailed examination of the composition of an industry is provided by information on the nature of the workforce in an industry. Data on occupations of workers allow an alternate method of classifying an industry as being one that relies heavily on skilled workers of a certain type. As such, occupational data 
allow us to examine how intense the knowledge activity is within an industry. Moreover, data on occupations have been collected for several decades and thus potentially allow us to plot changes over time.

Of course, many studies of changes that have occurred over time are hampered by shifts or breaks in classifications or by a lack of consistent data sources. This is also the case for occupational data. Occupational classifications have changed frequently, some times drastically. In 1991, Statistics Canada introduced a new Standard Occupational Classification (SOC) that replaced the 1980 SOC. The new classification "differs substantially in structure and content from earlier systems" (Marshall, 1996). One of the goals of this paper is to attempt to overcome these changes by creating a concordance based on aggregate-level occupation groups using previous taxonomies and average wage rates.

This paper contributes to the discussion of Canada's 'new economy' by addressing a number of related questions:

- To what extent has there been growth in knowledge-based occupations and what are the dimensions and characteristics of this change between 1971 and 1996 ?

- How has the growth of knowledge-based occupations differed across Canadian industries?

- Are there geographic or regional differences in the development and growth of a knowledge-based economy?

We use the Canadian Census of Population and occupational classifications derived therefrom to address these questions. Data from the 1971, 1981, 1986, 1991, and 1996 Censuses are employed to examine how the proportion of knowledge-based occupations has changed over this 25-year period.

The remainder of the paper is organized as follows:

Chapter 2 provides an overview of previous research that has classified and defined Canada's knowledge-based economy. Chapter 3 introduces and develops the taxonomy used in this paper to define knowledge-based occupations. Chapter 4 presents an overview of how Canada's knowledge-based economy has evolved over the 25-year period between 1971 and 1996 and examines the gender, education, wage, and sectoral characteristics of this change. Chapters 5 and 6 extend this analysis to examine the industrial and geographic dimensions of Canada's evolving knowledge-economy in more detail. Chapter 5 examines 15 broad industries within the business sector through an occupational lens. Due to the heterogeneity of the manufacturing sector, we examine this sector in more detail. Chapter 6 investigates how the business sector has evolved across Canada's vast landscape by examining the regional and urban-rural dimensions of this evolution. Chapter 7 uses a multivariate analysis to determine whether or not geographic differences persist after controlling for differences in industrial structure. A summary of our key findings and their importance is presented in chapter 8 . 


\section{Chapter 2. Defining the 'New Economy'}

Studies that have addressed the emergence or evolution of the so-called 'new economy' $\mathcal{N}$ have defined the new economy in different ways. Some have adopted a firm- or industrybased level of analysis to identify and measure shifts in the Canadian economy, while others have examined the same issue from a human capital or labour market perspective.

In the first case, technology use, research and development (R\&D) intensity, and other measures of technological advance have been used to argue that the Canadian economy is undergoing (or has undergone) a significant transformation. Some have examined employment, output and productivity changes from an industrial perspective to make a similar argument (Gera and Massé, 1996; Gera and Mang, 1997).

In contrast, others have adopted a skill-based approach, using educational attainment, training, and occupation to examine the changing dimensions of Canada's human capital stock and the Canadian labour market (Lavoie and Roy, 1998; Boothby, 1999; Baldwin and Johnson, 1996; Gera, et al., 1999).

There is no single or perfect measure of knowledge intensity, production or use. These alternatives provide different insights into the complexities associated with an evolving and changing economy (Howitt, 1996). This study takes a human capital approach to defining and examining the evolution of Canada's knowledge-based labour force across regions and industries. To start with, we provide a review of previous empirical studies that have examined Canada's knowledge-based economy.

Lee and Has (1996) focus on defining high technology and knowledge-intensive industry sectors by ranking industries based on a number of human capital and research and development measures. The authors identify three human capital measures: the proportion of scientific personnel, the proportion of persons with post-secondary education, and the proportion of knowledge workers within an industry. Using the 1980 SOC, they define knowledge workers as belonging to occupations in natural sciences, engineering and mathematics, education, managers and administrators, social sciences, law and jurisprudence, medicine and health, and writing.

Gera and Massé (1996) use Statistics Canada's input-output tables to examine how Canada's industrial structure has changed over the period between 1971 and 1991 from an employment perspective. They divide the manufacturing sector into three sectors (high, medium and low knowledge) using a number of different classification schemes that discriminate on the 
basis of knowledge, technology, wage, and skill intensity. The service sector is divided into three sub-sectors based on level of knowledge intensity. They find that employment growth has been concentrated in high skill, high wage, science-based, high technology, and high knowledge industries.

The approaches of both Lee and Has (1996) and Gera and Massé (1996) mask the heterogeneity of firms and labour markets within industries. To overcome this, other researchers have tried to address the measurement of knowledge intensity using occupationbased approaches. Following approaches used in the United States, Lavoie and Roy (1998) study employment change in Canada between 1971 and 1991. They classify workers into five occupational groupings (knowledge, management, data, services, and goods) based on the 1980 SOC. Arguing that knowledge workers are not a homogenous group, they subdivide knowledge workers into five groups: pure science, applied science, computer science, engineering, and social sciences and humanities.

Using census data from 1971, 1981, 1986, and 1991', Lavoie and Roy (1998) examine the growth of occupation groups and find that employment in what they define as knowledgebased occupations grew faster than other categories, with the exception of management occupations. Boothby (1999) modifies Lavoie and Roy's classification system by distinguishing between skilled and unskilled goods workers and further subdividing data workers into those who manipulate data and those who apply (but do not create) a high degree of knowledge in their tasks. Using data from the International Adult Literacy Survey (IALS), Boothby (1999) examines the differences in knowledge and literacy skills of particular occupational groupings. He finds that basic skills such as reading and writing are pervasive across occupational categories, but that knowledge workers, data workers, and managers use these skills more intensively and that knowledge workers have higher levels of education than other occupations.

Gera, et al. (1999) use the framework developed by Lavoie and Roy (1998), as well as the National Occupational Classification ${ }^{2}$ (NOC) to classify industries by the skill levels of the workers employed therein. They ask whether skill intensity rose across industries between 1981 and 1994, and whether or not biased technological change was the main reason for an increased demand for skilled workers. Using data from a number of different Statistics Canada surveys, their results indicate that skill intensity increased over the period, especially in the service sector. Moreover, most industries increased their percentage of knowledge workers, suggesting that a shift towards a knowledge-based economy was pervasive across industrial sectors. Using a shift-share analysis, Gera et al. (1999) determine that withinindustry shifts accounted for most of the upskilling in the labour force.

Recently, Statistics Canada investigated the movement of knowledge workers between Canada and other countries, with particular emphasis on the United States (Zhao et al., 2000a, 2000b). This study uses the 1991 SOC to define fourteen broad knowledge-based occupational categories, ranging from engineers, doctors, and teachers to athletes, writers, and entertainers. ${ }^{3}$ Using data from a wide variety of Canadian and American sources, Zhao et al. (2000a, 2000b) find that there is a 'brain drain' to the United States in occupations and 
industries viewed as being 'knowledge-based'. However, this is tempered by a 'brain gain' of educated migrants from elsewhere. Moreover, the magnitude of these gains and losses is relatively small, although there has been an upward trend in emigration in recent years. 


\section{Endnotes}

${ }^{1}$ Lavoie and Roy (1998) provide 1996 estimates using Statistics Canada's Labour Force Survey (LFS) since this survey maintains occupational coding that uses the 1980 SOC. Census data for 1996 uses the 1991 SOC, which can not be easily mapped into their occupational framework.

2 The NOC is maintained by Human Resources Development Canada (HRDC) and divides workers into four skill levels (excluding managers): professional workers (skill level A), technical skilled workers (skill level B), intermediate workers (skill level C), and unskilled workers (skill level D). This classification is linked to the 1980 SOC.

3 Since the data used to discuss occupations are from the post-1991 period, the authors did not have to address the issues related to disparate classification schemes. 


\section{Chapter 3. Data and definitions}

A s discussed above, studies that have focussed on the human capital elements of the knowledge economy have encountered the problem of defining 'knowledge workers'. Some studies have tried to examine knowledge from the perspective of education level or 'skill'. Others have used occupational definitions. As a result of a new Canadian standard adopted in 1991, difficulty arises in using occupational definitions to study changes over time since there have been significant changes in the way that occupations were defined and coded. While a number of Canadian studies have defined knowledge workers from an occupational perspective, none have developed a mechanism or means for overcoming this data discontinuity over time to study changes since 1971 into the 1990s. In this chapter, we present a method for overcoming this break in occupational classifications, thereby allowing for the analysis of changes in broad occupation categories over the last thirty years.

The analysis presented in this paper uses data from the 1971, 1981, 1986, 1991, and 1996 Censuses. As is often the case in time series analysis, there are problems related to historical comparability and definitional consistency. Specifically, changes occur in the definition of the labour force and the classification of industries and occupations. A number of steps were taken to overcome these problems.

First, we limit our discussion to the employed labour force, using the 1971 Census labour force activity concept to ensure consistency and historical comparability. ${ }^{4}$ Second, industrial sectors are defined using the 1980 Standard Industrial Classification (SIC). Industry data for the 1971 and 1981 Censuses used the 1970 SIC. Thus, these data are adjusted to ensure comparability over the entire 25-year study period. The 1986 Census has industry level data for both of these industrial classifications and, therefore, provides a mechanism for building a concordance to adjust the 1971 and 1981 Census data to the 1980 SIC (see Appendix 1).

More problematic is the creation of consistent occupational groups. In this paper, we create a taxonomy that uses 47 broad occupation groups that we use to track changes over time. ${ }^{5}$ We then create a statistical concordance between the 1971, 1980, and 1991 SOC systems to allocate each individual to one of these 47 broad occupational categories. This provides consistent occupational groups for our analysis. Given the complexities of creating a statistical concordance, in this chapter we provide only a summary of this exercise (refer to Appendix 2 for details). 
We define 47 occupation groups based on the 1991 classification. Drawing upon previous work, we identify several of these as heavily involving knowledge workers (see Lee and Has, 1996; Lavoie and Roy, 1998; Zhao, et al., 2000a). We recognize that all occupations require a knowledge base, but we define a set as requiring a different knowledge base and for this study refer to this group as being 'knowledge workers'. Knowledge workers are defined using the 1991 SOC. Eight of the forty-seven occupation groups were considered to be knowledge-based. When uncertainty arose as to whether a particular occupation should be classified to one of the broad knowledge categories, we used relative wage rates to determine which of the 47 broad occupational groupings it should be assigned to (see Appendix 2).

The knowledge occupations fall into three broad classes. These are:

- professional occupations - characterized by high relative wages and a high proportion of persons who have completed university-level education;

- management occupations - characterized by high relative wages but with a lower proportion of persons who have completed university-level education; and

- technical occupations - characterized by lower relative wage rates and a high proportion of persons with post-secondary education or above.

The specific 1991 SOC occupations included in the three knowledge worker categories are described in Table 1.

Following the creation of the 47 occupation groups, a method of concordance was developed to assign the occupations in the censuses before 1991 to one of these groups. There are three different occupational systems — one each associated with the 1971, 1980 and 1991 SOC systems. Figure 1 depicts the availability of occupational data for each Census year.

We produce a statistical concordance between the three systems and the 47 broad occupational categories based on the 1991 Standard Occupational Classification. We then use this grouping to produce consistent estimates of the size and extent of the knowledge-based economy over time.

Figure 1. Conceptualizing an occupational concordance

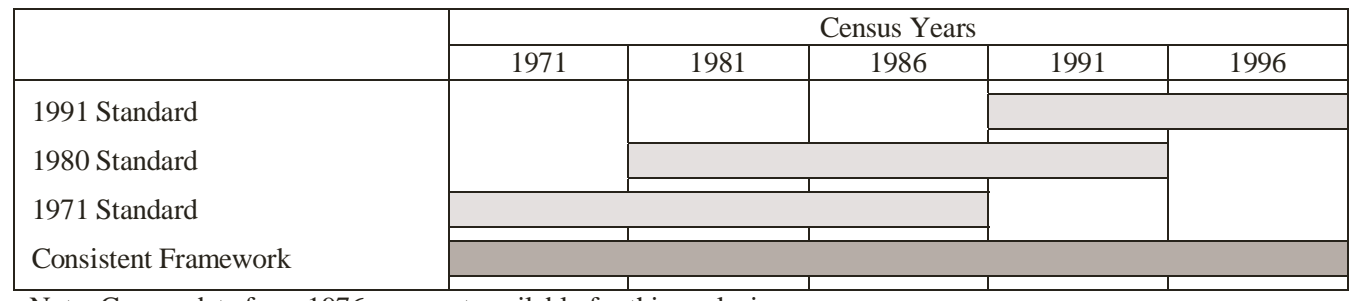

Note: Census data from 1976 were not available for this analysis. 
Table 1. Description of 'knowledge worker' categories

\begin{tabular}{|c|c|}
\hline Type of Knowledge Worker & Description \\
\hline Professional occupations & 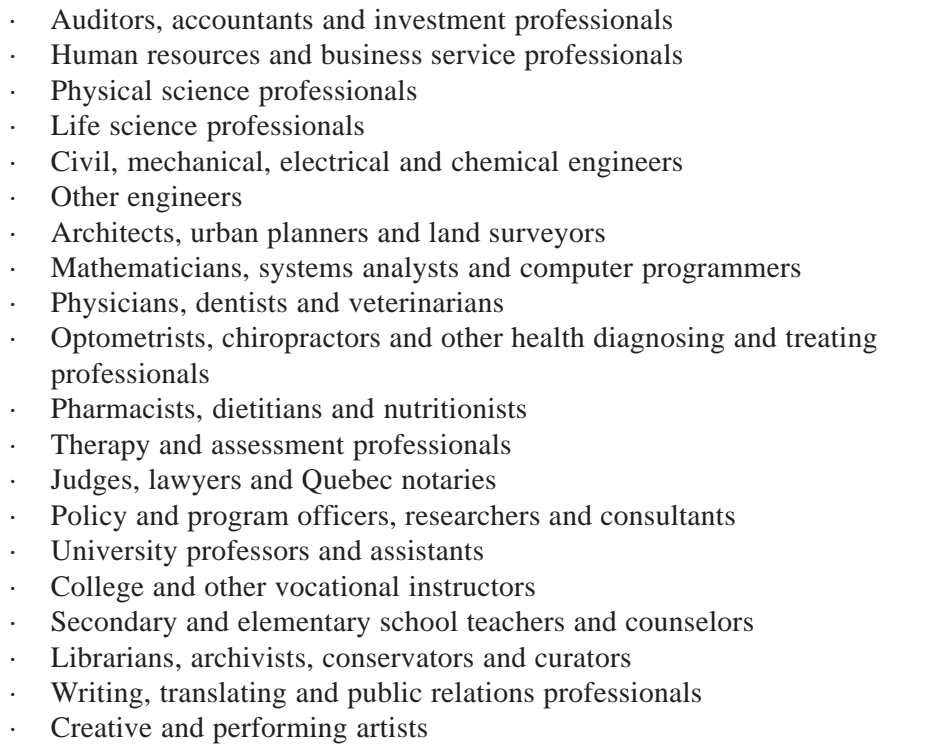 \\
\hline Management occupations & 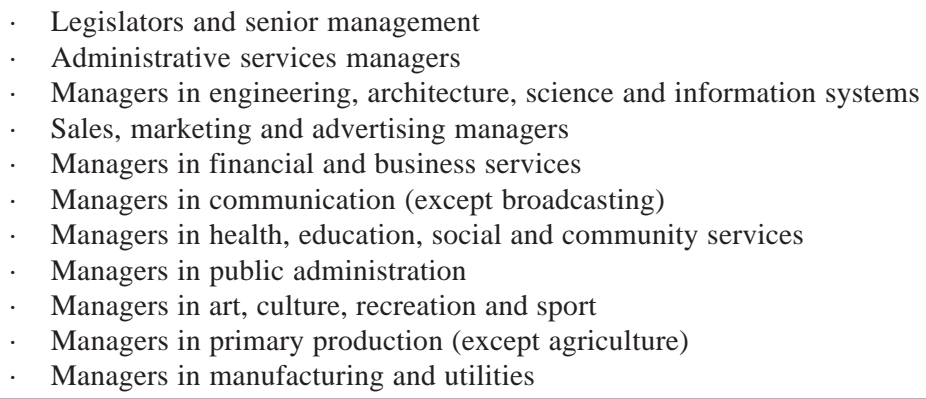 \\
\hline Technical occupations & $\begin{array}{l}\text { Technical occupations in physical sciences } \\
\text { Technical occupations in life sciences } \\
\text {. Technical occupations in civil, mechanical and industrial engineering } \\
\text {. Technical occupations in electronics and electrical engineering } \\
\text {. } \quad \text { Technical occupations in architecture, drafting, surveying and mapping } \\
\text {. } \quad \text { Other technical inspectors and regulatory officers } \\
\text {. } \quad \text { Transportation officers and controllers } \\
\text {. Nurse supervisors and registered nurses } \\
\text {. Medical technologists and technicians (except dental health) }\end{array}$ \\
\hline
\end{tabular}

Note: Occupation descriptions are based on the 1991 Standard Occupational Classification. See also Appendix 2. 


\section{Endnotes}

${ }^{4}$ While the Census labour force concept has remained reasonably constant between 1971 and 1996 there have been some minor changes to the concept, as well as to the questions asked and the processing procedures used. See Statistics Canada (1999) for a discussion of changes in the Census labour force concepts used over the period between 1971 and 1996.

5 While detailed occupational information would be more desirable than aggregate groups, it is difficult to maintain detail over the study period due to the disparate nature of the occupational classification systems. 


\section{Chapter 4. Changing dimensions of Canada's knowledge base}

$\Gamma^{\text {his }}$ chapter examines the occupational shifts between 1971 and 1996 by applying the consistent occupational framework developed in chapter 3 to Census data. In doing so, we examine the education, gender, sectoral and wage dimensions of this change, especially for the knowledge-based occupations.

\subsection{Overall change}

Between 1971 and 1996, Canada experienced a substantial increase in its knowledge worker base. ${ }^{6}$ Moreover, the knowledge worker segment of the employed labour force grew faster than the overall workforce (Figure 2).

Evidence that the proportion of the employed labour force in knowledge occupations has steadily increased is presented in Table 2. In 1971, only 14\% of the employed labour force were in knowledge occupations; by 1996, this had increased to $22 \%$. While this increase was experienced by all three groups of knowledge workers, professional occupations account for the largest proportion of knowledge workers throughout the study period. However, growth over the period was highest in management occupations (225\%) as compared to professional occupations $(43 \%)$ or technical occupations $(31 \%){ }^{7}$

\begin{tabular}{|lrrrrrr|}
\hline Table 2. Employed labour force by occupation, 1971-1996 \\
\cline { 2 - 7 } & \multicolumn{7}{c|}{ Share of employment ${ }^{1}(\%)$} \\
\cline { 2 - 7 } & 1971 & $1976^{2}$ & 1981 & 1986 & 1991 & 1996 \\
\hline All Knowledge-based occupations & 13.8 & 15.7 & 17.5 & 19.5 & 21.5 & 22.2 \\
Management occupations & 1.6 & 2.6 & 3.6 & 4.6 & 5.4 & 5.2 \\
Professional occupations & 8.7 & 9.3 & 9.9 & 10.8 & 11.3 & 12.4 \\
Technical occupations & 3.5 & 3.7 & 4.0 & 4.2 & 4.7 & 4.6 \\
All other occupations & 86.2 & 84.3 & 82.5 & 80.5 & 78.5 & 77.8 \\
All occupations & $\mathbf{1 0 0}$ & $\mathbf{1 0 0}$ & $\mathbf{1 0 0}$ & $\mathbf{1 0 0}$ & $\mathbf{1 0 0}$ & $\mathbf{1 0 0}$ \\
\hline
\end{tabular}

1 Defined as the employed labour force using the 1971 Census labour force concept.

2 Data for 1976 is estimated as the midpoint between 1971 and 1981. 
Figure 2. Change in employment, 1971-1996 (1971=100)

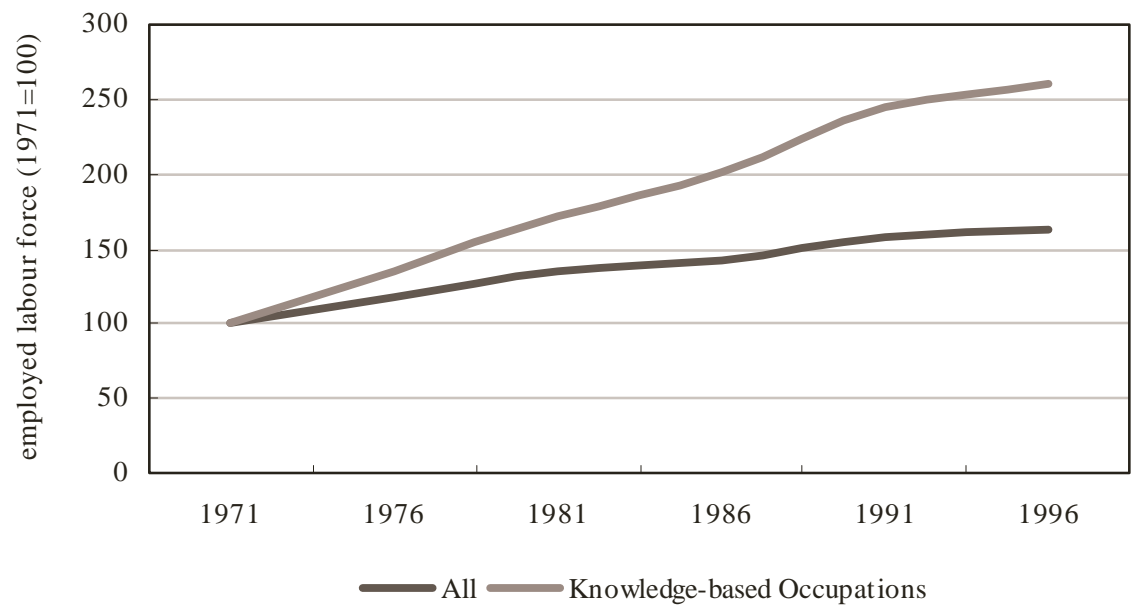

Note: Includes only the employed labour force defined using the 1971 Census labour force concept.

Data for 1976 is estimated as the midpoint between 1971 and 1981.

\subsection{Educational attainment}

In this section, we examine the extent to which knowledge workers are typified by higher levels of education and how this has changed through time. The general increase in the education level of the workforce in general over the past few decades has been welldocumented (Gera and Massé, 1996; Picot and Heisz, 2000). Therefore, our findings should be placed in the context of this phenomenon.

We use two education variables to investigate the prevalence of higher levels of education in the workforce and how this varies across occupation classes. First, we examine the proportion of the workforce with a university-level or professional degree. The second measure takes a broader approach to higher education and includes all persons in the employed labour force who have any post-secondary education.

There has been an increase in the proportion of the labour force that has completed a university-level degree (Figure 3); this concurs with other studies. It is also evident that there is a significant difference in the incidence of degree completion between knowledgebased occupations and other occupations. In 1971, 34\% of knowledge workers had university level degrees compared to slightly less than $3 \%$ of other workers. By 1996, more than half of the people in knowledge-based occupations had university-level degrees compared to less than $10 \%$ of other occupations and $20 \%$ of the total employed labour force. While knowledge-based occupations have a significantly larger proportion of degree holders, the proportion of degree holders is growing faster in other occupational groups (Table 3). These findings confirm that the upskilling of the workforce has affected all occupations within the labour force, but that there are still occupational groups that have relatively higher levels of education. 
Figure 3. Employed labour force with university-level degree, 1971-1996

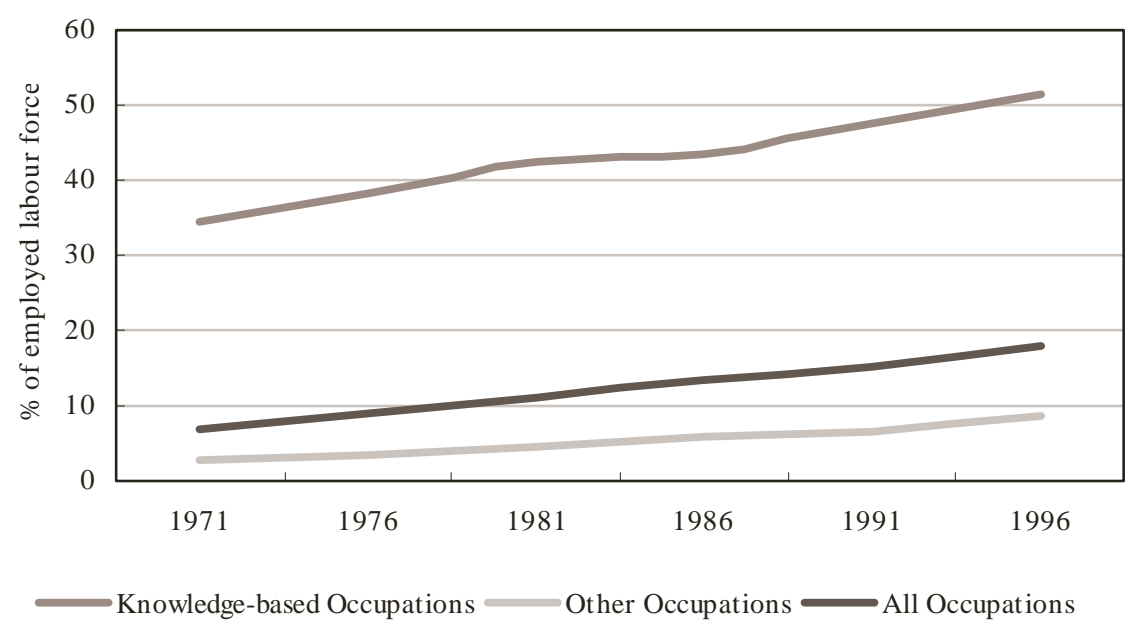

Note: Includes only the employed labour force defined using the 1971 Census labour force concept.

Data for 1976 is estimated as the midpoint between 1971 and 1981.

Degree completion includes the completion of bachelor, professional, masters or doctorate level university degree.

Within knowledge-based occupations, it is evident that there is a general increase in the proportion of persons with degrees in professional and technical occupations (Table 3). In 1971, slightly less than $45 \%$ of professionals had university degrees; by 1996 this had increased to slightly less than $70 \%$. While professionals represent the group with the highest proportion of university graduates, the highest growth rate was experienced in the technical occupation group. The proportion of management occupations with university degrees was relatively constant over the study period and-in fact-experienced a decrease during the 1980s. This may reflect the differences in the types of work done by managers and the value placed on work experience rather than formal education in the ability of managers to perform their tasks (Lavoie and Roy, 1998).

\begin{tabular}{|c|c|c|c|c|c|c|c|}
\hline & 1971 & $1976^{2}$ & 1981 & 1986 & 1991 & 1996 & Growth $^{3}$ \\
\hline All knowledge-based occupations & 34.3 & 38.3 & 42.4 & 43.6 & 47.7 & 51.3 & 1.6 \\
\hline Management occupations & 37.4 & 34.3 & 31.3 & 33.2 & 37.8 & 40.9 & 0.4 \\
\hline Professional occupations & 44.4 & 51.9 & 59.3 & 60.3 & 66.4 & 68.4 & 1.7 \\
\hline Technical occupations & 7.7 & 9.1 & 10.5 & 11.9 & 14.2 & 17.2 & 3.3 \\
\hline All other occupations & 2.7 & 3.6 & 4.5 & 5.9 & 6.5 & 8.6 & 4.8 \\
\hline All occupations & 7.1 & 9.1 & 11.2 & 13.3 & 15.3 & 18.0 & 3.8 \\
\hline
\end{tabular}


Figure 4. Employed labour force with post-secondary education, 1971-1996

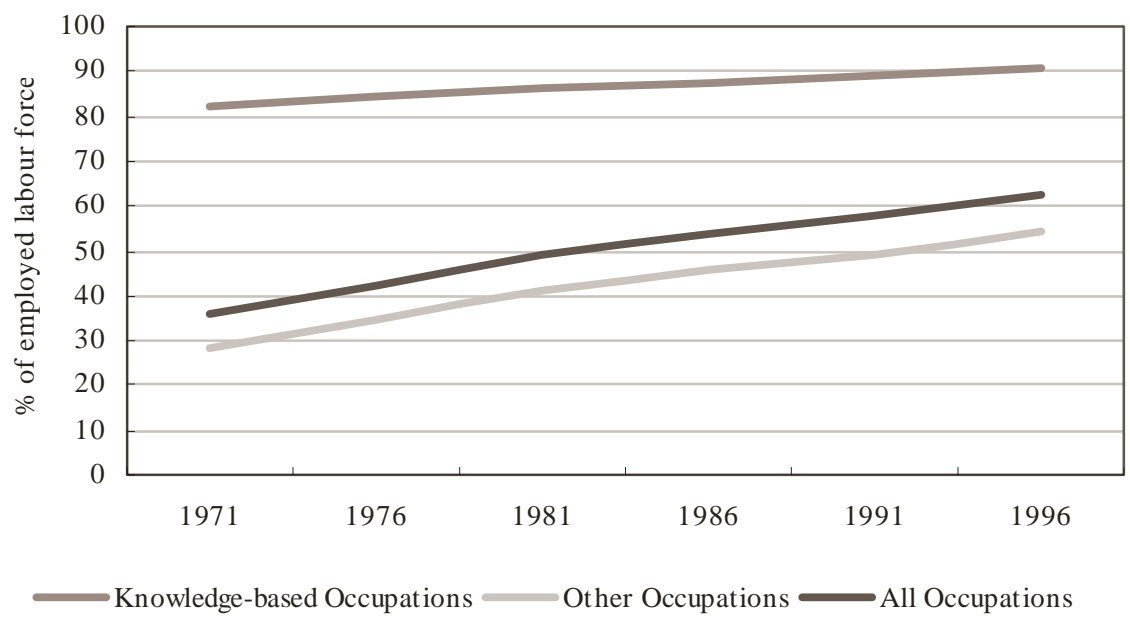

Note: Includes only the employed labour force defined using the 1971 Census labour force concept. Data for 1976 is estimated as the midpoint between 1971 and 1981.

Post-secondary education includes any college, university or other training.

Figure 5. Wage bill and employment shares for knowledge-based occupations, 1971-1996 (in percentage)

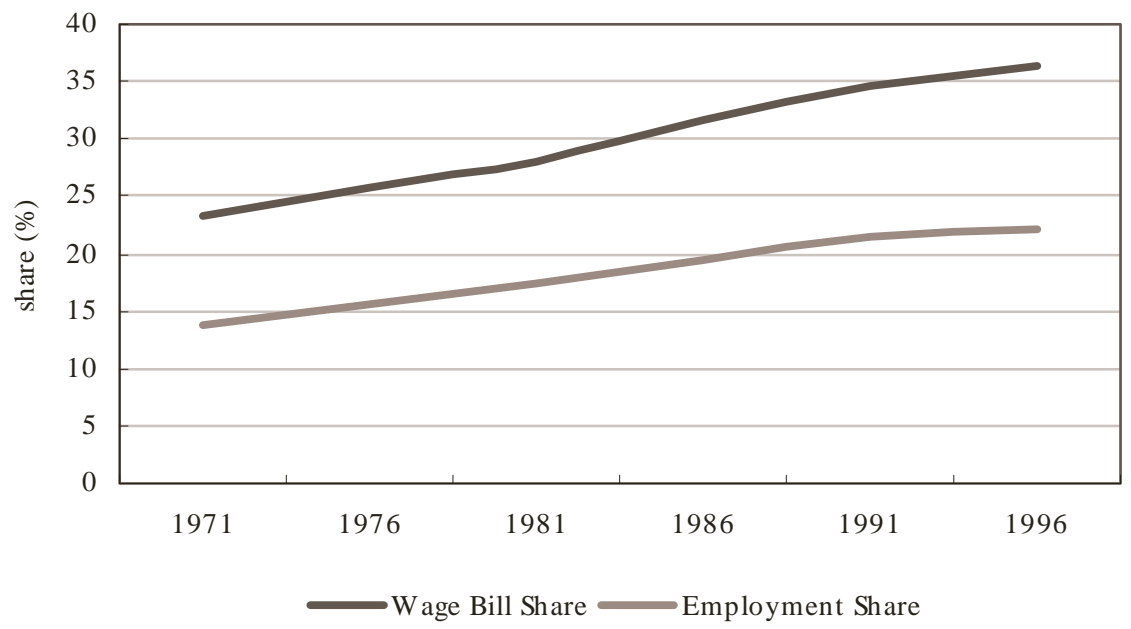

Note: Includes only the employed labour force defined using the 1971 Census labour force concept.

Data for 1976 is estimated as the midpoint between 1971 and 1981.

The trend towards a more educated labour force can be seen even more clearly if we extend our definition of educated persons to include persons with any post-secondary education. Between 1971 and 1996 the proportion of the total employed labour force with some postsecondary education increased from slightly more than $35 \%$ to over $60 \%$ (Figure 4 ). There is a higher proportion of persons with post-secondary education in knowledge-based occupations compared to other occupations, although this gap is slowly narrowing. 


\begin{tabular}{|c|c|c|c|c|c|c|c|}
\hline & 1971 & $1976^{2}$ & 1981 & 1986 & 1991 & 1996 & Growth $^{3}$ \\
\hline All knowledge-based occupations & 82.0 & 84.2 & 86.4 & 87.2 & 89.2 & 90.9 & 0.4 \\
\hline Management occupations & 69.9 & 71.3 & 72.8 & 75.0 & 78.9 & 81.5 & 0.6 \\
\hline Professional occupations & 85.4 & 88.1 & 90.7 & 91.3 & 93.9 & 94.7 & 0.4 \\
\hline Technical occupations & 79.1 & 83.6 & 88.0 & 89.9 & 89.7 & 91.4 & 0.6 \\
\hline All other occupations & 28.2 & 34.6 & 41.1 & 45.5 & 49.2 & 54.5 & 2.7 \\
\hline All occupations & 35.6 & 42.3 & 49.0 & 53.6 & $\mathbf{5 7 . 8}$ & 62.6 & 2.3 \\
\hline \multicolumn{8}{|c|}{$\begin{array}{l}1 \text { The employed labour force is defined using the } 1971 \text { Census labour force concept. Post-secondary education includes any } \\
\text { college, university or other training. }\end{array}$} \\
\hline \multicolumn{7}{|c|}{2 Data for 1976 is estimated as the midpoint between 1971 and 1981.} & \\
\hline
\end{tabular}

The general upskilling of the labour force can be seen in the growth rates of the various occupation groups (Table 4). It is not surprising that growth is highest outside of the knowledge-based occupations, since the latter group already had high proportions of educated persons. By 1996, more than $90 \%$ of knowledge-based occupations were held by persons with at least some level of post-secondary education. When the education measure is broadened to include any level of post-secondary education, the differences between professional and technical occupations are greatly reduced and-in fact-there is a higher proportion of educated persons in the technical group compared to the management category.

\subsection{Earnings and wages of knowledge-based occupations}

At the root of many discussions surrounding the knowledge economy is the notion that knowledge-based jobs receive higher levels of compensation. We use relative average hourly wage rates to determine if knowledge-based occupations receive higher levels of compensation (relative to all occupations) and whether this has changed substantially over the study period.

Estimates of hours were not available for 1971. Consequently, this part of the analysis only covers the period from 1981 to 1996. Additionally, some error is introduced in estimating the total number of hours worked using Census data due to differences in the reference periods for the variables needed to calculate the total number of hours worked in a year (see Appendix 2 for a discussion of these data limitations).

Overall, there is a significant difference between the wage rates of knowledge-based occupations and other occupations (Figure 6). Knowledge occupations maintained wage rates that were substantially higher over the period. There was very little change in the relationship between wage rates for knowledge-based occupations and overall wage rates. Moreover, the average hourly compensation rate for occupations outside of the knowledge group has declined slightly (relative to overall average wage rates) over the period between 1981 and 1996.

We examine the three knowledge-based occupation groups (management, professional, and technical occupations) separately. There is a hierarchy in the relative levels of compensation received by each group with managers receiving the highest wages and technical workers receiving the lowest. However, all receive higher wages relative to other occupations (Figure 7). 
Figure 6. Relative average hourly wage rates by occupation, 1981-1996

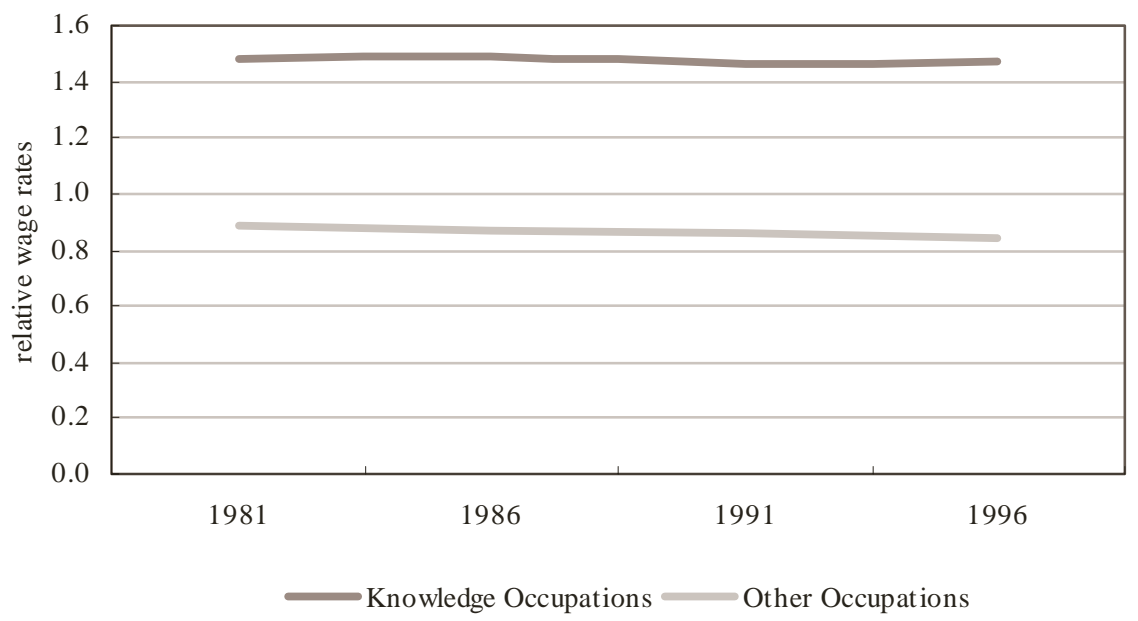

Note: Includes only the employed labour force defined using the 1971 Census labour force concept.

Relative wage rates are equal to one if wage rates are equal to the wage rates for the employed labour force.

Figure 7. Relative average hourly wage rates for knowledge-based occupations, 1981-1996

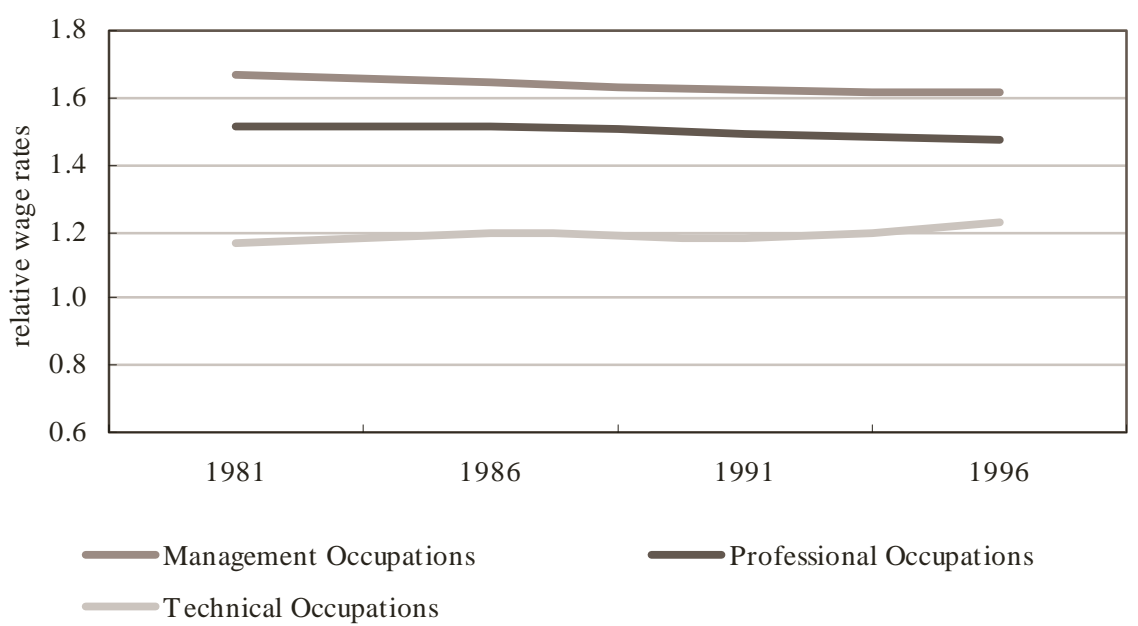

Note: Includes only the employed labour force defined using the 1971 Census labour force concept.

Relative wage rates are equal to one if wage rates are equal to the wage rates for the employed labour force.

While there was stability in the overall relative wages of knowledge-based occupations, there are differences within this group. Both management and professional occupations have experienced a decline in their relative wage rates between 1981 and 1996, whereas technical occupations have experienced an increase in their relative wages during this same period. 
Figure 8. Knowledge intensity by sector, 1971-1996

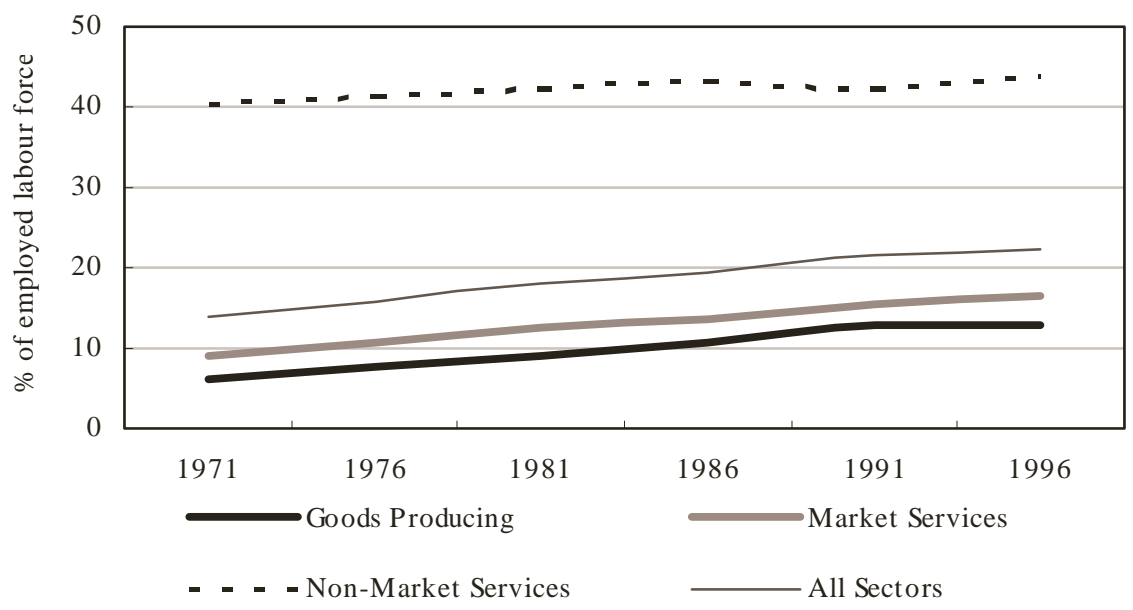

Note: Includes only the employed labour force defined using the 1971 Census labour force concept.

Data for 1976 is estimated as the midpoint between 1971 and 1981.

\subsection{Shifts in Canada's knowledge base: Sectoral evidence}

For the purposes of this analysis, we divide the overall economy into three sectors: goods producing $^{8}$, market services, and non-market services. ${ }^{9}$ It is evident that the growth in Canada's knowledge-based economy has been spurred by growth in the business sector (goods producing and market services). Both the goods producing and market services sector experienced an increase in their level of knowledge intensity (Figure 8). In 1971, the market services sector was slightly more knowledge intensive than the goods producing sector (9\% as compared to 6\%). In 1996 this remained true, as knowledge intensity had increased to $17 \%$ in the market services sector and $13 \%$ in the goods producing sector. The public sector (non-market services) had a much higher level of knowledge intensity throughout the study period, rising from $40 \%$ to $44 \%$. This is not surprising given that we define knowledge workers broadly and include a large number of occupations that are primarily in the public sector, such as doctors, nurses, and university professors. Over the study period there was a much smaller increase in the level of knowledge intensity within the non-market service sector.

As Table 5 indicates, the increase in knowledge intensity has been concentrated in the business sector (goods producing and market services). While the market service sector had a higher proportion of knowledge workers, the goods producing sector experienced a higher growth rate. Growth was strong through the 1970s and 1980s; however growth in knowledge intensity declined in the early 1990s. It is interesting to note that while overall growth in knowledge intensity was low in the early 1990s, the market services sector had a higher growth rate during this period. While the knowledge intensity of the non-market services sector is high, it has had a much slower growth rate over the 25 -year study period. 
Table 5. Average annual growth rates of knowledge intensity by sector (\%), 1971-1996

\begin{tabular}{|lrrrrr|}
\hline & $1971-81$ & $1981-86$ & $1986-91$ & $1991-96$ & $1971-96$ \\
\hline Goods producing & 3.9 & 2.9 & 3.9 & 0.4 & 3.0 \\
Market services & 3.4 & 1.5 & 2.9 & 1.2 & 2.5 \\
Non-market services & 0.4 & 0.5 & $(0.4)$ & 0.6 & 0.3 \\
All sectors & $\mathbf{2 . 4}$ & $\mathbf{2 . 2}$ & $\mathbf{1 . 9}$ & $\mathbf{0 . 6}$ & $\mathbf{1 . 9}$ \\
\hline
\end{tabular}

Note: Knowledge intensity is measured as the employment share of knowledge-based occupations. Average annual growth rates are calculated as compound rates of growth. Includes only the employed labour force defined using the 1971 Census labour force concept.

The shift of employment from the goods-producing sector to the service sector has been well documented. However, despite stagnation in the overall level of employment in the goods producing sector, the number of knowledge workers in this sector continued to increase until the 1990s (Figure 9). In the market services sector, the overall level of employment increased, as did the number of knowledge workers. Indeed, the growth in the absolute number of knowledge workers in both the goods producing and market service sectors outpaced the growth of each sector as a whole.

The market service sector has a higher proportion of employment in knowledge-based occupations compared to the goods producing sector. In addition to small differences in the size and growth rate of each sector, there are some differences in the composition of the knowledge-based workforce (Table 6).

Growth levels in the management category are high across each sub-sector. It should be noted that some of the growth prior to 1981 in this category is artificial, as it results from changes in the occupational coding procedures used between the 1971 Occupational Classification Manual (OCM) and the 1980 Standard Occupational Classification (SOC) (Lavoie and Roy, 1998). While there may be upward bias in these estimates, it affects each sector equally. The management category exhibits consistent growth until the 1990s, when there is a slight decline in the proportion of managers.

\begin{tabular}{|lrrrrrr|r|}
\hline \multicolumn{7}{|l}{ Table 6. Composition of knowledge-based occupations in the business sector, 1971-1996 } \\
\hline \multicolumn{7}{r}{} & \multicolumn{7}{c|}{ Share of employment ${ }^{1}$ (\%) } \\
\cline { 2 - 8 } & 1971 & $1976^{2}$ & 1981 & 1986 & 1991 & 1996 & Growth $^{3}$ \\
\hline Business sector & $\mathbf{7 . 7}$ & $\mathbf{9 . 4}$ & $\mathbf{1 1 . 1}$ & $\mathbf{1 2 . 4}$ & $\mathbf{1 4 . 6}$ & $\mathbf{1 5 . 4}$ & $\mathbf{2 . 8}$ \\
Management & 1.3 & 2.3 & 3.4 & 4.2 & 5.5 & 5.2 & 5.8 \\
Professional & 4.5 & 5.0 & 5.6 & 6.2 & 6.6 & 7.6 & 2.1 \\
Technical & 1.9 & 2.0 & 2.1 & 1.9 & 2.5 & 2.6 & 1.3 \\
Goods producing & $\mathbf{6 . 3}$ & $\mathbf{7 . 7}$ & $\mathbf{9 . 2}$ & $\mathbf{1 0 . 6}$ & $\mathbf{1 2 . 8}$ & $\mathbf{1 3 . 0}$ & $\mathbf{3 . 0}$ \\
Management & 1.2 & 2.1 & 3.1 & 4.1 & 5.3 & 5.1 & 6.0 \\
Professional & 3.3 & 3.6 & 3.9 & 4.4 & 4.3 & 4.6 & 1.3 \\
Technical & 1.8 & 2.0 & 2.1 & 2.1 & 3.2 & 3.4 & 2.5 \\
Market services & $\mathbf{8 . 9}$ & $\mathbf{1 0 . 7}$ & $\mathbf{1 2 . 5}$ & $\mathbf{1 3 . 5}$ & $\mathbf{1 5 . 6}$ & $\mathbf{1 6 . 6}$ & $\mathbf{2 . 5}$ \\
Management & 1.4 & 2.5 & 3.6 & 4.3 & 5.5 & 5.3 & 5.6 \\
Professional & 5.6 & 6.2 & 6.8 & 7.3 & 7.9 & 9.0 & 1.9 \\
Technical & 2.0 & 2.1 & 2.2 & 1.9 & 2.2 & 2.2 & 0.5 \\
\hline
\end{tabular}

1 Includes only the employed labour force defined using the 1971 Census labour force concept.

2 Data for 1976 is estimated as the midpoint between 1971 and 1981.

3 Average annual compound rate of growth between 1971 and 1996. 
Figure 9. Change in employment by sector, 1971-1996 (1971=100)

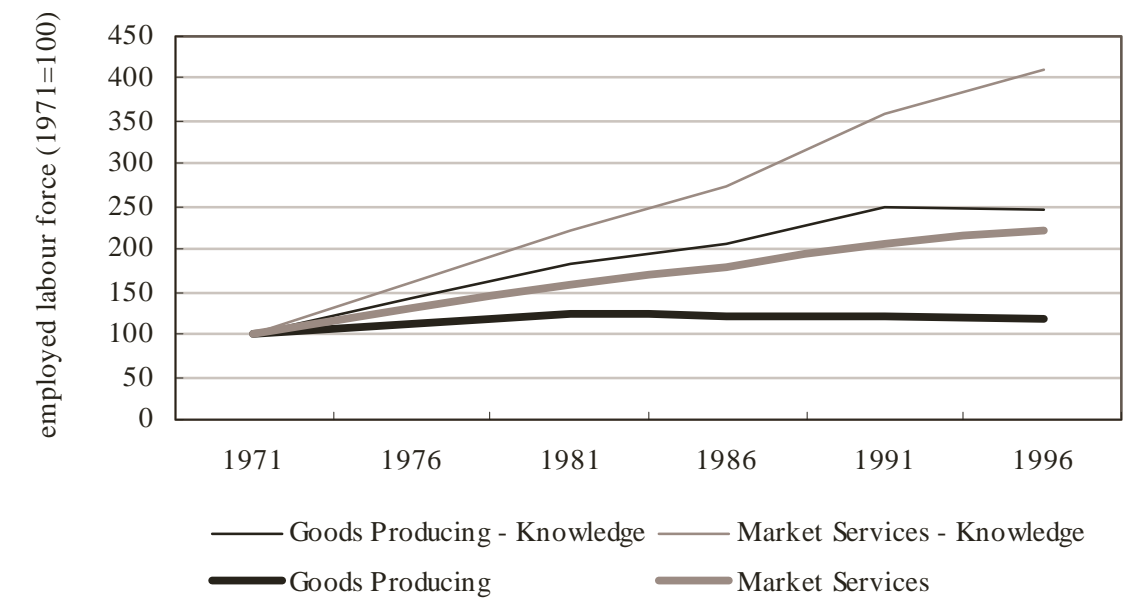

Note: Includes only the employed labour force defined using the 1971 Census labour force concept.

Data for 1976 is estimated as the midpoint between 1971 and 1981.

The real differences lie in the proportion of technical and professional occupations within each sector. Each sector had a similar proportion of knowledge workers in technical occupations until the mid-1980s, when the proportion of technical workers began to grow in the goods producing sector whereas it remained relatively constant in the market services sector. The shares of professional occupations increased in both the goods producing and market services sector. While growth in professional occupations was much higher in the market services sector, growth in technical occupations was much higher in the goods producing sector.

\subsection{Gender dimensions of Canada's knowledge base}

It has been well documented that women have substantially increased their presence in the workforce over the past few decades (Drolet, 2000; Picot and Heisz, 2000). In this section we investigate whether or not these gender shifts in the overall labour force are reflected in the knowledge-based labour force. As we can see in Figure 10, the gender composition of knowledge-based occupations closely mirrors the composition of the total employed labour force. However, it is evident that the pace of change is slower in knowledge-based occupations compared to all occupations. In the early portion of the study period, females accounted for a greater proportion of the knowledge-based workforce than they did in the overall workforce. By the end of the study period, the opposite was true.

To remove the effect of growth in the overall labour force, we examine the proportion of knowledge-based occupations within each gender group. The subset of the male employed labour force that is knowledge-based has grown faster than its female counterpart (Table 7). Growth has been concentrated in the management group for both males and females, although this is more pronounced for females. 
Figure 10. Composition of employed labour force by gender and occupation, 1971-1996 (in percentage)

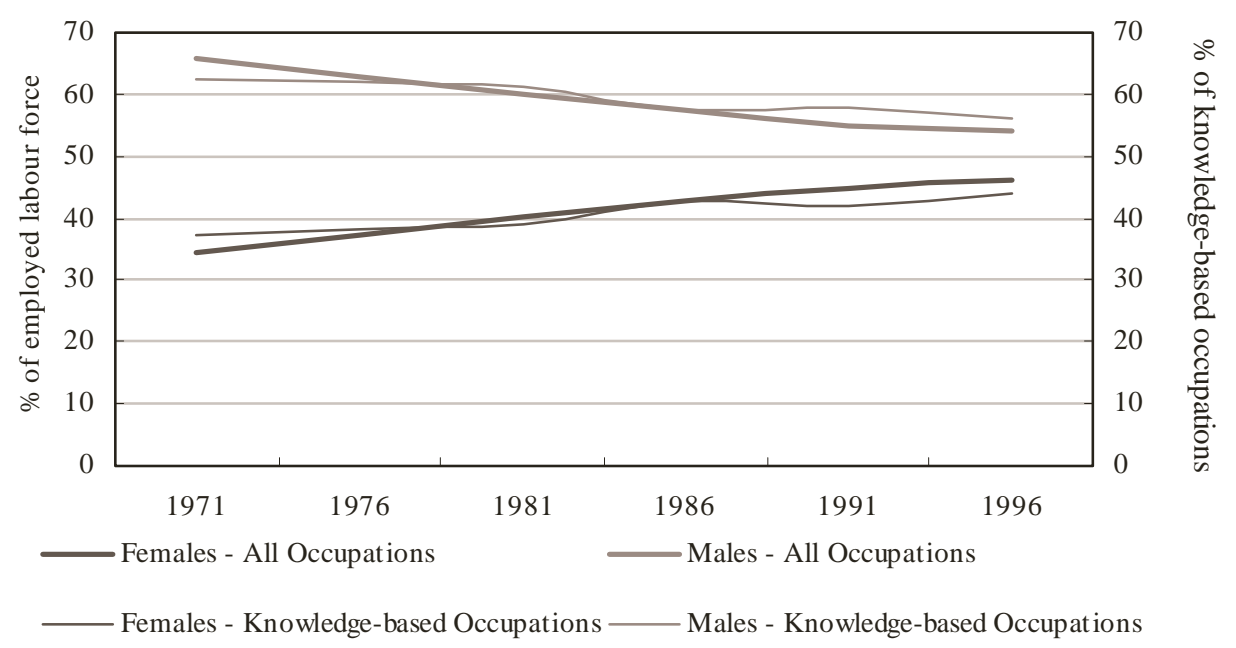

Note: Includes only the employed labour force defined using the 1971 Census labour force concept.

Data for 1976 is estimated as the midpoint between 1971 and 1981.

As noted previously, within each group the overall proportion of knowledge-based occupations has been similar with women having a slightly higher proportion in the early period and men having a higher proportion in the later part of the period. When this is further divided into the three main groups of knowledge-based occupations, we can see that the proportion of professionals within each group is similar. However, on a proportional basis, more female knowledge workers are in technical occupations and more male knowledge workers are in management occupations.

In the previous section, we illustrated that there were differences between sectors in the economy. Specifically, the business sector (goods producing and market services industries) and the public sector (non-market services) have experienced significantly different growth rates. Therefore, in the following sections we examine gender differences in the business and public sectors separately. 
Table 7. Composition of knowledge-based occupations by gender (all sectors), 1971-1996

\begin{tabular}{|lrrrrrrr|}
\hline & \multicolumn{7}{c|}{ Share of employment ${ }^{1}(\%)$} \\
\cline { 2 - 7 } & 1971 & $1976^{2}$ & 1981 & 1986 & 1991 & 1996 & Growth $^{3}$ \\
\hline Both & $\mathbf{1 3 . 8}$ & $\mathbf{1 5 . 9}$ & $\mathbf{1 7 . 5}$ & $\mathbf{1 9 . 5}$ & $\mathbf{2 1 . 5}$ & $\mathbf{2 2 . 2}$ & $\mathbf{1 . 9}$ \\
Management & 1.6 & 2.8 & 3.6 & 4.6 & 5.4 & 5.2 & 4.7 \\
Professional & 8.7 & 9.4 & 9.9 & 10.8 & 11.3 & 12.4 & 1.4 \\
Technical & 3.5 & 3.8 & 4.0 & 4.2 & 4.7 & 4.6 & 1.2 \\
Females & $\mathbf{1 5 . 1}$ & $\mathbf{1 6 . 2}$ & $\mathbf{1 7 . 0}$ & $\mathbf{1 9 . 5}$ & $\mathbf{2 0 . 0}$ & $\mathbf{2 1 . 1}$ & $\mathbf{1 . 3}$ \\
Management & 0.8 & 1.5 & 1.9 & 3.0 & 3.3 & 3.5 & 6.1 \\
Professional & 9.3 & 9.5 & 9.6 & 10.7 & 11.0 & 12.3 & 1.1 \\
Technical & 5.0 & 5.3 & 5.4 & 5.8 & 5.7 & 5.4 & 0.3 \\
Males & $\mathbf{1 3 . 2}$ & $\mathbf{1 5 . 8}$ & $\mathbf{1 7 . 9}$ & $\mathbf{1 9 . 5}$ & $\mathbf{2 2 . 6}$ & $\mathbf{2 3 . 1}$ & $\mathbf{2 . 3}$ \\
Management & 2.1 & 3.5 & 4.7 & 5.8 & 7.1 & 6.6 & 4.7 \\
Professional & 8.4 & 9.3 & 10.1 & 10.8 & 11.6 & 12.4 & 1.6 \\
Technical & 2.7 & 2.9 & 3.1 & 2.9 & 3.9 & 4.0 & 1.7 \\
\hline
\end{tabular}

1 Includes only the employed labour force defined using the 1971 Census labour force concept.

2 Data for 1976 is estimated as the midpoint between 1971 and 1981.

3 Average annual compound rate of growth between 1971 and 1996.

\subsubsection{Gender differences in the business sector}

Similar to the overall economy, the trend in the changing gender composition of the knowledge-based workforce has followed that of all occupations in the business sector (Figure 11). However, there remains a large difference in the distribution of the total employed labour force and the knowledge-based employed labour force in the business sector. The knowledge workforce is composed of a higher proportion of males compared to the overall business sector labour force.

In the business sector, the proportion of knowledge workers was substantially higher in the male employed labour force compared to the female employed labour force (Table 8). In 1971, slightly less than $3 \%$ of the female employed labour force was in knowledge-based occupations compared to almost $9 \%$ of the male employed labour force. By 1996, slightly less than $11 \%$ of the female employed labour force was knowledge-based compared to $18.5 \%$ of the male employed labour force.

\begin{tabular}{|lrrrrrrr|}
\hline \multicolumn{7}{|c|}{ Table 8. Composition of knowledge-based occupations by gender (business sector), 1971-1996 } \\
\hline & \multicolumn{7}{c|}{ Share of Employment ${ }^{1}(\%)$} \\
\cline { 2 - 8 } & 1971 & $1976^{2}$ & 1981 & 1986 & 1991 & 1996 & Growth $^{3}$ \\
\hline Both & $\mathbf{7 . 7}$ & $\mathbf{9 . 7}$ & $\mathbf{1 1 . 1}$ & $\mathbf{1 2 . 4}$ & $\mathbf{1 4 . 6}$ & $\mathbf{1 5 . 4}$ & $\mathbf{2 . 8}$ \\
Management & 1.3 & 2.5 & 3.4 & 4.2 & 5.5 & 5.2 & 5.8 \\
Professional & 4.5 & 5.1 & 5.6 & 6.2 & 6.6 & 7.6 & 2.1 \\
Technical & 1.9 & 2.0 & 2.1 & 1.9 & 2.5 & 2.6 & 1.3 \\
Females & $\mathbf{2 . 9}$ & $\mathbf{5 . 1}$ & $\mathbf{6 . 3}$ & $\mathbf{8 . 2}$ & $\mathbf{9 . 6}$ & $\mathbf{1 0 . 8}$ & $\mathbf{5 . 3}$ \\
Management & 0.5 & 1.3 & 1.8 & 2.6 & 3.2 & 3.4 & 8.1 \\
Professional & 2.0 & 3.0 & 3.7 & 4.8 & 5.2 & 6.3 & 4.8 \\
Technical & 0.5 & 0.7 & 0.8 & 0.8 & 1.1 & 1.1 & 3.3 \\
Males & $\mathbf{9 . 6}$ & $\mathbf{1 1 . 9}$ & $\mathbf{1 3 . 8}$ & $\mathbf{1 4 . 9}$ & $\mathbf{1 7 . 9}$ & $\mathbf{1 8 . 5}$ & $\mathbf{2 . 7}$ \\
Management & 1.6 & 3.1 & 4.3 & 5.2 & 6.9 & 6.4 & 5.8 \\
Professional & 5.5 & 6.1 & 6.6 & 7.1 & 7.5 & 8.4 & 1.7 \\
Technical & 2.4 & 2.7 & 2.9 & 2.6 & 3.4 & 3.6 & 1.6 \\
\hline
\end{tabular}

1 Includes only the employed labour force defined using the 1971 Census labour force concept.

2 Data for 1976 is estimated as the midpoint between 1971 and 1981.

3 Average annual compound rate of growth between 1971 and 1996. 
Figure 11. Composition of employed labour force by gender and occupation (business sector), 1971-1996 (in percentage)

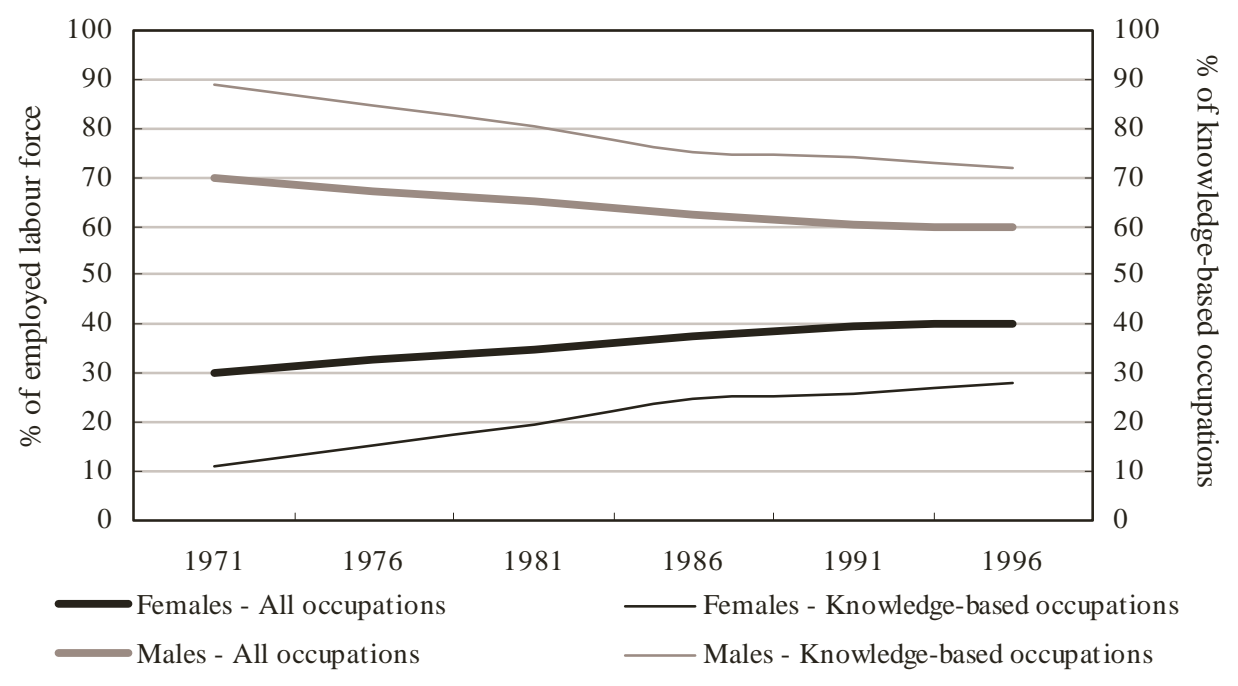

Note: Includes only the employed labour force defined using the 1971 Census labour force concept.

Data for 1976 is estimated as the midpoint between 1971 and 1981.

Contrary to the economy as a whole, the proportion of female knowledge workers has grown faster than its male counterpart. However, similar to the overall trend, growth was highest for both males and females in the management group, although the growth rate for women was much higher. The largest gains for women were in the shares for management and professional occupations.

\subsubsection{Gender differences in the public sector}

Similar to the business sector, the trend in the changing gender composition of the knowledgebased workforce has followed that of all occupations in the public sector (Figure 12). Again, the pace of change in the knowledge-based workforce in the public sector lags that of the public sector as a whole. As in the business sector, the proportion of the workforce accounted for by women is increasing. However, in this case, the shift is from an even split between males and females towards a workforce that is made up of over $65 \%$ females.

Again, to remove the effect of growth in the public sector labour force, we examine the proportion of knowledge-based occupations within each gender group. Overall, the proportion of females in knowledge-based occupations decreased slightly from 1971 to 1996, whereas the proportion of males has increased (Table 9). This change is reflected in the growth rates for each group. For men, growth was spread across all three knowledgebased occupation groups whereas for women high growth in the management group was offset by declines in the proportions of professional and technical occupations. Unlike the business sector, the female knowledge worker population is more heavily weighted towards technical occupations. This is not the case within the male knowledge worker population. The male knowledge worker population is composed of a high proportion of professional and management occupations. 
Figure 12. Composition of the employed labour force by gender and occupation (public sector), 1971-1996 (in percentage)

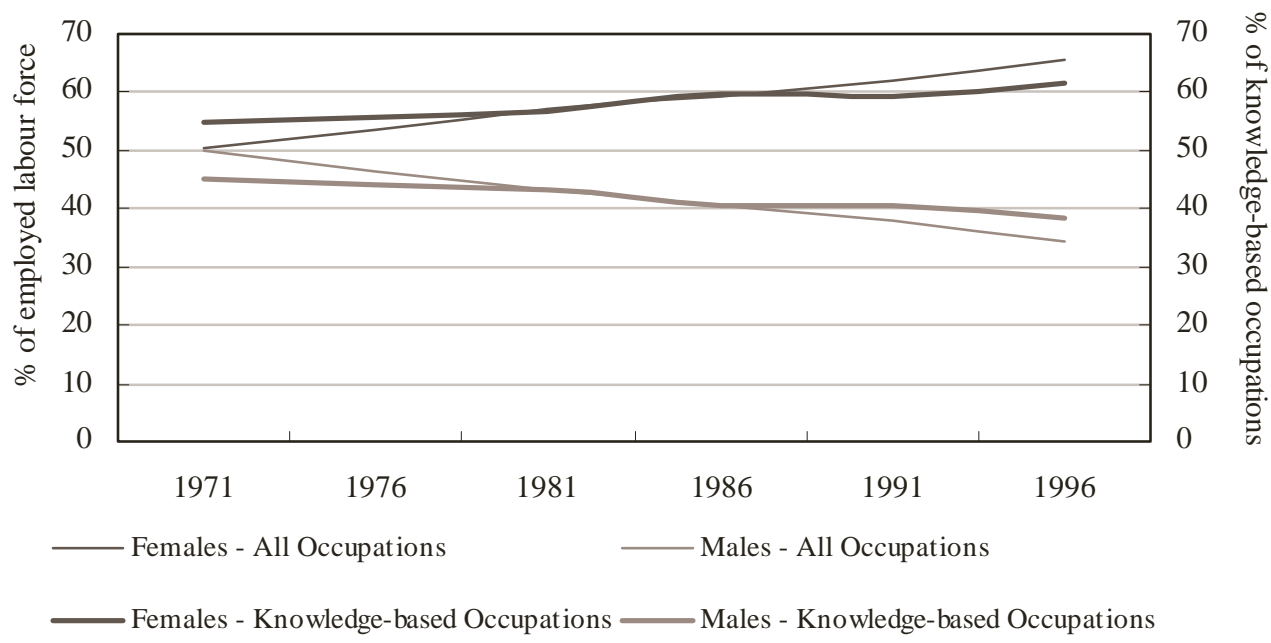

Note: Includes only the employed labour force defined using the 1971 Census labour force concept.

Data for 1976 is estimated as the midpoint between 1971 and 1981.

\begin{tabular}{|c|c|c|c|c|c|c|c|}
\hline & \multicolumn{7}{|c|}{ Share of employment ${ }^{1}(\%)$} \\
\hline & 1971 & $1976^{2}$ & 1981 & 1986 & 1991 & 1996 & Growth $^{3}$ \\
\hline Both & 40.3 & 41.4 & 42.2 & 43.2 & 42.4 & 43.7 & 0.3 \\
\hline Management & 3.5 & 4.2 & 4.7 & 5.8 & 5.2 & 4.9 & 1.4 \\
\hline Professional & 26.6 & 26.4 & 26.3 & 25.9 & 25.7 & 27.7 & 0.2 \\
\hline Technical & 10.3 & 10.8 & 11.1 & 11.6 & 11.5 & 11.1 & 0.3 \\
\hline Females & 44.2 & 42.8 & 41.9 & 43.4 & 40.4 & 41.2 & -0.3 \\
\hline Management & 1.6 & 2.1 & 2.5 & 3.7 & 3.4 & 3.5 & 3.2 \\
\hline Professional & 26.8 & 24.7 & 23.4 & 23.2 & 22.3 & 23.9 & -0.5 \\
\hline Technical & 15.8 & 15.9 & 16.0 & 16.5 & 14.6 & 13.8 & -0.5 \\
\hline Males & 36.5 & 39.8 & 42.5 & 42.9 & 45.7 & 48.6 & 1.2 \\
\hline Management & 5.4 & 6.7 & 7.7 & 8.8 & 8.1 & 7.6 & 1.4 \\
\hline Professional & 26.4 & 28.4 & 30.1 & 29.8 & 31.3 & 34.8 & 1.1 \\
\hline Technical & 4.7 & 4.7 & 4.6 & 4.4 & 6.4 & 6.2 & 1.1 \\
\hline
\end{tabular}

1 Includes only the employed labour force defined using the 1971 Census labour force concept.

2 Data for 1976 is estimated as the midpoint between 1971 and 1981.

3 Average annual compound rate of growth between 1971 and 1996. 


\subsection{Summary}

Overall, we have seen that the proportion of the employed labour force that was knowledgebased has increased from slightly less than $14 \%$ to over $22 \%$ between 1971 and 1996. This suggests that the supply of skilled, knowledge-based workers has increased through this period. The general increase in the level of education across the employed labour force provides further evidence of the changes that have been taking place in the labour force.

It is important to note that the profile of knowledge-based occupations is different from other parts of the labour market. First, despite increases in the level of education achieved across all occupations, the proportion of people in knowledge-based occupations who have completed university remains substantially higher. Moreover, by 1996 , more than $90 \%$ of knowledge workers had at least some post-secondary education compared to just over $50 \%$ in the remainder of the workforce. Second, relative wage rates for persons in knowledgebased occupations are substantially higher than overall wage rates throughout the period.

While the increase in the knowledge base of the economy has been widespread, there are some differences beneath the surface. First, while the proportion of knowledge-based occupations grew at a compound rate of $1.9 \%$ per year between 1971 and 1996, this rate varies substantially between the broad sectors of the economy. Second, the business sector grew at an annual rate of $2.8 \%$ (3.0\% in the goods producing sector and $2.5 \%$ in the market services sector). Canada's public sector, comprised of government, health and education services, had a labour force with a high proportion of knowledge workers, but exhibited a very low growth rate of $0.3 \%$ per year. The business sector, like the overall economy, witnessed the highest growth rates in management occupations.

Second, there are some differences in the proportion of men and women within knowledgebased occupations beyond the differences associated with the general structure of the labour force. Overall, the proportion of the male labour force in knowledge-based occupations grew faster than the proportion of the female labour force in knowledge-based occupations. There are greater gender differences when we examine the business and public sectors separately. In the business sector, knowledge-based occupations accounted for an increasing percentage of workers in both the male and female labour forces. While growth rates for female knowledge workers were higher than for male knowledge workers, a substantially higher proportion of the male labour force was in knowledge-based occupations compared to the female labour force. Within the male public sector workforce, there has been an increase in the proportion of knowledge-based occupations, whereas the opposite is true of the female public sector workforce. These changes are reflected in their growth rates. However, growth rates for female managers were higher than for other knowledge-based occupations across all sectors. 
As we have shown in this section, the business sector has been the key engine for the growth and shift towards a more knowledge intensive economy within Canada. Therefore, in the next two chapters, we examine differences within the business sector. Chapter 5 examines the differences across industries in more detail. Chapter 6 examines whether or not there are geographical dimensions to shifts in the Canadian experience. Finally, chapter 7 uses a multivariate analysis to determine whether or not these geographic and industrial patterns persist after controlling for industrial and spatial structure. 


\section{Endnotes}

${ }^{6}$ While the term 'knowledge worker' has been used extensively in both the popular and academic press, in this paper it refers to the 3 broad groups of knowledge-based occupations (management, professional, technical) as described in chapter 3. The term 'knowledge intensity' refers to the proportion or percentage of knowledge workers within a given class or category of the employed labour force.

${ }^{7}$ Growth in the management category has been documented elsewhere. Differences in the coding procedures between the 1971 OCM and the 1980 SOC result in an upward bias in the growth of the management category between 1971 and 1981. Moreover, it is often difficult to assign managers to specific managerial occupations if the respondent does not provide detailed information (see Picot and Lavallée, 1986; Lavoie and Roy, 1998; Marshall, 1996).

${ }^{8}$ In this analysis, the goods producing sector includes agriculture; fishing and trapping; logging and forestry; mining, quarrying and oil wells; manufacturing; and construction. Our convention differs slightly from the 1980 Standard Industrial Classification in which the 'other utility industry' (part of the Communication and Other Utility industry division) is classified as part of the goods producing sector. For ease of exposition, we treat the 'other utility industry' as a service in order to draw simple distinctions between industry divisions - the industry level used throughout most of this paper.

9 Non-market services include government, educational, and health and social services. It should be noted that even though there are crown corporations and some private firms operating in these industries, these are excluded from the business sector in this analysis. Similarly, there are some non-commercial enterprises operating in the goods producing and market services sectors. 


\section{Chapter 5. Shifts in Canada's knowledge-base: Industry dimensions}

D revious studies have provided evidence that output and employment growth has been particularly concentrated in high-technology industries (Lee and Has, 1996; Gera and Massé, 1996; Gera and Mang, 1997). However, other studies have indicated that the growth of knowledge-based occupations has not been limited to industries commonly thought of as high-technology (Lavoie and Roy, 1998). In this study, we ask if this growth has been concentrated in some industries or whether it has been dispersed across the Canadian economy. Thus, this chapter explores how the growth in knowledge occupations has varied across Canada's industries.

Similar to the trend we saw at the aggregate sector level, there has been an increase in the level of knowledge intensity across all industry divisions, with the exception of the accommodation, food, and beverage services industry (Table 10). This suggests that the increase in knowledge intensity (i.e., the proportion of the employed labour force in knowledge-based occupations) has been pervasive and has affected all aspects of the Canadian economy.

The largest absolute increases in the level of knowledge intensity were seen in the logging and forestry (14\%), wholesale trade (13\%), finance and insurance (14\%), and business services industries (10\%). While the latter three are in the market service sector, the former is in the goods producing sector and is related to natural resources.

The data suggest that most of the industries in the primary sector (agriculture; fishing and trapping; logging and forestry; and mining, quarrying, and oil wells) experienced high average annual increases in their level of knowledge intensity. This is an interesting finding given that these same sectors have experienced declining employment shares throughout the study period.

In the market services sector, the highest rate of growth was experienced in wholesale trade. Despite a substantial increase in the proportion of knowledge workers, the business services industries posted lower levels of annual growth. This is probably due to the fact that the business services sector was much more knowledge intensive throughout the entire 25-year period.

As seen above, there were high rates of growth in knowledge intensity in sectors not often associated with the 'new economy'. To further explore this finding, we examine only the changes and growth of professional occupations related to the natural and applied sciences, 


\begin{tabular}{|c|c|c|c|c|c|c|c|c|}
\hline \multirow[b]{2}{*}{ Industry division } & \multicolumn{8}{|c|}{ Share of employment ${ }^{2}(\%)$} \\
\hline & 1971 & $1976^{3}$ & 1981 & 1986 & 1991 & 1996 & Change $^{4}$ & ${ }^{4}$ Growth $^{5}$ \\
\hline Agriculture and related services & 0.6 & 0.9 & 1.3 & 1.8 & 3.3 & 3.6 & 3.1 & 7.8 \\
\hline Fishing and trapping & 2.3 & 3.8 & 5.3 & 4.1 & 6.8 & 7.8 & 5.4 & 4.9 \\
\hline Logging and forestry & 6.3 & 9.2 & 12.1 & 13.3 & 15.3 & 19.9 & 13.6 & 4.7 \\
\hline Mining, quarrying and oil wells & 13.9 & 16.8 & 19.8 & 23.2 & 24.4 & 23.4 & 9.5 & 2.1 \\
\hline Manufacturing & 7.9 & 9.5 & 11.1 & 13.1 & 16.5 & 16.5 & 8.6 & 3.0 \\
\hline Construction & 4.6 & 4.9 & 5.2 & 6.0 & 7.3 & 7.2 & 2.5 & 1.8 \\
\hline All goods producing industries & 6.3 & 7.7 & 9.2 & 10.6 & 12.8 & 13.0 & 6.8 & 3.0 \\
\hline Transportation and storage & 7.1 & 8.7 & 10.3 & 11.2 & 10.3 & 9.8 & 2.7 & 1.3 \\
\hline Communication and other utility & 13.8 & 16.9 & 20.1 & 20.7 & 24.2 & 23.6 & 9.8 & 2.2 \\
\hline Wholesale trade & 6.5 & 7.5 & 8.5 & 10.2 & 17.0 & 19.0 & 12.5 & 4.4 \\
\hline Retail trade & 3.2 & 3.3 & 3.4 & 4.0 & 4.5 & 3.8 & 0.7 & 0.8 \\
\hline Finance and insurance & 19.5 & 23.1 & 26.7 & 30.8 & 28.1 & 33.6 & 14.2 & 2.2 \\
\hline Real estate operator and insurance agent & 6.9 & 8.8 & 10.7 & 11.0 & 12.1 & 13.0 & 6.1 & 2.5 \\
\hline Business service & 40.6 & 42.0 & 43.4 & 44.4 & 48.2 & 50.6 & 10.0 & 0.9 \\
\hline $\begin{array}{l}\text { Accommodation, food and beverage } \\
\text { services }\end{array}$ & 1.2 & 1.3 & 1.3 & 1.8 & 2.2 & 1.2 & 0.0 & -0.1 \\
\hline Other services & 6.4 & 9.0 & 11.6 & 11.5 & 12.4 & 12.6 & 6.1 & 2.7 \\
\hline All market services & 8.9 & 10.7 & 12.5 & 13.5 & 15.6 & 16.6 & 7.6 & 2.5 \\
\hline Total business sector & 7.7 & 9.4 & 11.1 & 12.4 & 14.6 & 15.4 & 7.8 & 2.8 \\
\hline \multicolumn{9}{|c|}{1 Knowledge intensity is measured as the employment share of knowledge-based occupations. } \\
\hline \multicolumn{9}{|c|}{2 Includes only the employed labour force defined using the 1971 Census labour force concept. } \\
\hline \multicolumn{9}{|c|}{3 Data for 1976 is estimated as the midpoint between 1971 and 1981.} \\
\hline \multicolumn{9}{|c|}{4 Difference in employment shares between 1971 and 1996. Numbers may not add due to rounding. } \\
\hline
\end{tabular}

a category that includes scientists, engineers, and computer specialists. This sub-group of workers is often considered to be at the forefront of technological advance and innovation, viewed as key ingredients in the development of the 'new economy' (Lee and Has, 1996).

Overall, professionals in sciences-related occupations increased their share from $1.8 \%$ to $3.0 \%$ of the employed business sector labour force over the 25 -year study period (Table 11). In 1971, there was a slightly higher proportion of science-related professionals in the goods producing sector $(2.0 \%)$ compared to the market services sector (1.6\%). By 1996, the reverse was true. Only $2.8 \%$ of the employed labour force in the goods producing sector were science-related professionals, as compared to $3.1 \%$ in the market services sector.

There was an absolute increase in the proportion of science-related professionals across almost all industry divisions, with the exception of construction where there was a slight decline, and in the accommodation, food, and beverage services industry where there was little change over the study period. These same two industries were the only industries to experience declines rather than growth on average in the proportion of science-related professionals over the 25-year period. The largest increases were experienced in logging and forestry (2\%), finance and insurance (2\%), and business services (4\%). Business services was characterized by a very high proportion of scientific personnel, followed by communications and other utilities and mining, quarrying, and oil wells.

Similar to the overall trend for knowledge-based occupations, when we examine only science-related occupations there is growth across most industry sectors. Again, this suggests 
Figure 13. Proportion of knowledge-based occupations in Canadian manufacturing by Robson ${ }^{1}$ innovative sector, 1971-1996

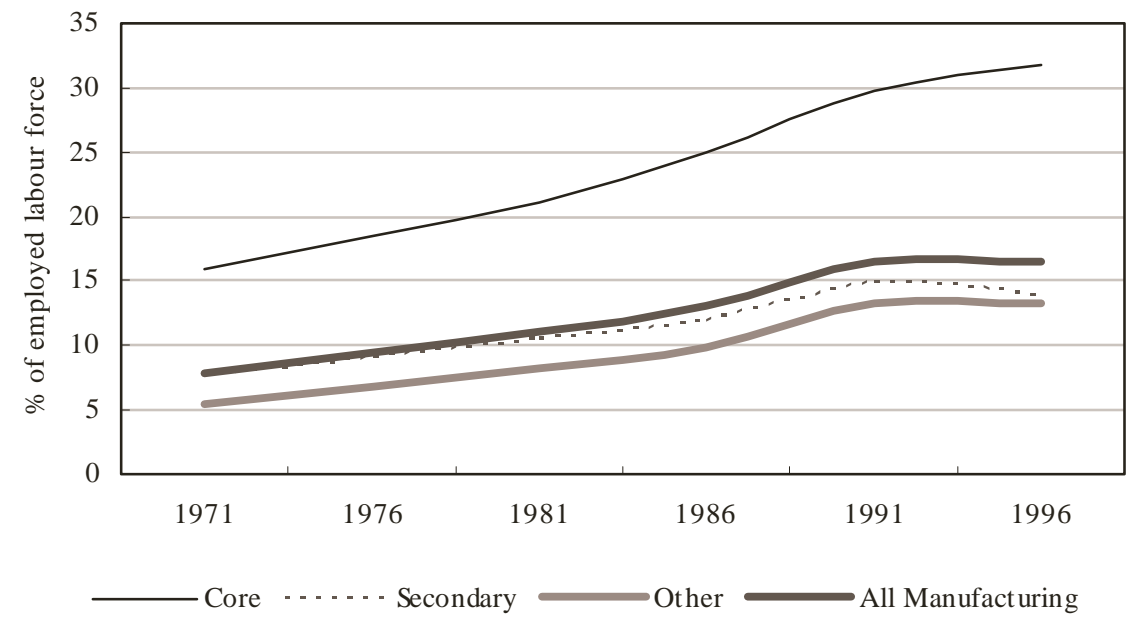

Note: Includes only the employed labour force defined using the 1971 Census labour force concept.

Data for 1976 is estimated as the midpoint between 1971 and 1981.

1 See Robson et al., 1988.

proportion of knowledge-based occupations, followed by the secondary manufacturing sector, and then the remainder of the manufacturing sector. It is evident that the most significant difference is between the core manufacturing sector and the other two manufacturing sectors.

Table 12 shows the changes by knowledge-based occupation across the three sectors of the Canadian manufacturing industry, as well as average annual growth rates. The core sector has the highest proportion of knowledge workers across all categories and experienced the largest increases, more than doubling its proportion of knowledge-based employment. It is also interesting to note that, despite possessing lower levels of knowledgebased employment, the 'other' manufacturing sector had the highest growth rate and more than doubled its proportion of knowledge-based employment. The management category experienced the largest increases and high growth rates across all manufacturing sectors. 


\begin{tabular}{|c|c|c|c|c|c|c|c|c|}
\hline & \multicolumn{8}{|c|}{ Share of Employment ${ }^{2}(\%)$} \\
\hline & 1971 & $1976^{3}$ & 1981 & 1986 & 1991 & 1996 & Change $^{4}$ & Growth $^{5}$ \\
\hline Manufacturing & 7.9 & 9.5 & 11.1 & 13.1 & 16.5 & 16.5 & 8.6 & 3.0 \\
\hline Management & 1.6 & 3.0 & 4.3 & 5.6 & 7.7 & 7.1 & 5.5 & 6.2 \\
\hline Professional & 4.1 & 4.2 & 4.3 & 5.1 & 5.3 & 5.8 & 1.7 & 1.4 \\
\hline Technical & 2.3 & 2.4 & 2.5 & 2.5 & 3.5 & 3.6 & 1.4 & 1.9 \\
\hline Core & 15.8 & 18.4 & 21.1 & 25.0 & 29.7 & 31.7 & 15.9 & 2.8 \\
\hline Management & 2.2 & 4.1 & 6.0 & 8.0 & 11.0 & 10.2 & 8.1 & 6.4 \\
\hline Professional & 7.8 & 8.3 & 8.7 & 10.6 & 10.6 & 12.6 & 4.8 & 1.9 \\
\hline Technical & 5.8 & 6.1 & 6.4 & 6.4 & 8.1 & 8.8 & 3.0 & 1.7 \\
\hline Secondary & 7.6 & 9.0 & 10.4 & 11.9 & 14.8 & 13.8 & 6.2 & 2.4 \\
\hline Management & 1.4 & 2.7 & 3.9 & 4.9 & 6.5 & 5.7 & 4.3 & 5.8 \\
\hline Professional & 3.9 & 4.0 & 4.1 & 4.7 & 4.9 & 4.7 & 0.8 & 0.8 \\
\hline Technical & 2.3 & 2.4 & 2.4 & 2.3 & 3.4 & 3.4 & 1.1 & 1.6 \\
\hline Other & 5.4 & 6.8 & 8.2 & 9.8 & 13.2 & 13.2 & 7.8 & 3.6 \\
\hline Management & 1.5 & 2.8 & 4.0 & 5.1 & 7.3 & 7.0 & 5.5 & 6.4 \\
\hline Professional & 2.9 & 3.0 & 3.0 & 3.5 & 3.8 & 4.2 & 1.3 & 1.5 \\
\hline Technical & 1.0 & 1.1 & 1.1 & 1.2 & 2.1 & 2.0 & 1.0 & 2.7 \\
\hline
\end{tabular}

1 See Robson et al., 1988.

2 Includes only the employed labour force defined using the 1971 Census labour force concept.

3 Data for 1976 is estimated as the midpoint between 1971 and 1981.

4 Difference between 1971 and 1996. Numbers may not add due to rounding.

5 Average annual compound rate of growth between 1971 and 1996. 


\section{Chapter 6. Geographic dimensions of Canada's evolving knowledge economy}

$W$ hile a number of studies have examined the industrial dimensions of the evolving knowledge economy, few have explored the geographic dimensions of Canada's knowledge-based economy from an occupational perspective. In this chapter, we pose two questions. First, we ask how the knowledge economy has developed across Canada's provinces and regions. Second, we ask if there is an urban-rural dimension to this development.

To explore whether there are geographic differences in the development of Canada's knowledge-based economy (defined from an occupational perspective), we examine the changing proportion of knowledge workers found across Canada's ten provinces and two territories. ${ }^{10}$ A steady increase in the proportion of knowledge-based occupations was experienced across all of Canada's provinces and territories (Table 13). The highest proportions of knowledge-based workers were found in Quebec and Ontario, followed by Alberta, British Columbia and the Territories. These same provinces and territories also experienced the largest increase over the 25-year study period. There were very few differences in the average annual compound growth rates between the provinces and territories. However, growth rates were slightly higher in Saskatchewan, New Brunswick and Prince Edward Island.

\begin{tabular}{|c|c|c|c|c|c|c|c|c|}
\hline & \multirow[b]{2}{*}{1971} & \multirow[b]{2}{*}{$1976^{2}$} & \multicolumn{6}{|c|}{ Share of Employment ${ }^{1}(\%)$} \\
\hline & & & 1981 & 1986 & 1991 & 1996 & Change $^{3}$ & Growth ${ }^{4}$ \\
\hline Newfoundland & 5.8 & 6.8 & 7.8 & 8.6 & 9.8 & 11.1 & 5.2 & 2.6 \\
\hline Prince Edward Island & 3.7 & 5.2 & 6.7 & 6.8 & 7.7 & 8.6 & 4.9 & 3.4 \\
\hline Nova Scotia & 6.1 & 7.6 & 9.2 & 9.8 & 11.1 & 11.4 & 5.3 & 2.5 \\
\hline New Brunswick & 5.4 & 6.9 & 8.4 & 9.2 & 10.3 & 11.2 & 5.8 & 3.0 \\
\hline Quebec & 8.4 & 9.9 & 11.3 & 12.9 & 15.5 & 16.5 & 8.1 & 2.7 \\
\hline Ontario & 8.2 & 10.1 & 12.0 & 13.2 & 16.0 & 16.7 & 8.5 & 2.9 \\
\hline Manitoba & 6.2 & 7.6 & 9.1 & 9.9 & 11.2 & 11.7 & 5.5 & 2.6 \\
\hline Saskatchewan & 3.9 & 5.3 & 6.7 & 7.6 & 8.6 & 9.0 & 5.2 & 3.4 \\
\hline Alberta & 7.4 & 9.9 & 12.4 & 13.5 & 14.4 & 14.7 & 7.4 & 2.8 \\
\hline British Columbia & 7.7 & 9.1 & 10.5 & 11.9 & 13.8 & 15.2 & 7.5 & 2.7 \\
\hline Yukon Territory & 8.1 & 10.4 & 12.7 & 12.5 & 13.3 & 14.8 & 6.7 & 2.4 \\
\hline Northwest Territories & 7.9 & 10.8 & 13.6 & 14.8 & 13.4 & 14.3 & 6.4 & 2.4 \\
\hline CANADA & 7.7 & 9.4 & 11.1 & 12.4 & 14.6 & 15.4 & 7.8 & 2.8 \\
\hline
\end{tabular}

1 Includes only the employed labour force defined using the 1971 Census labour force concept.

2 Data for 1976 is estimated as the midpoint between 1971 and 1981.

3 Difference between 1971 and 1996. Numbers may not add due to rounding.

4 Average annual compound rate of growth between 1971 and 1996. 
Figure 14. Knowledge intensity by region, 1971-1996

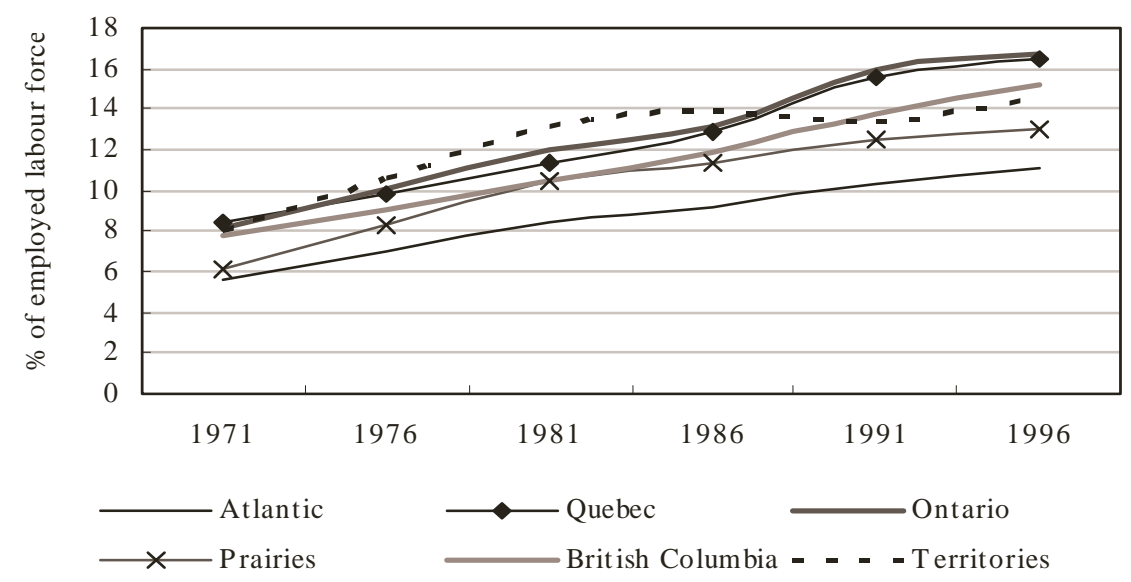

Note: Includes only the employed labour force defined using the 1971 Census labour force concept.

Data for 1976 is estimated as the midpoint between 1971 and 1981.

For ease of exposition, we illustrate this trend graphically for Canada's six main regions: Atlantic, Quebec, Ontario, Prairies, British Columbia and the Territories ${ }^{11}$ (Figure 14). The Ontario and Quebec regions had similar patterns of growth increasing from just over $8 \%$ to approximately $17 \%$ over the 25 -year period. The Prairies experienced a sharp increase in the 1970s, but growth flattened in the 1980s and 1990s. A similar pattern can be noted for the Territories.

This regional trend can be seen in Table 14, which shows the average annual rates of growth across all five regions. As seen earlier, growth was strongest in the early period and slowed considerably in the 1990s. It is also evident that —in the long run-all six regions experienced similar growth rates, with the knowledge-based labour force growing by approximately $2.8 \%$ per year.

Even though these regions have similar growth rates, there are differences in the geographic structure of these regions that may explain the absolute differences in the proportion of knowledge workers. One plausible explanation for these absolute regional disparities is the degree of urbanization in each region. Ontario, Quebec, and British Colombia, with the highest proportion of knowledge workers, are also home to Canada's largest urban centres, as well as a number of small- and medium-sized cities. Furthermore, predominantly rural areas are often construed as being backwaters of the 'new economy'. The Prairie and Atlantic regions have more rural areas, but are also home to some of Canada's larger urban centres (e.g., Calgary, Edmonton, Winnipeg, Regina, and Saskatoon in the Prairies and Halifax, St. John's, and Fredericton in the Atlantic region). Therefore, we examine whether or not there is an urban-rural dimension to the development of Canada's knowledge-based labour force. 


\begin{tabular}{|lrrrrr|}
\hline \multicolumn{6}{|c|}{ Table 14. Average annual knowledge intensity growth rates by region (\%), 1971-1996 } \\
\hline & $1971-1981$ & $1981-1986$ & $1986-1991$ & $1991-1996$ & $1971-1996$ \\
\hline Atlantic region & 4.2 & 1.6 & 2.4 & 1.3 & 2.7 \\
Quebec region & 3.0 & 2.6 & 3.8 & 3.9 & 2.7 \\
Ontario region & 3.8 & 2.0 & 1.9 & 0.9 & 2.9 \\
Prairies region & 5.5 & 1.6 & 2.9 & 2.0 & 3.0 \\
British Columbia & 3.1 & 1.1 & -0.8 & 1.7 & 2.7 \\
Territories & 5.1 & $\mathbf{2 . 2}$ & $\mathbf{3 . 3}$ & $\mathbf{1 . 1}$ & 2.4 \\
Overall & $\mathbf{3 . 8}$ & & & $\mathbf{2 . 8}$ \\
\hline
\end{tabular}

\begin{tabular}{|ll|}
\hline \multicolumn{2}{|l|}{ Table 15. Urban-rural definitions based on Census data } \\
\hline Category & Description \\
\hline Urban & $\begin{array}{l}\text { Minimum population of } 1000 \text { and population density of at least } 400 \text { persons per } \\
\text { square kilometre }\end{array}$ \\
Large Urban Areas & Urban population of at least 100,000 \\
Medium Urban Areas & Urban population between 30,000 and 100,000 \\
Small Urban Areas & Urban population of less than 30,000 \\
Rural & Population less than 1000 or population density of less than 400 persons per square \\
& kilometre
\end{tabular}

Note: See Statistics Canada (1999) for more discussion of the urban area concept. For reasons of historical comparability, there were some limitations to the urban size categories we could develop.

Canada's urban-rural hierarchy can be delineated in a number of different ways (see Du Plessis, et al., 2001). In this paper, we utilize Statistics Canada's census definition of 'rural' areas, which identifies rural areas on the basis of population size and density. Urban areas are defined as those areas that have a minimum population of 1000 and a population density of at least 400 persons per square kilometre, based on the previous census. ${ }^{12}$ All persons living outside of these centres are considered part of the rural population. Using this definition, we first divide Canada's population into urban and rural sub-populations. We further subdivide the urban population into three categories based on population size (Table 15).

We examine how the urban-rural relationship has changed across Canada. Again, for ease of exposition, we examine differences across Canada's six major regions. First, we investigate how the urban-rural split manifests itself across Canada's regions. Second, we further disaggregate the urban component into the three categories described in Table 15 by examining the overall national urban-rural hierarchy and then the extent to which this hierarchy exists across Canada's regions.

Throughout the study period, the level of knowledge intensity was much higher in urban areas than in rural areas, but this disparity lessened over the study period in all regions except for British Columbia and the Territories (Figure 15). The biggest change occurred in the 1970s when the differences between urban and rural areas were reduced considerably over the decade. This gap was reduced even further throughout the 1980s and 1990s. In this period, Canada's regions (with the exception of the Prairies region) converged to have similar urban-rural ratios with urban areas having a knowledge-based workforce that was between 1.5 and 1.8 times larger on a proportional basis. In the Prairies region, the urban areas continued to have an even higher proportion of knowledge workers compared to rural areas. 
Figure 15. Ratio of urban-rural knowledge intensities by region, 1971-1996

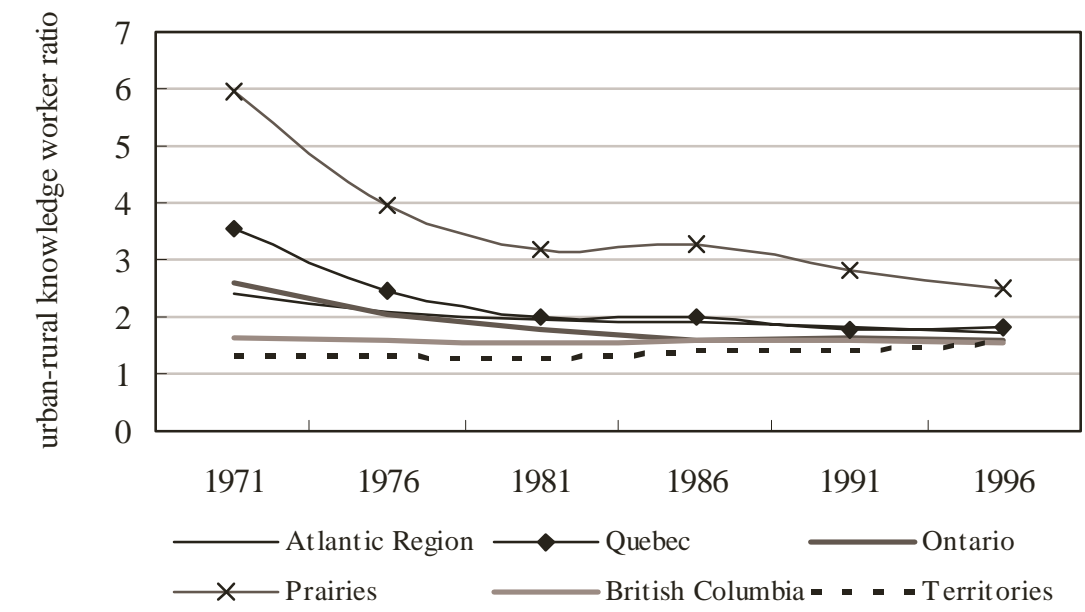

Note: Includes only the employed labour force defined using the 1971 Census labour force concept.

Data for 1976 is estimated using 1971 and 1981 data.

We extend this analysis to examine the full urban-rural hierarchy, rather than using just a simple urban-rural split. We examine the extent to which this hierarchy exists at the national level and how it has changed through time. As can be seen in Figure 16, there is a clear correlation between urban population size and the level of knowledge-intensity. There have been some shifts in the nature of this relationship. Over the 1971 to 1996 period, the largest gains have been in the rural areas and large urban areas. There has been a divergence in the levels of knowledge intensity between the largest urban centres and other parts of the country. Moreover, the data indicate a convergence in the levels of knowledge intensity between rural areas and small- and medium-sized urban areas. However, it is important to note that the level of knowledge intensity has increased across all parts of Canada's urban-rural hierarchy over the study period.

This trend becomes more evident in examining average annual growth rates for knowledgebased occupations across Canada's urban-rural hierarchy (Table 16). The rate of growth was highest in rural Canada. Rural employment in knowledge-based occupations grew at slightly less than $5 \%$ per year over the 25 -year study period, higher than in urban areas of any size. Within urban areas, the highest rates of knowledge-based employment growth were experienced in the largest urban centres.

The hierarchy observed at the national level can also be seen across Canada's regions, with large urban centres having the highest proportion of knowledge-based occupations and rural areas having the lowest (Table 16). However, the degree to which this hierarchy exists differs between regions. The hierarchy is most pronounced in the Prairies region and least pronounced in British Columbia. 
Figure 16. Knowledge intensity across Canada's urban-rural hierarchy, 1971-1996

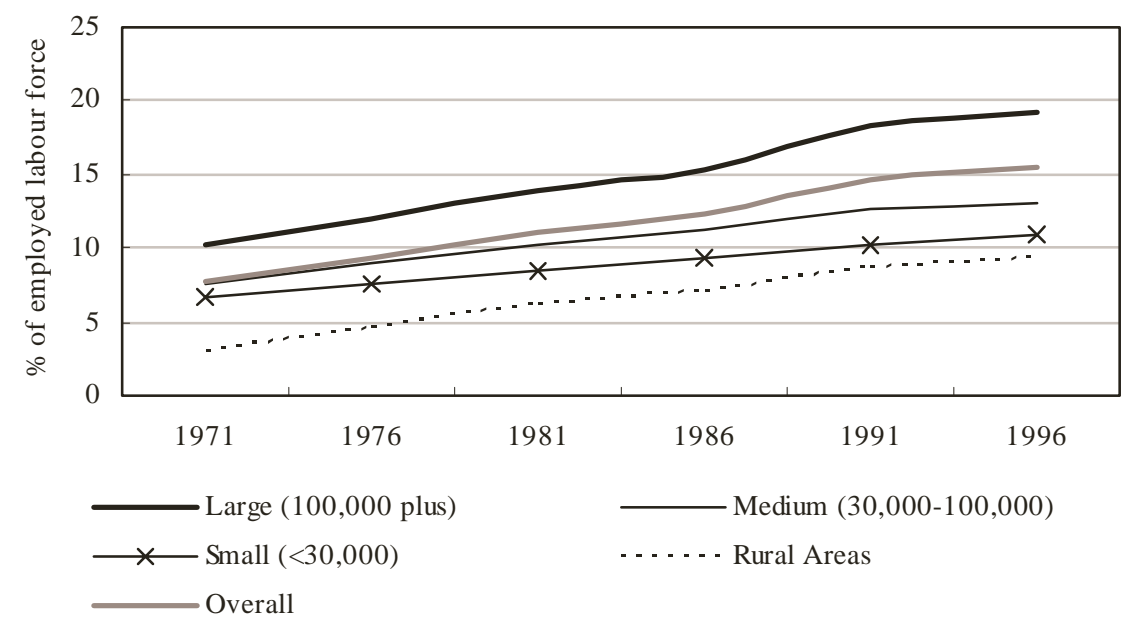

Note: Includes only the employed labour force defined using the 1971 Census labour force concept.

Data for 1976 is estimated as the midpoint between 1971 and 1981.

Overall, these data indicate that the sites of the so-called new economy are not limited to one specific region of Canada, nor is it solely a phenomenon occurring in Canada's largest urban centres. However, the data do suggest that large urban centres are faring better than other urban areas. Moreover, rural areas are converging with these smaller centres in terms of their proportion of knowledge-based occupations. It is not clear from this picture whether or not urban-rural differences and regional disparities are heightened or lessened after accounting for industrial structure. Thus, the last chapter of this paper addresses the combined effects of geographic and industrial structure. 


\begin{tabular}{|c|c|c|c|c|c|c|c|}
\hline & \multicolumn{7}{|c|}{ Share of employment ${ }^{1}(\%)$} \\
\hline & 1971 & 1981 & 1986 & 1991 & 1996 & Change $^{2}$ & Growth $^{3}$ \\
\hline CANADA & 7.7 & 11.1 & 12.4 & 14.6 & 15.4 & 7.8 & 2.8 \\
\hline Urban & 9.0 & 12.6 & 13.9 & 16.4 & 17.1 & 8.1 & 2.6 \\
\hline Large & 10.1 & 13.9 & 15.4 & 18.3 & 19.1 & 9.0 & 2.6 \\
\hline Medium & 7.7 & 10.3 & 11.2 & 12.7 & 13.1 & 5.4 & 2.2 \\
\hline Small & 6.6 & 8.5 & 9.3 & 10.2 & 10.9 & 4.3 & 2.0 \\
\hline Rural & 3.0 & 6.1 & 7.0 & 8.7 & 9.3 & 6.4 & 4.7 \\
\hline Atlantic region & 5.6 & 8.5 & 9.2 & 10.4 & 11.1 & 5.4 & 2.7 \\
\hline Urban & 7.5 & 10.8 & 11.8 & 13.2 & 13.9 & 6.3 & 2.5 \\
\hline Large & 10.8 & 14.3 & 15.0 & 17.0 & 17.1 & 6.3 & 1.9 \\
\hline Medium & 8.6 & 12.0 & 13.4 & 14.2 & 15.3 & 6.7 & 2.3 \\
\hline Small & 5.8 & 8.1 & 8.6 & 9.4 & 10.1 & 4.3 & 2.2 \\
\hline Rural & 3.1 & 5.6 & 6.2 & 7.3 & 8.0 & 4.9 & 3.8 \\
\hline Quebec & 8.4 & 11.3 & 12.9 & 15.5 & 16.5 & 8.1 & 2.7 \\
\hline Urban & 9.6 & 12.6 & 14.4 & 17.2 & 18.2 & 8.7 & 2.6 \\
\hline Large & 10.9 & 13.9 & 15.8 & 18.9 & 20.2 & 9.3 & 2.5 \\
\hline Medium & 7.0 & 10.2 & 11.1 & 13.4 & 13.7 & 6.7 & 2.7 \\
\hline Small & 6.6 & 8.1 & 9.2 & 10.8 & 11.6 & 5.0 & 2.3 \\
\hline Rural & 2.7 & 6.3 & 7.3 & 9.7 & 10.1 & 7.4 & 5.4 \\
\hline Ontario & 8.2 & 12.0 & 13.2 & 16.0 & 16.7 & 8.5 & 2.9 \\
\hline Urban & 9.2 & 13.0 & 14.2 & 17.3 & 17.9 & 8.7 & 2.7 \\
\hline Large & 10.0 & 13.9 & 15.2 & 18.7 & 19.4 & 9.4 & 2.7 \\
\hline Medium & 8.0 & 11.2 & 11.6 & 13.5 & 13.8 & 5.8 & 2.2 \\
\hline Small & 7.2 & 9.1 & 9.8 & 11.1 & 11.5 & 4.3 & 1.9 \\
\hline Rural & 3.6 & 7.3 & 8.8 & 10.6 & 11.1 & 7.6 & 4.7 \\
\hline Prairies & 6.1 & 10.5 & 11.4 & 12.5 & 13.0 & 6.9 & 3.0 \\
\hline Urban & 8.7 & 12.8 & 14.0 & 15.1 & 15.4 & 6.8 & 2.3 \\
\hline Large & 9.7 & 14.4 & 15.8 & 17.2 & 17.7 & 8.0 & 2.4 \\
\hline Medium & 5.7 & 8.4 & 10.3 & 10.8 & 10.3 & 4.6 & 2.4 \\
\hline Small & 6.0 & 8.7 & 9.2 & 9.3 & 9.7 & 3.7 & 1.9 \\
\hline Rural & 1.5 & 4.0 & 4.3 & 5.4 & 6.2 & 4.7 & 6.0 \\
\hline British Columbia & 7.7 & 10.5 & 11.9 & 13.8 & 15.2 & 7.5 & 2.7 \\
\hline Urban & 8.5 & 11.3 & 12.8 & 14.8 & 16.2 & 7.7 & 2.6 \\
\hline Large & 9.4 & 13.0 & 14.6 & 17.2 & 18.5 & 9.1 & 2.7 \\
\hline Medium & 6.5 & 8.7 & 10.1 & 11.0 & 12.1 & 5.6 & 2.5 \\
\hline Small & 6.7 & 7.7 & 8.7 & 9.1 & 10.6 & 4.0 & 1.9 \\
\hline Rural & 5.2 & 7.3 & 8.1 & 9.3 & 10.6 & 5.4 & 2.9 \\
\hline Territories & 8.0 & 13.2 & 13.9 & 13.4 & 14.5 & 6.5 & 2.4 \\
\hline Urban & 8.8 & 14.3 & 15.5 & 15.4 & 17.1 & 8.3 & 2.7 \\
\hline Large & - & - & - & - & - & - & - \\
\hline Medium & - & - & - & - & - & - & - \\
\hline Small & 8.8 & 14.3 & 15.5 & 15.4 & 17.1 & 8.3 & 2.7 \\
\hline Rural & 6.6 & 11.1 & 11.1 & 10.9 & 11.1 & 4.5 & 2.1 \\
\hline
\end{tabular}




\section{Endnotes}

${ }^{10}$ In 1999, the Northwest Territories was divided into two portions: Nunavut and the Northwest Territories. However, given that the data cover the period from 1971 to 1996, the Northwest Territories are treated as a single entity.

11 The Atlantic region includes Newfoundland, Prince Edward Island, Nova Scotia, and New Brunswick. The Prairies region includes Alberta, Saskatchewan, and Manitoba.

12 While the Census definition remained constant for the 1981, 1986, 1991 and 1996 Census, the 1971 definition is slightly different. For 1971, the minimum density requirement was 1000 persons per square mile (or approximately 386 persons per square kilometre). Additionally, all incorporated cities, towns, and villages with a population over 1000 were included in the urban component (see Statistics Canada, 1999). 


\section{Chapter 7. Regional differences and industrial structure}

7 he previous chapters demonstrated that there are differences across the urban-rural 1 hierarchy, as well as across provinces and industries and that there have been some shifts over the 25-year study period within the business sector. However, the differences across these parameters were investigated separately. Therefore, in this chapter, we perform a multivariate analysis to determine whether or not there are differences between provinces after controlling for differences in industrial and spatial structure. To do this, we estimate the probability of an individual being a knowledge worker in the business sector using microdata from each of the 1971 and 1996 Censuses.

We use the following model specification:

$$
K_{i}=f\left(P_{i,} I_{i}, U_{i}\right)
$$

where $K_{i}$ takes on a value of one if a persons belongs to a knowledge occupation and zero otherwise. $P_{i}$ refers to the province in which the individual lives, $I_{i}$ represents industry in which he/she works, and $U_{i}$ represents the individual's location within the urban-rural hierarchy.

The model was estimated separately for each of the 1971 and 1996 Censuses.

\subsection{Dependent variable}

The dependent variable is a dichotomous variable measuring the incidence of knowledgebased occupations. The variable takes a value of one if the respondent reports belonging to a knowledge-based occupation. Otherwise it takes a value of zero. A knowledge-based occupation is defined as being a professional, management, or technical occupation in the framework developed and used in this paper.

\subsection{Explanatory variables}

We investigate the combined effects of three of the variables explored in previous chapters of this analysis: industry, province, and level of urbanization. A set of twelve binary variables captures the province or territory of the respondent. To capture differences in the spatial structure and organization, we use four binary variables, representing Canada's urban-rural continuum. Finally, 15 binary variables correspond with the industry divisions used earlier 
in the paper and are used to capture industry effects in the business sector. The descriptive statistics associated with the dependent and independent variables for the beginning and end periods of the study can be found in Table 17 (1971) and Table 18 (1996).

\subsection{Estimation procedures}

Since the dependent variable is a dichotomous variable, we use a logit regression in order to overcome the problems associated with using other regression methods. ${ }^{13}$ In order to examine the effects of spatial and industrial structure, as well as geographic variation across Canada, the following logistic regression model (logit) is specified as follows:

$$
K=\beta_{0}+\beta_{1} * I N D+\beta_{2} * P R O V+\beta_{3} * U R B A N+\varepsilon
$$

where $K$ refers to a variable indicating the presence of a knowledge-based occupation. IND, PROV, and URBAN refer to the explanatory variables for industry, province, and level of urbanization respectively.

\subsection{Empirical results}

The results of the logistic regression models can be found in Table 19 and Table 20 for the beginning and end periods. The regressions are estimated against an individual from Ontario, in a large urban centre, working in the 'other services' industry division.

In both of the models (1971 and 1996), most of the explanatory variables are statistically significant. However, in each case, there are over two million observations. Therefore, most variables will be significant regardless of their quantitative effect on the outcome. Therefore, we also provide probability estimates to place the signs and strength of the coefficients in context. Probability estimates are calculated by estimating the logit equation at the sample means. ${ }^{14}$

There is a change in the overall magnitude of the estimated probabilities between 1971 and 1996 since the overall observed probability of being a knowledge worker in Canada's business sector increased from $7.7 \%$ to $15.4 \%$. Therefore, in this context, we only examine relative differences and changes. In both 1971 and 1996, there are strong industry effects, weaker urban-rural and virtually no real provincial effects. Each of these is outlined below.

As discussed earlier, there are differences amongst industries. The magnitude and differences of the probabilities in each year suggest that the industry effect is much larger than either the provincial or urban-rural effect. In 1971, the probability of being a knowledge worker was highest in the business services industry (36\%), followed by finance and insurance (17\%), mining, quarrying, and oil wells (15\%), and the communication and other utilities industry (13\%). By 1996, the probability of being a knowledge worker had increased in most industries. The highest probability of being a knowledge worker was still in the business services industries (48\%), followed by finance and insurance (32\%), mining, quarrying, and oil wells (26\%), logging and forestry (24\%), and communication and other utilities (23\%). This confirms the findings presented earlier in this paper, which suggested that 
these industries had a high proportion of knowledge workers, but that there were increases across most industries. In each year, the probability of being a knowledge worker was lowest in the retail trade and accommodation, food, and beverage services industries.

In both years, there are highly statistically significant differences between urban and rural areas. The probability of being a knowledge worker increases with the level of urbanization. In 1971, the probability of being a knowledge worker in large urban centres (6.7\%) was more than double that of rural areas (3.1\%). In 1996, the probability of being a knowledge worker increased with urbanization from $7.7 \%$ in the most rural areas to $12.5 \%$ in the largest urban centres. Therefore, after controlling for differences in province and the industry of work, a worker in a rural area is less likely to be in a knowledge-based occupation than a worker in a more urbanized area.

After controlling for spatial and industrial structure, there are very few real differences between the provinces and territories. In 1971, there are some differences across the provinces and territories, but in many cases these are not statistically significant. Only workers in Quebec and the Yukon Territory have a higher probability of being a knowledge worker compared to Ontario. However, the differences in the estimated probabilities are very small. In 1996, differences across the provinces and territories remain and may have widened, since in several cases (e.g. Prince Edward Island, Northwest Territories) differences in the estimated probability of being a knowledge worker have become statistically significant. However, once again the differences in the estimated probabilities are small. Overall, these findings suggest that the observed differences between the provinces are a function of industrial structure and - to a lesser extent — the degree of urbanization. 


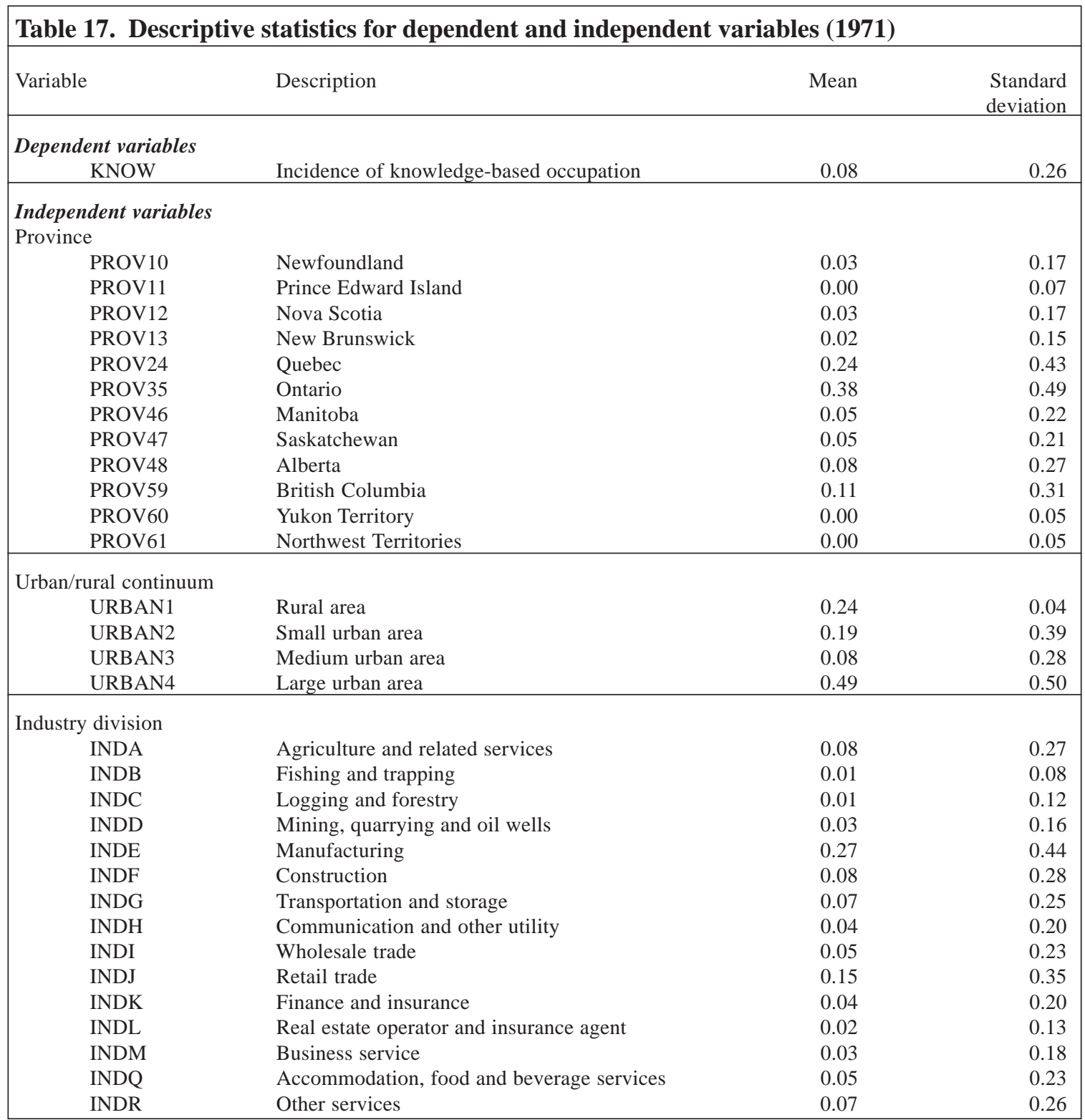

Note: Includes only the employed labour force (1971 concept) within the business sector as defined in this paper. 


\begin{tabular}{|c|c|c|c|}
\hline Variable & Description & Mean & $\begin{array}{r}\text { Standard } \\
\text { deviation }\end{array}$ \\
\hline \multicolumn{4}{|l|}{ Dependent variables } \\
\hline KNOW & Incidence of knowledge-based occupation & 0.15 & 0.36 \\
\hline \multirow{2}{*}{\multicolumn{4}{|c|}{$\begin{array}{l}\text { Independent variables } \\
\text { Province }\end{array}$}} \\
\hline & & & \\
\hline PROV10 & Newfoundland & 0.01 & 0.11 \\
\hline PROV11 & Prince Edward Island & 0.00 & 0.07 \\
\hline PROV12 & Nova Scotia & 0.03 & 0.16 \\
\hline PROV13 & New Brunswick & 0.02 & 0.14 \\
\hline PROV24 & Quebec & 0.23 & 0.42 \\
\hline PROV35 & Ontario & 0.38 & 0.48 \\
\hline PROV46 & Manitoba & 0.04 & 0.20 \\
\hline PROV47 & Saskatchewan & 0.04 & 0.19 \\
\hline PROV48 & Alberta & 0.11 & 0.31 \\
\hline PROV59 & British Columbia & 0.13 & 0.34 \\
\hline PROV60 & Yukon Territory & 0.00 & 0.05 \\
\hline PROV61 & Northwest Territories & 0.01 & 0.09 \\
\hline \multicolumn{4}{|c|}{ Urban/rural continuum } \\
\hline URBAN1 & Rural area & 0.24 & 0.43 \\
\hline URBAN2 & Small urban area & 0.13 & 0.33 \\
\hline URBAN3 & Medium urban area & 0.09 & 0.28 \\
\hline URBAN4 & Large urban area & 0.55 & 0.50 \\
\hline \multicolumn{4}{|l|}{ Industry division } \\
\hline INDA & Agriculture and related services & 0.05 & 0.22 \\
\hline INDB & Fishing and trapping & 0.00 & 0.07 \\
\hline INDC & Logging and forestry & 0.01 & 0.09 \\
\hline INDD & Mining, quarrying and oil wells & 0.02 & 0.13 \\
\hline INDE & Manufacturing & 0.18 & 0.38 \\
\hline INDF & Construction & 0.07 & 0.25 \\
\hline INDG & Transportation and storage & 0.06 & 0.23 \\
\hline INDH & Communication and other utility & 0.04 & 0.20 \\
\hline INDI & Wholesale trade & 0.06 & 0.25 \\
\hline INDJ & Retail trade & 0.16 & 0.37 \\
\hline INDK & Finance and insurance & 0.05 & 0.22 \\
\hline INDL & Real estate operator and insurance agent & 0.02 & 0.16 \\
\hline INDM & Business service & 0.08 & 0.28 \\
\hline INDQ & Accommodation, food and beverage services & 0.09 & 0.28 \\
\hline INDR & Other services & 0.10 & 0.30 \\
\hline
\end{tabular}

Note: Includes only the employed labour force (1971 concept) within the business sector as defined in this paper. 


\begin{tabular}{|c|c|c|c|}
\hline Variable & Description & Coefficient ${ }^{1}$ & $\begin{array}{l}\text { Estimated } \\
\text { probability }\end{array}$ \\
\hline Intercept & & $-2.497 * * *$ & - \\
\hline \multicolumn{4}{|l|}{ Province } \\
\hline PROV10 & Newfoundland & 0.001 & 5.2 \\
\hline PROV11 & Prince Edward Island & -0.013 & 5.2 \\
\hline PROV12 & Nova Scotia & $-0.035 *$ & 5.0 \\
\hline PROV13 & New Brunswick & $-0.088 * * *$ & 4.8 \\
\hline PROV24 & Quebec & $0.036 * * *$ & 5.4 \\
\hline PROV35 & Ontario $^{2}$ & - & 5.2 \\
\hline PROV46 & Manitoba & $-0.146 * * *$ & 4.5 \\
\hline PROV47 & Saskatchewan & $-0.204 * * *$ & 4.3 \\
\hline PROV48 & Alberta & 0.009 & 5.2 \\
\hline PROV59 & British Columbia & -0.015 & 5.2 \\
\hline PROV60 & Yukon Territory & $0.232 * * *$ & 6.5 \\
\hline PROV61 & Northwest Territories & 0.122 & 5.2 \\
\hline \multicolumn{4}{|c|}{ Urban/rural continuum } \\
\hline URBAN1 & Rural area & $-0.812 * * *$ & 3.1 \\
\hline URBAN2 & Small urban area & $-0.359 * * *$ & 4.8 \\
\hline URBAN3 & Medium urban area & $-0.213 * * *$ & 5.5 \\
\hline URBAN4 & Large urban area ${ }^{2}$ & - & 6.7 \\
\hline \multicolumn{4}{|l|}{ Industry division } \\
\hline INDA & Agriculture and related services & $-1.908 * * *$ & 0.9 \\
\hline INDB & Fishing and trapping & $-0.581 * * *$ & 3.3 \\
\hline INDC & Logging and forestry & $0.375 * * *$ & 8.2 \\
\hline INDD & Mining, quarrying and oil wells & $1.050 * * *$ & 14.9 \\
\hline INDE & Manufacturing & $0.217 * * *$ & 7.1 \\
\hline INDF & Construction & $-0.285 * * *$ & 4.4 \\
\hline INDG & Transportation and storage & $0.146 * * *$ & 6.6 \\
\hline INDH & Communication and other utility & $0.849 * * *$ & 12.6 \\
\hline INDI & Wholesale trade & -0.008 & 5.8 \\
\hline INDJ & Retail trade & $-0.730 * * *$ & 2.9 \\
\hline INDK & Finance and insurance & $1.195 * * *$ & 16.9 \\
\hline INDL & Real estate operator and insurance agent & 0.017 & 5.8 \\
\hline INDM & Business service & $2.229 * * *$ & 36.3 \\
\hline INDQ & Accommodation, food and beverage services & $-1.693 * * *$ & 1.1 \\
\hline INDR & Other services ${ }^{2}$ & - & 5.8 \\
\hline
\end{tabular}

1 Denoted as follows: *** significant at $1 \%$ level; ** significant at $5 \%$ level; * significant at $10 \%$ level.

2 Category excluded from the regression analysis.

Note: Includes only the employed labour force (1971 concept) within the business sector as defined in this paper. 


\begin{tabular}{|c|c|c|c|}
\hline Variable & Description & Coefficient $^{1}$ & $\begin{array}{l}\text { Estimated } \\
\text { probability }\end{array}$ \\
\hline Intercept & & $-1.769 * * *$ & - \\
\hline \multicolumn{4}{|l|}{ Province } \\
\hline PROV10 & Newfoundland & $-0.074 * * *$ & 9.8 \\
\hline PROV11 & Prince Edward Island & $-0.105 * * *$ & 9.6 \\
\hline PROV12 & Nova Scotia & $-0.137 * * *$ & 9.3 \\
\hline PROV13 & New Brunswick & $-0.040 * *$ & 10.1 \\
\hline PROV24 & Quebec & $0.061 * * *$ & 11.1 \\
\hline PROV35 & Ontario $^{2}$ & - & 10.5 \\
\hline PROV46 & Manitoba & $-0.228 * * *$ & 8.6 \\
\hline PROV47 & Saskatchewan & $-0.324 * * *$ & 7.8 \\
\hline PROV48 & Alberta & $-0.051 * * *$ & 10.0 \\
\hline PROV59 & British Columbia & 0.002 & 10.5 \\
\hline PROV60 & Yukon Territory & $0.355 * * *$ & 14.3 \\
\hline PROV61 & Northwest Territories & $0.304 * * *$ & 13.7 \\
\hline \multicolumn{4}{|c|}{ Urban/rural continuum } \\
\hline URBAN1 & Rural area & $-0.538 * * *$ & 7.7 \\
\hline URBAN2 & Small urban area & $-0.468 * * *$ & 8.2 \\
\hline URBAN3 & Medium urban area & $-0.298 * * *$ & 9.6 \\
\hline URBAN4 & Large urban area ${ }^{2}$ & - & 12.5 \\
\hline \multicolumn{4}{|l|}{ Industry division } \\
\hline INDA & Agriculture and related services & $-0.983 * * *$ & 4.8 \\
\hline INDB & Fishing and trapping & $-0.180 * * *$ & 10.2 \\
\hline INDC & Logging and forestry & $0.818 * * *$ & 23.5 \\
\hline INDD & Mining, quarrying and oil wells & $0.953 * * *$ & 26.0 \\
\hline INDE & Manufacturing & $0.332 * * *$ & 15.9 \\
\hline INDF & Construction & $-0.570 * * *$ & 7.1 \\
\hline INDG & Transportation and storage & $-0.233 * * *$ & 9.7 \\
\hline INDH & Communication and other utility & $0.765 * * *$ & 22.5 \\
\hline INDI & Wholesale trade & $0.484 * * *$ & 18.0 \\
\hline INDJ & Retail trade & $-1.265 * * *$ & 3.7 \\
\hline INDK & Finance and insurance & $1.221 * * *$ & 31.5 \\
\hline INDL & Real estate operator and insurance agent & 0.005 & 11.9 \\
\hline INDM & Business service & $1.911 * * *$ & 47.8 \\
\hline INDQ & Accommodation, food and beverage services & $-2.462 * * *$ & 1.1 \\
\hline INDR & Other services $^{2}$ & - & 11.9 \\
\hline
\end{tabular}

1 Denoted as follows: *** significant at $1 \%$ level; ** significant at 5\% level; * significant at $10 \%$ level.

2 Category excluded from the regression analysis.

Note: Includes only the employed labour force (1971 concept) within the business sector as defined in this paper. 


\section{Endnotes}

${ }^{13}$ See Baldwin, et al. (2000) for further discussion of model choices for dichotomous dependent variables.

${ }^{14}$ Probabilities (p) are estimated using the following equation: $\mathrm{p}=\exp (\hat{a} \mathrm{x}) /[1+\exp (\hat{a} \mathrm{x})]$. 


\section{Chapter 8. Conclusion}

$I$ n this paper, we used an occupational framework to examine the changing knowledgeintensity of the Canadian economy over time, how it varied across industrial sectors, and whether or not there were regional or urban-rural dimensions to these shifts. Overall, we have seen that knowledge intensity has increased across Canada.

However, even though we see that the shift towards a more knowledge-intensive economy has been a widespread and gradual process, there are some underlying differences across the boundaries of wages, education, gender, industries and geography. Knowledge workers have higher wage rates and higher levels of education. Shifts in the gender composition of the knowledge-based workforce have followed the trends in the overall labour force, although at a slightly slower pace. It is interesting to note that in the business sector, women knowledge workers as a percentage of the female labour force have grown faster than their male counterparts.

While most industries have undergone an increase in knowledge intensity over the study period, the level of knowledge intensity is highest in the non-market (public) sector, but the highest levels of growth have been in the business sector. Business sector industries such as business services, mining, and finance have exhibited higher levels of knowledge use compared to others. We find that after controlling for differences in industrial and spatial structure, there are only very small differences across Canada's provinces. However, there are urban and rural differences that persist through the study period. The probability of being in a knowledge-based occupation increases with the level of urbanization.

Our analysis confirms the findings of previous studies and indicates that the shift towards a more knowledge intensive economy has been a gradual process, ongoing since at least 1971. Moreover, this increase has been experienced to some extent across all sectors of the Canadian economy. The sites of the knowledge-based economy are widespread, reaching across industries, provinces and the urban-rural divide. This suggests a general upskilling of the Canadian labour force and an increase in the importance and use of skills, knowledge, and human capital amongst firms and industries competing in the new economy. 


\section{Appendix 1: A method of creating a file of occupational groups from Census data over the period 1971-1996}

\section{Summary}

7 his paper describes how a longitudinal classification of occupational categories was developed using the 1971, 1981, 1991 and 1996 censuses. The standard occupational classifications used in the 1970s differed slightly from the 1980s. But both of these classifications differed substantially from the one used in the 1990s.

Several steps were involved. They were:

1) Given that the 1991 Standard Occupational Classification (SOC91) was the most recent classification system available for Census data, the structure of the SOC91 was used as the framework for delineating the knowledge categories. The classifications available from the 1996 Census were allocated to a set of knowledge categories (largely based on previous research) or a set of remaining categories (mainly based on the 2 digit level of aggregation) - there were 47 categories in total.

2) When the assignment of a detailed category to the aggregate was uncertain, a Tukey test was used; this test was based on similarity of the average wage of the individual category and the aggregate.

3) A classification procedure was then developed to assign a four-digit $1980 \mathrm{SOC}$ to the 47 group total. A forced one-to-one match was made using a proportional matrix created from the 1991 Census that was double-coded on both the 1980 and the 1991 Standard Occupational Classifications. This allowed the Census data from the 1980 s to be assigned to the 47 occupational categories.

4) A concordance was developed from the 1970 SOC to the 1980 SOC and then the procedure outlined in step 3 is employed to classify the 1970 census data into our 47-occupation framework.

\section{Introduction}

Statistics Canada maintains a Standard Occupational Classification system that is periodically updated. The most recent update resulted in a major overhaul of the classification scheme, which "differs substantially in structure and content from earlier systems" (Marshall, 1996). While necessary to maintain currency in the concepts being used to define occupations, such a change poses a number of challenges for researchers and analysts. Specifically, the ability to conduct research over time that incorporates occupation is significantly hindered by the existence of disparate systems and a lack of a straightforward statistical concordance 
between them. In particular, at the finest level of detail, the 1980 and 1991 occupational classification systems contain numerous many-to-many matches, which make concordances at this level problematic.

While the merit of a statistical occupational concordance is recognized, such a tool is generally not used at the most detailed occupational level due to the significant differences in the structure, composition, and content between the 1980 and 1991 Standard Occupational Classifications. ${ }^{15}$ The complexity of such a task has meant that, in most analyses that have been conducted of a particular labour force phenomenon that cover the last thirty years, occupation has been excluded from consideration.

While concordances at a detailed level may be difficult to create, it is easier and more defensible to use a concordance that employs broader more aggregate occupational groups. This appendix describes the method that was used to overcome the discord between the 1971, 1980 and 1991 classification schemes to create a set of categories for this study.

The appendix is divided into two parts. First, a framework for defining 47 categories of knowledge and non-knowledge based occupations is presented and applied to the 1991 Standard Occupational Classification. This is done using 1991 Census data.

In the second part, we address the issue of occupational concordances and the problems arising from the incompatibility between the 1980 and 1991 Standard Occupational Classifications. We outline the method that is used to assign occupations defined under the 1980 Standard Occupational Classification to the same 47 broad occupational categories. This concordance is then extended to the 1971 Occupational Classification Manual. The result is a framework that provides occupational groupings that cover the period from 1971 to present.

\section{A framework for knowledge intensive and non-knowledge intensive occupations}

Our work has two objectives. First, we are interested in the construction of a manageable number of occupational groupings that can be followed through time. Second, we want to ensure that the occupational groups include several "knowledge worker" categories, since the main purpose of this paper is to study how the importance of knowedge workers has changed over time.

To do so, we define and develop an aggregate classification system that involves about 47 categories and then present a method for assigning the detailed 1991 Standard Occupational Classification to each member of this aggregate occupational framework. In the small number of cases where there was some doubt about the aggregate category to which the individual 1991 classifications should be classified, we use relative wage rates to determine the inclusion or exclusion of specific detailed occupations on the margins of these aggregate groupings. 
When it comes to defining the aggregate classes that are considered as 'knowledge' workers, we make use of information derived from previous research. Previous studies have defined 'knowledge workers' based on occupational classification structures, as well as additional information on education and skill levels (Zhao, et al., 2000a, Lavoie and Roy, 1998, Gera, et al., 1999).

We build on this tradition by identifying three broad knowledge worker categories within our 47 broad occupational aggregates. The knowledge worker occupations contain a total of eight components:

\section{Management Occupations.}

2. Professional Occupations:

- Science and engineering professionals;

- Business professionals;

- Health professionals;

- Arts and culture professionals; and

- Education, law and social science-related professionals.

3. Technical Occupations:

- Technical occupations related to science and engineering; and

- Technical occupations related to health.

There are two main steps required to implement this framework. First, a method for assigning specific detailed occupations to an aggregate knowledge or non-knowledge (residual) category using the 1991 Standard Occupational Classification must be devised. Second, in order to provide time series data, a concordance between the three standards used to classify occupations over the period 1971-1996 must be created.

\section{Data sources and limitations}

In the next sections, we address this first challenge by discussing the data sources and limitations, as well as the method used to apply our framework to the 1991 Standard Occupational Classification. Following this, the latter part of our discussion addresses the issue of how we built the occupational concordances for previous census years.

In the first part of this analysis, we use the 1991 Census (20\% sample) to group occupations into 47 knowledge and non-knowledge categories. In the second part of the analysis, which includes the creation of an occupational concordance between the 1971, 1980, and 1991 classifications and these 47 occupational categories, we use the $20 \%$ samples from the 1981, 1986, 1991, and 1996 Censuses.

There are two significant limitations to the data that are used here that should be kept in mind but that are common to all studies using Census data to study trends in hours worked. First, not all of the data used to create total hours worked per worker refer to the same time period. For example, the variable 'hours worked per week' refers to the reference week in 
the Census year, whereas 'the number of weeks worked' refers to the number of weeks worked in the previous year. We make the standard assumption that the wages and weeks reported from the previous year reflect the respondent's current working conditions (i.e., occupation, industry, etc.) and we calculate the total number of hours worked in a year by multiplying the number of weeks worked (previous year) and the number of hours worked in the reference week (in the Census year). Thus, some error may be introduced during the calculation of the number of total hours worked in a year (necessary for calculating average wage rates).

The second limitation is related to the accuracy of occupational coding on the Census. Occupation coding is a difficult task because it is dependent upon the description provided by the respondent. The coding error rate is felt to be high for certain occupation variables, particularly for management categories (Statistics Canada, 1999). For example, in the management category, there are 26 groups using the 1980 Standard Occupational Classification and 43 groups using the 1991 Standard Occupational Classification and it is difficult to assign one of these specific occupations to an individual record if the respondent simply says their primary task is "managing" (Marshall, 1996).

Responses to the 1991 Census were coded independently using each of the 1980 and 1991 Standard Occupational Classifications thereby providing information on the relationship between these two classification schemes. Similarly, each of the 1981 and 1986 Censuses were coded using both the 1971 and 1980 classifications.

It is important to outline one key difference in the procedures for coding occupations using the 1971, 1980 and 1991 occupational classification schemes. In the 1971 Occupation Classification, if a respondent did not state their occupation (and the respondent had an occupation), it was coded as ' 0000 ', meaning that there was no occupation information. In the 1980 Standard Occupation Classification, an imputation procedure was performed to assign an occupation code at the 3-digit level if it was not stated. In the 1991 Standard Occupation Classification, an imputation procedure was performed to assign an occupation code at the 4-digit level if it was not stated. Occupation was imputed for $3 \%$ to $4 \%$ of records in the population over 15 years of age. In cases where we could identify imputed occupations (i.e., data coded using the 1971 and 1980 classifications), these data are excluded from the creation of occupation groupings and in creating the occupational concordances since the treatment of imputations varies greatly over the twenty-five year study period.

\section{Applying the occupational framework to the 1991 standard occupational classification}

Using the 1991 Standard Occupation Classification at the 4-digit level (514 unit group occupations), the detailed job descriptions and titles in the 1991 Standard Occupation Classification manual, as well as reference to previous studies, we made a preliminary assignment of 4-digit occupations to the eight knowledge categories developed in our framework. 
Initially, our classification included (in most cases) entire 2-digit (major group) or 3-digit (minor group) occupation groups to our knowledge categories. This indicated that it was possible to simplify our classification procedure by operating at a more aggregate level. This is especially important since we had the additional task of creating a concordance through time.

Therefore, we chose to design our classification to identify knowledge-based occupations at the 3-digit level (minor group) and then assigned them to one of the eight knowledge worker categories. It should be noted that a large number of occupations were not assigned to any of the knowledge worker categories. These were assigned to 2-digit (major group) occupation groups based on their place in the 1991 occupation structure.

In the small number of cases where there was doubt about whether a particular detailed occupational class belonged to one of the aggregate knowledge groups, the Tukey test of means was employed. The Tukey test determines how similar or different the means of a particular variable are over a set of classes and provides output showing which classes have similar means by grouping them together. ${ }^{16}$ In this case, we used the natural logarithm of wage rates for each occupational group for the grouping test since the project ultimately was intended to divide workers up by wage rates.

Hourly wage rates are calculated for persons in the labour force with an occupation by dividing total earnings by the total hours worked. Workers are excluded from the analysis if any of earnings, hours, and weeks worked had values of zero.

The Tukey test also allows us to control for a number of other variables. In this paper, we controlled for age, sex, class of worker, highest level of education, and 2-digit industry (defined by the 1980 Standard Industrial Classification).

On the basis of this analysis, a small number of 3-digit occupations were reassigned from their initial classification. For example, transportation officers and controllers (C17, including pilots) had initially been excluded from knowledge worker categories, but were ultimately included on the basis of high wage rates and the high level of skill and training required in these occupations. The Tukey test on wage rates also confirmed the exclusion of a small number of specific 3-digit occupations from the aggregate knowledge category. For example, managers in retail trade (A21) and managers in food services and accommodation (A22) were both excluded since they have significantly lower wage rates than other 3-digit managerial occupations included in our knowledge worker taxonomy. Based on this analysis, we finalized the 1991 components of our eight knowledge worker categories.

Finally, to verify that the forty-seven newly created occupation groups (eight knowledge worker categories and thirty-nine non-knowledge worker categories) were statistically different from each other in terms of average wage rates, we also applied the Tukey test. The test confirmed that the majority of the forty-seven occupational categories were distinct and that the groups exhibited very little overlap in terms of average wage rates. Thus, these forty-seven knowledge and non-knowledge occupational groupings were used in the final 
occupational framework adopted in this paper to create a longitudinal concordance (Table 2A). We refer to this framework as KW-47.

\section{Creating an occupational concordance over time}

Having developed a 47 occupation grouping, we applied this framework to Census data that employed the 1971 and 1980 classification systems. The Standard Occupational Classification has experienced a number of changes and updates over the past thirty years, including substantial revisions in 1971 and 1991. This poses difficulties for conducting analysis over time.

Figure 1A. Conceptualizing an occupational concordance

\begin{tabular}{|c|c|c|c|c|c|c|}
\hline & \multicolumn{6}{|c|}{ Census Years } \\
\hline & 1971 & 1976 & 1981 & 1986 & 1991 & 1996 \\
\hline \multicolumn{7}{|l|}{$1991 \mathrm{SOC}$} \\
\hline \multicolumn{7}{|l|}{1980 SOC } \\
\hline \multicolumn{7}{|l|}{1971 OCM } \\
\hline KW-47 & & & & & & \\
\hline
\end{tabular}

In Figure 1A we show the occupational coding scheme used in each Census year between 1971 and 1996.

While a concordance between the 1971 and 1980 classification systems already exists since a similar though not completely identical structure was maintained between these census years, a concordance between these years and the 1991 occupational classifications presents a larger challenge. Radical changes were made to the occupational classification in 1991 as the classification scheme.

First, we consider the task of creating a concordance to express the 1980 Standard Occupational Classification in terms of its $1991 \mathrm{KW}-47$ equivalent. We then describe the task of expressing the 1971 Occupational Classification Manual in terms of its KW-47 equivalent (using its link to the 1980 Standard Occupational Classification as an intermediate step).

\section{A concordance between the 1980 and 1991 standard occupational classification systems}

There is a many-to-many relationship between the 1980 and 1991 Standard Occupational Classifications (i.e., an occupational group in 1980 is related to many occupational groups in 1991 and vice versa; there are very few one-to-one relationships). 


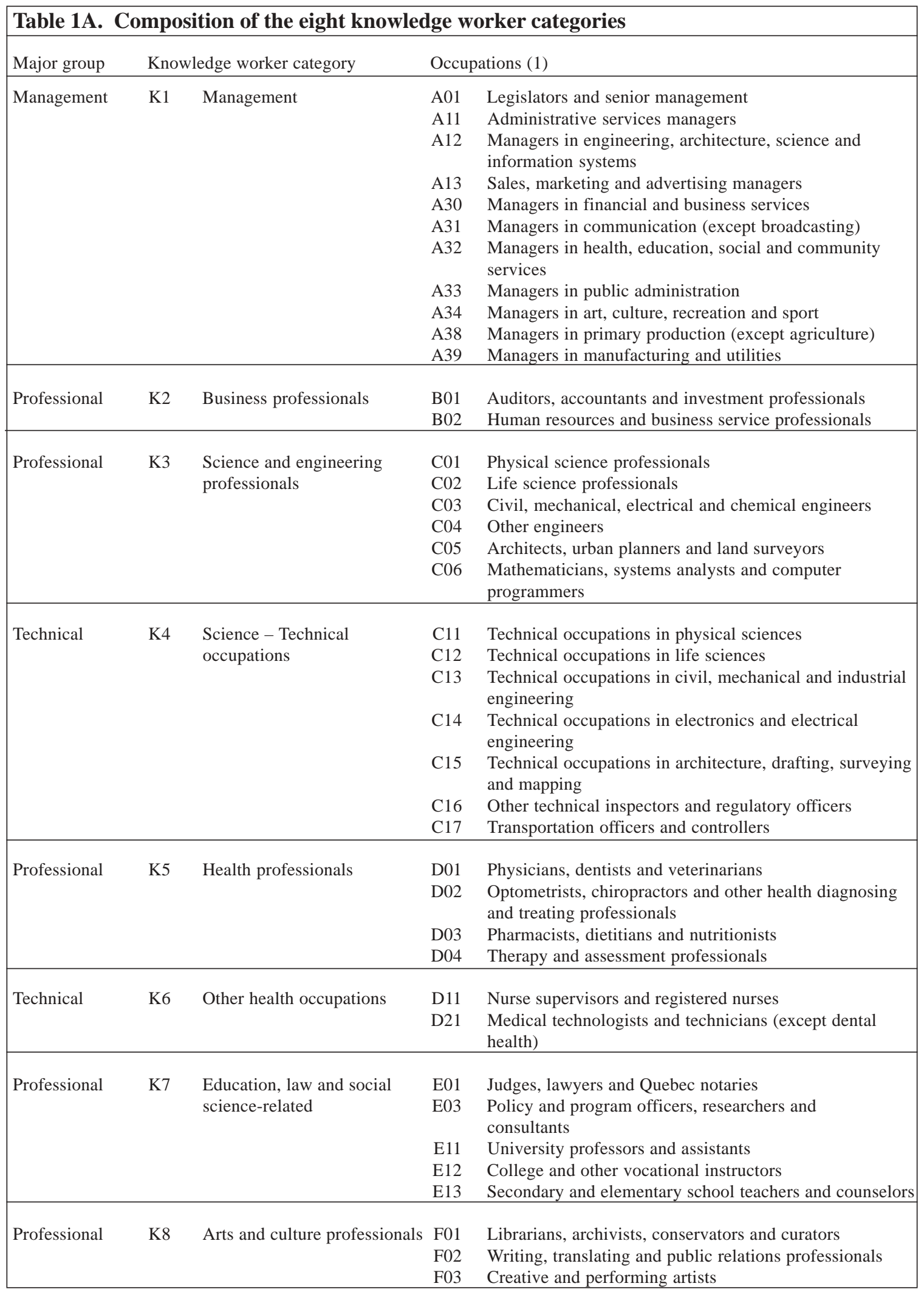

(1) Based on the 1991 Standard Occupational Classification. 


\begin{tabular}{|c|c|c|c|}
\hline \multicolumn{2}{|c|}{ Broad occupation group } & \multicolumn{2}{|c|}{ Occupation components (1) } \\
\hline A & Management & $\begin{array}{l}\text { A1 } \\
\text { A2 } \\
\text { A3 } \\
\text { K1 }\end{array}$ & $\begin{array}{l}\text { Specialist Managers (residual category) } \\
\text { Managers in Retail, Food, and Accommodation Services } \\
\text { Other managers, n.e.c. (residual category) } \\
\text { Managers (A0, A1*, } \mathbf{A 3}^{*} \text { ) }\end{array}$ \\
\hline B & Business, finance and administration & $\begin{array}{l}\text { B1 } \\
\text { B2 } \\
\text { B3 } \\
\text { B4 } \\
\text { B5 } \\
\text { K2 } \\
\end{array}$ & $\begin{array}{l}\text { Finance and insurance administrative } \\
\text { Secretaries } \\
\text { Administrative and regulatory } \\
\text { Clerical supervisors } \\
\text { Clerical } \\
\text { Business and finance - Professional (B0) }\end{array}$ \\
\hline $\mathrm{C}$ & Natural and applied sciences & $\begin{array}{l}\text { K3 } \\
\text { K4 } \\
\end{array}$ & $\begin{array}{l}\text { Science - Professional (C0) } \\
\text { Science - Technical (C1) }\end{array}$ \\
\hline $\mathrm{D}$ & Health & $\begin{array}{l}\text { D2 } \\
\text { D3 } \\
\text { K5 } \\
\text { K6 }\end{array}$ & $\begin{array}{l}\text { Technical and related (residual category) } \\
\text { Assisting occupations in support of health services } \\
\text { Health - Professional (D0) } \\
\text { Health - Technical (D1, D2*) }\end{array}$ \\
\hline $\mathrm{E}$ & $\begin{array}{l}\text { Social science, education, } \\
\text { government service and religion }\end{array}$ & $\begin{array}{l}\text { E0 } \\
\text { E2 } \\
\text { K7 }\end{array}$ & $\begin{array}{l}\text { Psychologists, social workers, etc. (residual category) } \\
\text { Paralegals, social services workers and occupations in } \\
\text { education and religion, n.e.c. } \\
\text { Social sciences and education - Professional (E0*, E1) }\end{array}$ \\
\hline $\mathrm{F}$ & Arts, culture, recreation and sport & $\begin{array}{l}\text { F1 } \\
\text { K8 }\end{array}$ & $\begin{array}{l}\text { Technical occupations in art, culture, recreation, and sport } \\
\text { Arts and culture - Professionals (F0) }\end{array}$ \\
\hline G & Sales and services & $\begin{array}{l}\text { G0 } \\
\text { G1 } \\
\text { G2 } \\
\text { G3 } \\
\text { G5 } \\
\text { G6 } \\
\text { G7 } \\
\text { G8 } \\
\text { G9 }\end{array}$ & $\begin{array}{l}\text { Sales and services supervisors } \\
\text { Wholesale, technical, insurance, and real estate sales specialists } \\
\text { and retail, wholesale and grain buyers } \\
\text { Retail salespersons and sales clerks } \\
\text { Cashiers } \\
\text { Chefs and Cooks } \\
\text { Occupations in food and beverage services } \\
\text { Occupations in protective service } \\
\text { Occupations in travel and accommodation } \\
\text { Childcare and homesupport workers } \\
\text { Sales and services occupations, n.e.c. }\end{array}$ \\
\hline $\mathrm{H}$ & $\begin{array}{l}\text { Trades, transport and equipment } \\
\text { operators }\end{array}$ & $\begin{array}{l}\mathrm{H} 0 \\
\mathrm{H} 1 \\
\mathrm{H} 2 \\
\mathrm{H} 3 \\
\mathrm{H} 4 \\
\mathrm{H} 5 \\
\mathrm{H} 6 \\
\mathrm{H} 7 \\
\mathrm{H} 8\end{array}$ & $\begin{array}{l}\text { Contractors and supervisors in trades and transportation } \\
\text { Construction trades } \\
\text { Stationary engineers, power station operators and electrical trades } \\
\text { and telecommunications operators } \\
\text { Machinists, metal forming, shaping and erecting } \\
\text { Mechanics } \\
\text { Other trades, n.e.c. } \\
\text { Heavy equipment and crane operators } \\
\text { Transportation equipment operators } \\
\text { Trades helpers, construction and transportation labourers }\end{array}$ \\
\hline I & $\begin{array}{l}\text { Occupations unique to primary } \\
\text { industry }\end{array}$ & $\begin{array}{l}\text { I0 } \\
\text { I1 } \\
\text { I2 }\end{array}$ & $\begin{array}{l}\text { Occupations unique to agriculture } \\
\text { Occupations unique to forestry, mining, oil and gas extraction, } \\
\text { and fishing } \\
\text { Primary production labourers }\end{array}$ \\
\hline $\mathrm{J}$ & $\begin{array}{l}\text { Occupations unique to processing, } \\
\text { manufacturing, and utilities }\end{array}$ & $\begin{array}{l}\mathrm{J} 0 \\
\mathrm{~J} 1 \\
\mathrm{~J} 2 \\
\mathrm{~J} 3\end{array}$ & $\begin{array}{l}\text { Supervisors in manufacturing } \\
\text { Machine operators in manufacturing } \\
\text { Assemblers in manufacturing } \\
\text { Labourers in processing, manufacturing, and utilities }\end{array}$ \\
\hline
\end{tabular}

(1) Based on the 1991 Standard Occupational Classification. 


\begin{tabular}{|lrr|}
\hline Table 3A. Comparison of computer programmers and systems analysts using SOC-80 and \\
SOC-91 & Number & Percentage \\
\hline & $\mathbf{1 4 9 , 8 8 5}$ & $\mathbf{1 0 0 . 0}$ \\
Computer Programmers and Systems Analysts (2183) & 58,140 & 38.8 \\
Records with SOC 1991 = C062 & 49,460 & 33.0 \\
Records with SOC 1991 =C063 & 42,285 & 28.2 \\
Records with other 1991 SOC codes & 313 & - \\
Number of other 1991 Codes & $\mathbf{7 6 , 7 1 5}$ & $\mathbf{1 0 0 . 0}$ \\
Computer Systems Analysts (C062) & 58,140 & 75.8 \\
Records with SOC 1980 = 2183 & 2,325 & 3.0 \\
Records with imputed 1980 Code & 16,250 & 21.2 \\
Records with other 1980 SOC codes & 277 & - \\
Number of other 1980 Codes & $\mathbf{5 5 , 8 8 5}$ & $\mathbf{1 0 0 . 0}$ \\
Computer Programmers (C063) & 49,460 & 88.5 \\
Records with SOC 1980 = 2183 & 1,690 \\
Records with imputed 1980 Code & 4,735 & 3.0 \\
Records with other 1980 SOC codes & 218 & 8.5 \\
Number of other 1980 Codes & - \\
\hline
\end{tabular}

Analysis of the 1991 Census provides statistical evidence that the concordance between the two classifications at the finest level of detail is imperfect. In most occupational classes, between $30 \%$ and $80 \%$ of the records do not follow the theoretical concordance. This is illustrated in Table 3A using 1991 Census data to show the relationship between the 1980 occupational classification for Computer Programmers and Systems Analysts (2183) and its theoretical 1991 counterparts: Computer Systems Analysts (C062) and Computer Programmers (C063).

It is evident that, while computer programmers and analysts (as identified by the 1980 classification) are only supposed to map into two occupational categories, this is true in only $71.8 \%$ of the cases. The remaining records (28.2\%) are assigned to 313 different occupations. Similar patterns hold true in the reverse situation. Moreover, the computer programmer/analyst example is relatively simple. The theoretical concordance indicates that most occupations in 1980 (or 1991) have a large number of counterparts in 1991 (or 1980).

Our approach avoids having to work at the finest level of detail. By choosing some 47 more aggregate categories, these occupation groups are then traced back through time.

We use data from the 1991 Census to create a statistical, forced one-to-one concordance between the 1980 Standard Occupational Classification and the KW-47 Framework (defined using the 1991 Standard Occupational Classification).

It should be noted that we tested a number of different strategies for converting the 1980 Standard Occupational Classification (Input) to the 1991 Standard Occupational Classification (Output). These conversion levels are presented in Table 4A. 
Table 4A. Conversion levels tested

\begin{tabular}{|c|c|}
\hline Input & Output \\
\hline 4-digit 1980 Standard Occupational Classification & 4-digit 1991 Standard Occupational Classification \\
\hline 3-digit 1980 Standard Occupational Classification & 3-digit 1991 Standard Occupational Classification \\
\hline & KW-47 Occupational Framework \\
\hline
\end{tabular}

Note: Using 2-digit level occupations on the output side would not allow conversion to the KW-47 framework. The results for the 3- and 4-digit levels on the output side were converted to the KW-47 framework for analysis of the effectiveness of the forced one-to-one match.

We used three criteria to determine which conversion level was best:

1) To maximize the proportion of the input group that was classified to the output group;

2) To minimize the number of cases where less than $50 \%$ of the input group was classified to the output group; and

3) To minimize the number of missing KW-47 categories.

We found that our results were better when we used the greatest level of detail on the input side (i.e., 4-digit level occupations from the 1980 Standard Occupational Classification) and the lowest level of detail on the output side (i.e., the KW-47 Occupational Framework). Therefore, prior to creating the concordance, we converted 1991 occupation data to the KW-47 framework and used this to assign each 4-digit occupation (1980) to an occupation based on the KW-47 framework.

The forced one-to-one match was made using a proportional matrix created from the doublecoded 1991 Census. The matrix included sets of input-output pairs, whereby each input group had one or (in most cases) many output groups. First, each 4-digit occupation (1980) was matched to a broad occupational category (A to J) based on the category accounting for the highest proportion of population-weighted records. Second, we matched each 4-digit occupation (1980) to the KW-47 group within the occupational category (A to J) selected in the previous step.

For example, a 4-digit occupation (1980) may be divided $90 \%$ to Management and $10 \%$ to Business and Finance. In that case, it would be assigned to the Management category. Within the Management category, we then chose the KW-47 group that accounted for the greatest proportion of population-weighted records. Using this method we were able to create a forced one-to-one conversion table, matching each 4-digit occupation (1980) to a single corresponding KW-47 group.

\section{A concordance between the 1971 Occupational Classification Manual and the 1980 Standard Occupational Classification Systems}

Deriving the concordance between the 1971 and 1980 classification systems was less complex. The majority of 4-digit occupations in the 1971 Occupational Classification Manual match one-to-one with their 1980 counterparts, since there were only minor revisions between 1971 and 1980 and few occupational groups were discontinued, aggregated, or split. Since 
more than $90 \%$ of the records had the same occupation regardless of the classification system, a direct concordance between the two systems at the 4-digit level was used.

Using a method similar to that used to create a one-to-one relationship between the 1980 Standard Occupational Classification and the KW-47 framework, a forced one-to-one match was then made to the KW-47 framework using a proportional matrix created from the doublecoded 1981 and 1986 Censuses. By converting 1971 occupations (4-digit level) to 1980 equivalents (4-digit level), we then reclassified the 1971 codes to the KW-47 framework. ${ }^{17}$ Our results were similar regardless of whether the 1981 or 1986 Census was used to produce the concordance. The 1986 Census was ultimately chosen to produce the final concordance.

It should be noted that in our final tables which assign 4-digit level occupations (1980) to the KW-47 framework that there were three occupational categories (A1, B1, and G0, Table 2A) where there was no match based on our methodology. Given the discontinuities between the 1980 and 1991 standards, this is not unexpected. However, the application of this concordance is at an even more aggregate level and our estimates at this aggregate level are fairly robust.

\section{Empirical results}

In order to evaluate the robustness of the methodology employed, we present the trajectory of the 10 major groupings of our 47-category framework below but use two different methods to assign the 1990 data to our 47 groups.

Figure 2A classifies all census data on the basis of the SOC 1980 from 1981 up to and including 1991, while Figure 3A uses the SOC 1980 from 1981 but only up to 1986. The difference between the two then allows us to evaluate how much difference is made to the aggregate level that we are using here by the dramatic change in occupational classifications in 1991.

It is clear that the aggregate trends are more or less the same in both cases. We conclude that for aggregate analyses, our concordances give us more or less smooth trends. 
Figure 2A. Converted to KW-47 framework using the following: 1971 occupations use OCM-70; 1976 is interpolated; 1981, 1986, and 1991 use SOC-80; 1996 uses SOC-91, by broad occupational categories

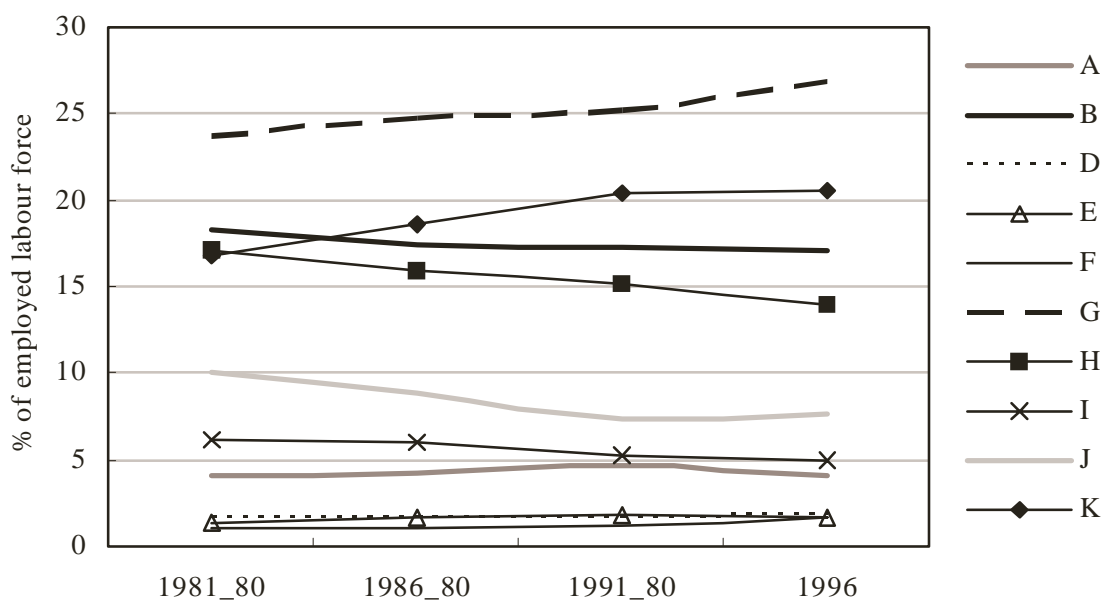

Figure 3A. Converted to KW-47 framework using the following: 1971 occupations use OCM-70; 1976 is interpolated; 1981 and 1986 use SOC-80; 1991 and 1996 use SOC-91, by broad occupational categories

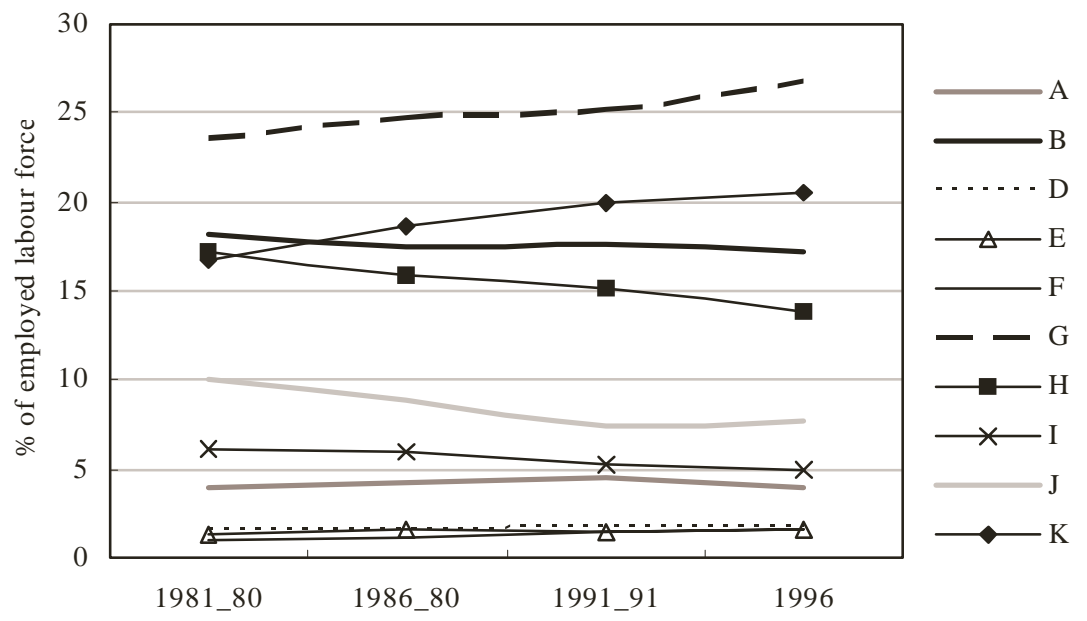




\section{Endnotes}

15 Similarly, there are differences between the 1971 and 1980 Standard Occupational Classification systems. However, the 1980 Standard Occupational Classification system involved only a minor revision of its predecessor.

${ }^{16}$ It is possible for a class to belong to more than one group.

17 In almost all cases, a straightforward matching algorithm sufficed. However, there was one minor revision between the 1981 and 1991 Censuses in the coding procedure used for farming occupations under the 1980 Standard Occupational Classification. In the 1991 Census, all farmers were coded as ' 7111 '. In the 1981 Census, farmers were coded either as '7113', '7115', or '7119'. Therefore, adjustments were made to ensure data consistency. 


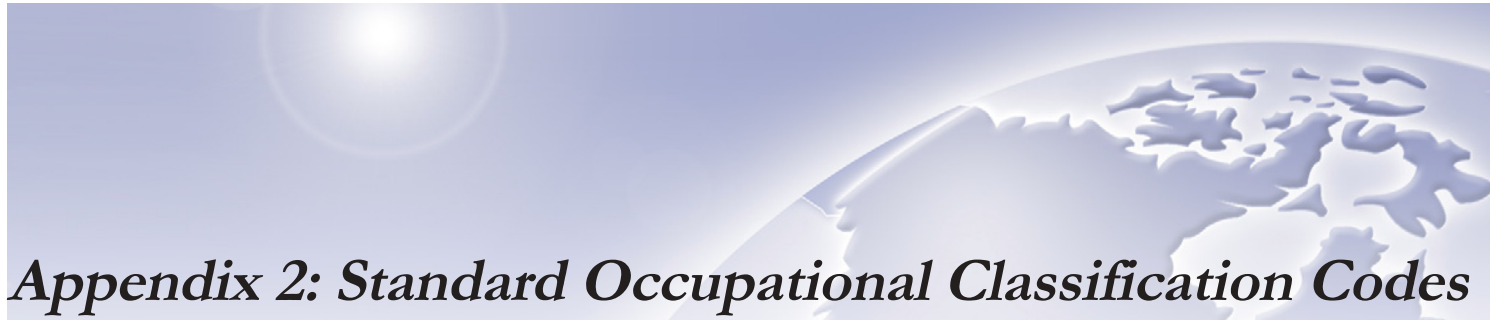

\begin{tabular}{|c|c|c|}
\hline Code & $\begin{array}{l}\text { Knowledge } \\
\text { Category }\end{array}$ & Description \\
\hline $\mathrm{A} 01.001$ & $\mathrm{~K} 1$ & Legislators and Senior Management \\
\hline A11.011 & K1 & Administrative Services Managers \\
\hline A12.021 & K1 & Managers in Engineering, Architecture, Science and Information Systems \\
\hline A13.061 & K1 & Sales, Marketing and Advertising Managers \\
\hline A30.012 & $\mathrm{K} 1$ & Managers in Financial and Business Services \\
\hline A31.013 & $\mathrm{K} 1$ & Managers in Communication (except Broadcasting) \\
\hline A 32.031 & K1 & Managers in Health, Education, Social and Community Services \\
\hline A33.041 & $\mathrm{K} 1$ & Managers in Public Administration \\
\hline A34.051 & K1 & Managers in Art, Culture, Recreation and Sport \\
\hline A38.081 & K1 & Managers in Primary Production (except Agriculture) \\
\hline A39.091 & $\mathrm{K} 1$ & Managers in Manufacturing and Utilities \\
\hline B01.111 & $\mathrm{K} 2$ & Auditors, Accountants and Investment Professionals \\
\hline B02.112 & $\mathrm{K} 2$ & Human Resources and Business Service Professionals \\
\hline $\mathrm{C} 01.211$ & $\mathrm{~K} 3$ & Physical Science Professionals \\
\hline $\mathrm{C} 02.212$ & K3 & Life Science Professionals \\
\hline $\mathrm{C} 03.213$ & K3 & Civil, Mechanical, Electrical and Chemical Engineers \\
\hline $\mathrm{C} 04.214$ & K3 & Other Engineers \\
\hline $\mathrm{C} 05.215$ & $\mathrm{~K} 3$ & Architects, Urban Planners and Land Surveyors \\
\hline C06.216 & K3 & Mathematicians, Systems Analysts and Computer Programmers \\
\hline C11.221 & K4 & Technical Occupations in Physical Sciences \\
\hline $\mathrm{C} 12.222$ & K4 & Technical Occupations in Life Sciences \\
\hline C13.223 & K4 & Technical Occupations in Civil, Mechanical and Industrial Engineering \\
\hline C14.224 & K4 & Technical Occupations in Electronics and Electrical Engineering \\
\hline $\mathrm{C} 15.225$ & K4 & Technical Occupations in Architecture, Drafting, Surveying and Mapping \\
\hline C16.226 & K4 & Other Technical Inspectors and Regulatory Officers \\
\hline C17.227 & K4 & Transportation Officers and Controllers \\
\hline D01.311 & K5 & Physicians, Dentists and Veterinarians \\
\hline D02.312 & K5 & $\begin{array}{l}\text { Optometrists, Chiropractors and Other Health Diagnosing and Treating } \\
\text { Professionals }\end{array}$ \\
\hline D03.313 & K5 & Pharmacists, Dietitians and Nutritionists \\
\hline D04.314 & K5 & Therapy and Assessment Professionals \\
\hline D11.315 & K6 & Nurse Supervisors and Registered Nurses \\
\hline D21.321 & K6 & Medical Technologists and Technicians (except Dental Health) \\
\hline E01.411 & K7 & Judges, Lawyers and Quebec Notaries \\
\hline E03.416 & K7 & Policy and Program Officers, Researchers and Consultants \\
\hline E11.412 & K7 & University Professors and Assistants \\
\hline E12.413 & K7 & College and Other Vocational Instructors \\
\hline E13.414 & K7 & Secondary and Elementary School Teachers and Counsellors \\
\hline F01.511 & K8 & Librarians, Archivists, Conservators and Curators \\
\hline F02.512 & K8 & Writing, Translating and Public Relations Professionals \\
\hline F03.513 & K8 & Creative and Performing Artists \\
\hline
\end{tabular}




\begin{tabular}{|c|c|c|}
\hline Code & $\begin{array}{c}\text { Knowledge } \\
\text { Category }\end{array}$ & Description \\
\hline 1111 & $\mathrm{~K} 1$ & Members of Legislative Bodies \\
\hline 1113 & $\mathrm{~K} 1$ & Government Administrators \\
\hline 1130 & K1 & General Managers and Other Senior Officials \\
\hline 1131 & $\mathrm{~K} 1$ & Management Occupations, Natural Sciences and Engineering \\
\hline 1132 & $\mathrm{~K} 1$ & Management Occupations, Social Sciences and Related Fields \\
\hline 1133 & K1 & Administrators in Teaching and Related Fields \\
\hline 1134 & K1 & Administrators in Medicine and Health \\
\hline 1135 & $\mathrm{~K} 1$ & Financial Management Occupations \\
\hline 1136 & $\mathrm{~K} 1$ & Personnel and Industrial Relations Management Occupations \\
\hline 1143 & $\mathrm{~K} 1$ & Production Management Occupations \\
\hline 1147 & $\mathrm{~K} 1$ & Management Occupations, Transport and Communications Operations \\
\hline 1151 & $\mathrm{~K} 1$ & Other Managers (Mines and Oil Wells) \\
\hline 1152 & $\mathrm{~K} 1$ & Other Managers (Durable Goods Manufacturing) \\
\hline 1153 & $\mathrm{~K} 1$ & Other Managers (Non-Durable Goods Manufacturing) \\
\hline 1155 & $\mathrm{~K} 1$ & Other Managers (Transportation and Communication) \\
\hline 1157 & K1 & Other Managers (Service) \\
\hline 1158 & $\mathrm{~K} 1$ & Other Managers (Other Industries) \\
\hline 1171 & $\mathrm{~K} 2$ & Accountants, Auditors and Other Financial Officers \\
\hline 1173 & $\mathrm{~K} 2$ & Organization and Methods Analysts \\
\hline 1176 & K4 & Inspectors and Regulatory Officers, n.e.c. \\
\hline 2111 & K3 & Chemists \\
\hline 2112 & K3 & Geologists \\
\hline 2113 & K3 & Physicists \\
\hline 2114 & K3 & Meteorologists \\
\hline 2117 & K4 & Physical Sciences Technologists and Technicians \\
\hline 2119 & K4 & Occupations in Physical Sciences, n.e.c. \\
\hline 2131 & K3 & Agriculturists and Related Scientists \\
\hline 2133 & K3 & Biologists and Related Scientists \\
\hline 2135 & K4 & Life Sciences Technologists and Technicians \\
\hline 2139 & K4 & Occupations in Life Sciences, n.e.c. \\
\hline 2141 & K3 & Architects \\
\hline 2142 & $\mathrm{~K} 3$ & Chemical Engineers \\
\hline 2143 & K3 & Civil Engineers \\
\hline 2144 & K3 & Electrical Engineers \\
\hline 2145 & $\mathrm{~K} 3$ & Industrial Engineers \\
\hline 2146 & K3 & Agricultural Engineers \\
\hline 2147 & K3 & Mechanical Engineers \\
\hline 2151 & K3 & Metallurgical Engineers \\
\hline 2153 & K3 & Mining Engineers \\
\hline 2154 & K3 & Petroleum Engineers \\
\hline 2155 & K3 & Aerospace Engineers \\
\hline 2156 & K3 & Nuclear Engineers \\
\hline 2157 & K3 & Community Planners \\
\hline 2159 & $\mathrm{~K} 3$ & Professional Engineers, n.e.c. \\
\hline 2160 & $\mathrm{~K} 4$ & Supervisors: Other Occupations in Architecture and Engineering \\
\hline 2161 & $\mathrm{~K} 3$ & Surveyors \\
\hline 2163 & K4 & Draughting Occupations \\
\hline 2164 & $\mathrm{~K} 4$ & Architectural Technologists and Technicians \\
\hline 2165 & K4 & Engineering Technologists and Technicians \\
\hline 2169 & K4 & Other Occupations in Architecture and Engineering, n.e.c. \\
\hline 2181 & $\mathrm{~K} 3$ & Mathematicians, Statisticians and Actuaries \\
\hline 2183 & K3 & Systems Analysts, Computer Programmers and Related Occupations \\
\hline 2311 & K7 & Economists \\
\hline 2313 & K7 & Sociologists, Anthropologists and Related Social Scientists \\
\hline 2319 & K7 & Occupations in Social Sciences, n.e.c. \\
\hline 2341 & K7 & Judges and Magistrates \\
\hline 2343 & K7 & Lawyers and Notaries \\
\hline 2350 & K8 & Supervisors: Occupations in Library, Museum and Archival Sciences \\
\hline 2351 & K8 & Librarians, Archivists and Conservators \\
\hline 2391 & K7 & Educational and Vocational Counsellors \\
\hline
\end{tabular}




\begin{tabular}{|c|c|c|}
\hline Code & $\begin{array}{c}\text { Knowledge } \\
\text { Category }\end{array}$ & Description \\
\hline 2711 & K7 & University Teachers \\
\hline 2719 & K7 & University Teaching and Related Occupations, n.e.c. \\
\hline 2731 & K7 & Elementary and Kindergarten Teachers \\
\hline 2733 & K7 & Secondary School Teachers \\
\hline 2739 & K7 & Elementary and Secondary School Teaching and Related Occupations, n.e.c. \\
\hline 2791 & K7 & Community College and Vocational School Teachers \\
\hline 2792 & K8 & Fine Arts Teachers, n.e.c. \\
\hline 2793 & K7 & Post-secondary School Teachers, n.e.c. \\
\hline 2797 & K7 & Instructors and Training Officers, n.e.c. \\
\hline 2799 & K7 & Other Teaching and Related Occupations, n.e.c. \\
\hline 3111 & K5 & Physicians and Surgeons \\
\hline 3113 & K5 & Dentists \\
\hline 3115 & K5 & Veterinarians \\
\hline 3117 & K5 & Osteopaths and Chiropractors \\
\hline 3119 & K6 & Health Diagnosing and Treating Occupations, n.e.c. \\
\hline 3130 & K6 & Supervisors: Nursing, Therapy and Related Assisting Occupations \\
\hline 3131 & K6 & Nurses, Registered, Graduate and Nurses-in-Training \\
\hline 3136 & K5 & Audio and Speech Therapists \\
\hline 3137 & K5 & Physiotherapists \\
\hline 3138 & K5 & Occupational Therapists \\
\hline 3151 & $\mathrm{~K} 5$ & Pharmacists \\
\hline 3152 & K5 & Dietitians and Nutritionists \\
\hline 3153 & K5 & Optometrists \\
\hline 3155 & K6 & Radiological Technologists and Technicians \\
\hline 3156 & K6 & Medical Laboratory Technologists and Technicians \\
\hline 3162 & K6 & Respiratory Technicians \\
\hline 3311 & K8 & Painters, Sculptors and Related Artists \\
\hline 3330 & K8 & Producers and Directors, Performing and Audio-Visual Arts \\
\hline 3331 & K8 & Conductors, Composers and Arrangers \\
\hline 3332 & K8 & Musicians and Singers \\
\hline 3334 & $\mathrm{~K} 8$ & Dancers and Choreographers \\
\hline 3335 & K8 & Actors/Actresses \\
\hline 3351 & K8 & Writers and Editors \\
\hline 3355 & $\mathrm{~K} 8$ & Translators and Interpreters \\
\hline 3359 & K8 & Occupations in Writing, n.e.c. \\
\hline 5173 & $\mathrm{~K} 2$ & Sales Agents and Traders, Securities \\
\hline 7516 & $\mathrm{~K} 4$ & Log Inspecting, Grading, Scaling and Related Occupations \\
\hline 8535 & K4 & Electronic and Related Equipment Installing and Repairing Occupations, n.e.c. \\
\hline 8537 & K4 & Radio and Television Repairers \\
\hline 8585 & K4 & Business and Commercial Machine Mechanics and Repairers \\
\hline 8588 & K4 & Precision Instrument Mechanics and Repairers \\
\hline 8796 & K4 & Inspecting, Testing, Grading and Sampling Occupations: Other Construction Trades \\
\hline 9111 & K4 & Air Pilots, Navigators and Flight Engineers \\
\hline 9113 & K4 & Air Transport Operating Support Occupations \\
\hline 9151 & K4 & Deck Officers \\
\hline 9153 & K4 & Engineering Officers, Ship \\
\hline 9550 & $\mathrm{~K} 1$ & $\begin{array}{l}\text { Foremen/women: Electonic and Related Communications Equipment Operating } \\
\text { Occupations, n.e.c. }\end{array}$ \\
\hline 9559 & K4 & $\begin{array}{l}\text { Other Electronic and Related Communications Equipment Operating Occupations, } \\
\text { n.e.c. }\end{array}$ \\
\hline
\end{tabular}




\begin{tabular}{|c|c|c|}
\hline Code & $\begin{array}{c}\text { Knowledge } \\
\text { Category }\end{array}$ & Description \\
\hline 1111 & $\mathrm{~K} 1$ & Members of Legislative Bodies \\
\hline 1113 & $\mathrm{~K} 1$ & Government Administrators \\
\hline 1130 & $\mathrm{~K} 1$ & General Managers and Other Senior Officials \\
\hline 1131 & $\mathrm{~K} 1$ & Management Occupations, Natural Sciences and Engineering \\
\hline 1132 & $\mathrm{~K} 1$ & Management Occupations, Social Sciences and Related Fields \\
\hline 1133 & $\mathrm{~K} 1$ & Administrators in Teaching and Related Fields \\
\hline 1134 & $\mathrm{~K} 1$ & Administrators in Medicine and Health \\
\hline 1135 & $\mathrm{~K} 1$ & Financial Management Occupations \\
\hline 1136 & K1 & Personnel and Industrial Relations Management Occupations \\
\hline 1143 & $\mathrm{~K} 1$ & Production Management Occupations \\
\hline 1147 & $\mathrm{~K} 1$ & Management Occupations, Transport and Communications Operations \\
\hline 1151 & $\mathrm{~K} 1$ & Other Managers (Mines and Oil Wells) \\
\hline 1152 & $\mathrm{~K} 1$ & Other Managers (Durable Goods Manufacturing) \\
\hline 1153 & $\mathrm{~K} 1$ & Other Managers (Non-Durable Goods Manufacturing) \\
\hline 1155 & K1 & Other Managers (Transportation and Communication) \\
\hline 1157 & $\mathrm{~K} 1$ & Other Managers (Service) \\
\hline 1158 & $\mathrm{~K} 1$ & Other Managers (Other Industries) \\
\hline 1171 & $\mathrm{~K} 2$ & Accountants, Auditors and Other Financial Officers \\
\hline 1176 & K4 & Inspectors and Regulatory Officers, non-government \\
\hline 2111 & K3 & Chemists \\
\hline 2112 & K3 & Geologists \\
\hline 2113 & K3 & Physicists \\
\hline 2114 & K3 & Meteorologists \\
\hline 2117 & K4 & Physical Sciences Technologists and Technicians \\
\hline 2119 & K4 & Occupations in Physical Sciences, n.e.c. \\
\hline 2131 & K3 & Agriculturists and Related Scientists \\
\hline 2133 & K3 & Biologists and Related Scientists \\
\hline 2135 & K4 & Life Sciences Technologists and Technicians \\
\hline 2139 & K4 & Occupations in Life Sciences, n.e.c. \\
\hline 2141 & K3 & Architects \\
\hline 2142 & $\mathrm{~K} 3$ & Chemical Engineers \\
\hline 2143 & K3 & Civil Engineers \\
\hline 2144 & K3 & Electrical Engineers \\
\hline 2145 & K3 & Industrial Engineers \\
\hline 2147 & $\mathrm{~K} 3$ & Mechanical Engineers \\
\hline 2151 & K3 & Metallurgical Engineers \\
\hline 2153 & K3 & Mining Engineers \\
\hline 2154 & $\mathrm{~K} 3$ & Petroleum Engineers \\
\hline 2155 & K3 & Aeronautical Engineers \\
\hline 2157 & K3 & Nuclear Engineers \\
\hline 2159 & $\mathrm{~K} 3$ & Architects and Engineers, n.e.c. \\
\hline 2160 & $\mathrm{~K} 4$ & Supervisors: Other Occupations in Architecture and Engineering \\
\hline 2161 & K3 & Surveyors \\
\hline 2163 & $\mathrm{~K} 4$ & Draughtsmen \\
\hline 2165 & K4 & Architectural and Engineering Technologists and Technicians \\
\hline 2169 & K4 & Other Occupations in Architecture and Engineering, n.e.c. \\
\hline 2181 & $\mathrm{~K} 3$ & Mathematicians, Statisticians and Actuaries \\
\hline 2183 & K3 & Systems Analysts, Computer Programmers and Related Occupations \\
\hline 2311 & K7 & Economists \\
\hline 2313 & K7 & Sociologists, Anthropologists and Related Social Scientists \\
\hline 2319 & K7 & Occupations in Social Sciences, n.e.c. \\
\hline 2341 & K7 & Judges and Magistrates \\
\hline 2343 & K7 & Lawyers and Notaries \\
\hline 2350 & K8 & Supervisors: Occupations in Library, Museum and Archival Sciences \\
\hline 2351 & K8 & Librarians and Archivists \\
\hline 2391 & K7 & Educational and Vocational Counsellors \\
\hline 2711 & $\mathrm{~K} 7$ & University Teachers \\
\hline 2719 & K7 & University Teaching and Related Occupations, n.e.c. \\
\hline 2731 & K7 & Elementary and Kindergarten Teachers \\
\hline 2733 & K7 & Secondary School Teachers \\
\hline 2739 & K7 & Elementary and Secondary School Teaching and Related Occupations, n.e.c. \\
\hline
\end{tabular}




\begin{tabular}{|c|c|c|}
\hline Code & $\begin{array}{c}\text { Knowledge } \\
\text { Category }\end{array}$ & Description \\
\hline 2791 & K7 & Community College and Vocational School Teachers \\
\hline 2792 & K8 & Fine Arts School Teachers \\
\hline 2793 & K7 & Post-secondary School Teachers, n.e.c. \\
\hline 2797 & K7 & Instructors and Training Officers, n.e.c. \\
\hline 2799 & K7 & Other Teaching and Related Occupations, n.e.c. \\
\hline 3111 & K5 & Physicians and Surgeons \\
\hline 3113 & K5 & Dentists \\
\hline 3115 & K5 & Veterinarians \\
\hline 3117 & K5 & Osteopaths and Chiropractors \\
\hline 3119 & K6 & Health Diagnosing and Treating Occupations, n.e.c. \\
\hline 3130 & K6 & Supervisors: Nursing Occupations \\
\hline 3131 & K6 & Nurses, Graduate, Except Supervisors \\
\hline 3137 & K5 & Physiotherapists, Occupational and Other Therapists \\
\hline 3151 & K5 & Pharmacists \\
\hline 3152 & K5 & Dietitians and Nutritionists \\
\hline 3153 & K5 & Optometrists \\
\hline 3155 & K6 & Radiological Technologists and Technicians \\
\hline 3156 & K6 & Medical Laboratory Technologists and Technicians \\
\hline 3311 & $\mathrm{~K} 8$ & Painters, Sculptors and Related Artists \\
\hline 3330 & K8 & Producers and Directors, Performing and Audio-Visual Arts \\
\hline 3332 & K8 & Musicians \\
\hline 3333 & K8 & Dancers and Choreographers \\
\hline 3335 & K8 & Actors/Actresses \\
\hline 3352 & K8 & Writers and Editors \\
\hline 3355 & K8 & Translators and Interpreters \\
\hline 3359 & K8 & Occupations in Writing, n.e.c. \\
\hline 5173 & $\mathrm{~K} 2$ & Sales Agents and Traders, Securities \\
\hline 7516 & K4 & Log Inspecting, Grading, Scaling and Related Occupations \\
\hline 8535 & $\mathrm{~K} 4$ & Electronic and Related Equipment Installing and Repairing Occupations, n.e.c. \\
\hline 8537 & K4 & Radio and Television Service Repairmen \\
\hline 8585 & K4 & Business and Commercial Machine Mechanics and Repairmen \\
\hline 8588 & K4 & Precision Instrument Mechanics and Repairmen \\
\hline 8796 & K4 & $\begin{array}{l}\text { Inspecting, Testing, Grading and Sampling Occupations, Construction, Except } \\
\text { Electrical }\end{array}$ \\
\hline 9111 & K4 & Air Pilots, Navigators and Flight Engineers \\
\hline 9113 & K4 & Air Transport Operating Support Occupations \\
\hline 9151 & K4 & Deck Officers \\
\hline 9153 & K4 & Engineering Officers, Ship \\
\hline 9550 & $\mathrm{~K} 1$ & $\begin{array}{l}\text { Foremen: Electonic and Related Communications Equipment Operating } \\
\text { Occupations, n.e.c. }\end{array}$ \\
\hline 9559 & K4 & Electronic and Related Communications Equipment Operating Occupations, n.e.c. \\
\hline
\end{tabular}




\section{References}

Baldwin, J.R., P. Hanel and D. Sabourin. 2000. Determinants of Innovative Activity in Canadian Manufacturing Firms: The Role of Intellectual Property Rights. Analytical Studies Research Paper Series 11F0019MIE2000122. Analytical Studies Branch. Ottawa: Statistics Canada.

Baldwin, J.R. and G. Gellatly. 1998. Are there High-Tech Industries or Only High-Tech Firms? Evidence From New Technology-Based Firms. Analytical Studies Research Paper Series 11F0019MIE1998120. Analytical Studies Branch. Ottawa: Statistics Canada.

Baldwin, J.R. and J. Johnson. 1996. "Human capital development and innovation: A sectoral analysis." In The Implications of Knowledge-Based Growth for Micro-Economic Policies, P. Howitt, ed. Calgary: University of Calgary Press.

Boothby, D. 1999. Literacy Skills, the Knowledge Content of Occupations and Occupational Mismatch. Applied Research Branch Working Paper W-99-3E. Ottawa: Human Resources Development Canada.

Drolet, M. 2000. The Persistent Gap: New Evidence of the Canadian Gender Wage Gap. Analytical Studies Research Paper Series 11F0019MIE2000157. Analytical Studies Branch. Ottawa: Statistics Canada.

Du Plessis, V.R. Beshiri, R.D. Bollman and H. Clemenson. 2001. "Definitions of Rural." Rural and Small Town Canada Analysis Bulletin, 3 (3). Catalogue No. 21-006-XIE. Ottawa: Statistics Canada.

Gera, S. and K. Mang. 1997. The Knowledge-Based Economy: Shifts in Industrial Output. Working Paper 15. Micro-Economic Policy Analysis. Ottawa: Industry Canada.

Gera, S. and P. Massé. 1996. Employment Performance in the Knowledge-Based Economy. Working Paper 14. Micro-Economic Policy Analysis. Ottawa: Industry Canada.

Gera, S., W. Gu and Z. Lin. 1999. Technology and the Demand for Skills: An Industry-Level Analysis. Working Paper 28. Micro-Economic Policy Analysis. Ottawa: Industry Canada. 
Howitt, P. 1996. "On some problems in measuring knowledge-based growth." In The Implications of Knowledge-Based Growth for Micro-Economic Policies, P. Howitt, ed. Calgary: University of Calgary Press.

Lavoie, M. and R. Roy. 1998. Employment in the Knowledge-Based Economy: A Growth Accounting Exercise for Canada. Applied Research Branch Research Paper R-98-8E. Ottawa: Human Resources Development Canada.

Lee, F. and H. Has. 1996. "A quantitative assessment of high-knowledge vs. low-knowledge industries." In The Implications of Knowledge-Based Growth for Micro-Economic Policies, P. Howitt, ed. Calgary: University of Calgary Press.

Marshall, K. 1996. "The diversity of managers." Perspectives on labour and income. Catalogue No. 75-001-XPE. Vol. 8 (1), pp. 24-30. Ottawa: Statistics Canada.

Picot, G. and L. Lavallée. 1986. Structural change in employment of industries and occupations, 1971-81: An input-output analysis. Discussion Paper 316. Ottawa: Economic Council of Canada.

Picot, G. and A. Heisz. 2000. The Performance of the 1990s Canadian Labour Market. Analytical Studies Research Paper Series 11F0019MIE2000148. Analytical Studies Branch. Ottawa: Statistics Canada.

Robson, M., J. Townsend and K. Pavitt. 1988. "Sectoral patterns of production and use of innovations in the UK: 1945-1983." Research Policy, 17: 1-14.

Statistics Canada. 1999. 1996 Census Dictionary - Final Edition. Catalogue No. 92-351UIE. Ottawa: Statistics Canada.

Zhao, J., D. Drew and S. Murray. 2000a. "Brain Drain and Brain Gain: The Migration of Knowledge Workers from and to Canada." Education Quarterly Review. Catalogue No. 81003-XPE. Vol. 6 (3), pp. 8-35. Ottawa: Statistics Canada.

Zhao, J., D. Drew and S. Murray. 2000b. "Knowledge Workers on the Move." Perspectives on labour and income. Catalogue No. 75-001-XPE. Vol. 12 (2), pp. 32-46. Ottawa: Statistics Canada. 